\title{
Skeletal Muscle Arteriole Dysfunction and Microvessel Density in Metabolic Syndrome and Depression: How Exercise Can Be Used as an Intervention
}

Kayla Whitney Branyan

Follow this and additional works at: https://researchrepository.wvu.edu/etd

\section{Recommended Citation}

Branyan, Kayla Whitney, "Skeletal Muscle Arteriole Dysfunction and Microvessel Density in Metabolic Syndrome and Depression: How Exercise Can Be Used as an Intervention" (2017). Graduate Theses, Dissertations, and Problem Reports. 5255.

https://researchrepository.wvu.edu/etd/5255

This Dissertation is protected by copyright and/or related rights. It has been brought to you by the The Research Repository @ WVU with permission from the rights-holder(s). You are free to use this Dissertation in any way that is permitted by the copyright and related rights legislation that applies to your use. For other uses you must obtain permission from the rights-holder(s) directly, unless additional rights are indicated by a Creative Commons license in the record and/ or on the work itself. This Dissertation has been accepted for inclusion in WVU Graduate Theses, Dissertations, and Problem Reports collection by an authorized administrator of The Research Repository @ WVU.

For more information, please contact researchrepository@mail.wvu.edu. 


\section{Skeletal Muscle Arteriole Dysfunction and Microvessel Density in Metabolic Syndrome and Depression: How Exercise Can Be Used as an Intervention}

\section{Kayla Whitney Branyan}

Dissertation submitted to the School of Medicine at West Virginia University in partial fulfillment of the requirements of the degree of:

Doctor of Philosophy in Exercise Physiology

Paul D. Chantler, Ph.D., Committee Chair/Research Advisor

Jefferson C. Frisbee, Ph.D.

Randall Bryner, Ed.D.

I. Mark Olfert, Ph.D.

James Simpkins, Ph.D.

Division of Exercise Physiology

Morgantown, West Virginia

December 2017

Key Words: Peripheral microvessels, metabolic syndrome, depression, endothelial dysfunction, oxidative stress, nitric oxide

Copyright 2017 Kayla Branyan 


\section{ABSTRACT \\ Skeletal Muscle Arteriole Dysfunction and Microvessel Density in Metabolic Syndrome and Depression: How Exercise Can Be Used as an Intervention}

\section{Kayla W. Branyan}

The present study examined the effect of unpredictable chronic mild stress (UCMS) on peripheral microvessel function in healthy and metabolic syndrome (MetS) rodents, and whether exercise training could prevent the vascular dysfunction associated with UCMS. Our initial hypothesis was that: 1) LZRs exposed to UCMS would have peripheral microvascular dysfunction similar to that evident in the OZRs controls due to a reduction in NO bioavailability and an increase in ROS production; 2) the comorbidity between MetS exposed to UCMS will exacerbate the already existing peripheral microvascular dysfunction; 3) exercise could limit the peripheral microvascular dysfunction by decreasing oxidative stress and improving vasodilation associated with MetS exposed to chronic stress; 4) MVD will be reduced in rats exposed to UCMS but loss of MVD will be mitigated by exercise; and 5) the increase in MVD will be reflected by a change in angiogenesis and oxidative markers.

Lean and obese (model of MetS) Zucker rats (LZR; OZR) were exposed to 8 weeks of UCMS, exercise (Ex), UCMS+Ex, or control conditions. At the end of the intervention, gracilis arterioles (GAs) were isolated and hung in a pressurized myobath to assess endothelium-dependent (EDD) and -independent (EID) dilation. Levels of nitric oxide (NO) and reactive oxygen species (ROS) were measured through DAF-FM and DHE staining, respectively. Immunohistochemistry was used to determine the number of pericytes within the cortex and striatum of the brain.

The comorbidity between UCMS and MetS does not exacerbate the effects of one another on GA EDD responses, but does lead to the development of other vasculopathy adaptations, which can be partially explained by alterations in NO and ROS production. Importantly, exercise training alleviates most of the negative effects of UCMS on GA function. Compared to LZR controls, EDD and EID was lower in LZR-UCMS. The OZR-Ex group had a higher EDD and EID, compared to OZR-Controls; whereas only a difference in EDD was noted between LZR-Control and LZR-Ex groups. Importantly, EDD and EID were higher in the LZR and OZR UCMS+Ex groups compared to UCMS alone. Lower NO bioavailability and higher ROS were noted in the LZR-UCMS group, but not OZR-UCMS, compared to controls. Ex and UCMS-Ex groups had higher NO bioavailability compared to control and UCMS groups, but ROS levels remained high. UCMS significantly decreased MVD in LZR-UCMS but was not changed in OZR-UCMS. In LZR- and OZR-Ex, MVD was increased and when coupled with UCMS, Ex improved MVD in both LZRand OZR-UCMS+Ex. RT-PCR showed no differences in mRNA expression between groups in any of the angiogenic and oxidative stress markers examined.

Corticosterone levels were elevated in the Ex and UCMS+Ex groups vs. the controls which may, in part, reflect the slight stress induced by use of the forced treadmill Ex protocol. It has been shown that glucocorticoids can increase ROS directly, including superoxide, hydrogen peroxide, and peroxynitrite (1). Given that DHE can interact with these oxidants, it could be speculated the higher ROS levels seen in LZR-Ex and UCMS+Ex are a byproduct of increased corticosterone. The fact that in Ex and UCMS+Ex EDD was improved despite elevated corticosterone levels, suggests EDD augmentation was likely mediated from non-corticosterone pathways. Previous 
studies have also shown glucocorticoids can attenuate angiogenesis by inhibiting proliferation of cerebrovascular endothelial cells. In addition, pericyte apoptosis occurs with increased cortisol levels, where the glucocorticoid binds to receptors expressed on the pericytes to initiate cell death. L-NAME blunted maximum dilation back down to LZR- and OZR-Control+LNAME values, suggesting the Ex augmentation of EDD may be through a NO-dependent pathway. The expression and function of eNOS is upregulated after Ex training due to increased shear stress, thus could explain why EDD in LZR- and OZR-Ex was improved in the skeletal muscle arterioles. One possible factor that could have contributed to the increase in cerebral MVD could be the increase in NO production following Ex. Muscle contraction increases VEGF in the muscle interstitium, where VEGF acts on its receptors within the capillary endothelium to stimulate angiogenic processes, thus providing further support for exercise-induced angiogenesis. 


\section{Dedication}

To Mom, Dad, and Adam for your continuous support and encouragement

To my "labmates" (or better yet partners in crime) Evan, Kent, Roy, Shinichi, and Sara

To the rest of my family and friends who helped keep everything fun 


\section{Acknowledgements}

In my almost 5 years at WVU, I have grown to know so many interesting people and am happy to have had such a great experience. First, I got extremely lucky with my first-year classmates and they made all the difference. We became fast friends and I can't imagine my life without them. The HSC is a place where collaboration is both necessary and enjoyable. It is amazing how many people are willing to help when you need a reagent, a piece of equipment, or a little advice, all you have to do is ask (special shout out to all the labs on the $3^{\text {rd }}$ floor!).

I am grateful that Paul was willing and able to take me under his wing when I needed to leave my previous lab. I don't think I would have made it through my degree if that hadn't happened. Even though he's British, he's still a great mentor. I managed to avoid being called a “potted plant". Thankfully, getting my PhD didn't depend on how well I could play "football" because Paul would've been sorely disappointed in my foot skills. In all seriousness, Paul was always there for advice whether it was professional or personal, and for that I am grateful.

Our lab had a tight connection with the Olfert Lab. Chris, Kyle, Hannah, and Matt - you made coming to work fun. I'm so glad that I got to work with you guys! I loved our white elephant gift exchange at Christmas and eating 9 lbs. of ice cream at the Pokey Dot.

We have had many undergrad helpers along the way and I would like to thank them for doing my dirty work. I had a lot of fun teaching them things and loved seeing the recognition in their eyes when they connected a lab technique to one of their classes. 


\section{Table of Contents}

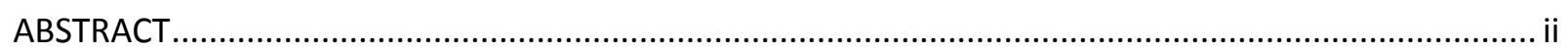

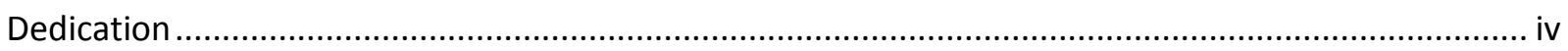

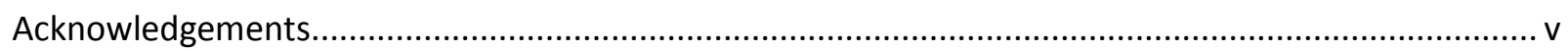

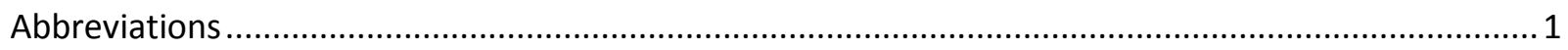

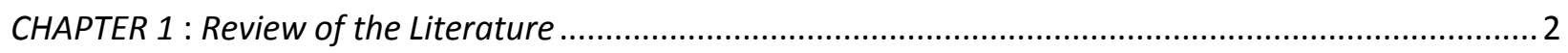

CHAPTER 2 : Role of Chronic Stress and Exercise on Microvascular Function in Metabolic Syndrome .....59

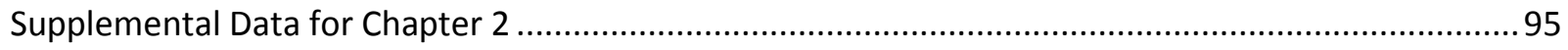

CHAPTER 3 : Microvessel Density in the Brain is Attenuated with MetS and Depression but Improved

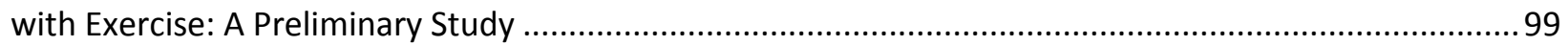

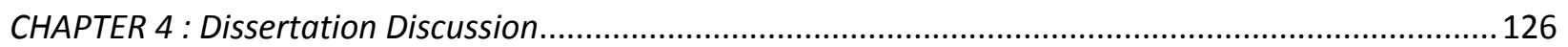




\section{Abbreviations}

4-Hydroxy-TEMPO

(TEMPOL)

4-Amino-5-Methylamino-2',7'- Difluorofluorescein

(DAF-FM)

Acetylcholine

(Ach)

Angiotensin II

(Ang II)

Cardiovascular Disease

(CVD)

Cyclooxygenase

$(\mathrm{COX})$

Dihydroethidium

(DHE)

Endothelin-1

Endothelial Nitric Oxide Synthase

$(\mathrm{eNOS})$

Endothelium-Dependent Dilation

(EDD)

Endothelium-Independent Dilation

Exercise

(Ex)

Gracilis Arteriole

(GA)

Lean Zucker Rat

$\mathrm{L}-\mathrm{N}^{\mathrm{G}}$-nitroarginine methyl ester

(L-NAME)

Metabolic Syndrome

(MetS)

Microvessel Density

(MVD)

Middle Cerebral Artery

(MCA)

Nitric Oxide

(NO)

Obese Zucker Rat

Peripheral Vascular Disease

(PVD)

Phenylephrine

(PE)

Physiological Saline Solution

(PSS)

Reactive Oxygen Species

(ROS)

Sodium Nitroprusside

$(\mathrm{SNP})$

Unpredictable Chronic Mild Stress

(UCMS) 


\section{CHAPTER 1 : Review of the Literature}

\section{Peripheral Microvascular Structure and Function}

Resistance arteries are essential to sufficient blood perfusion of tissue. The aorta has been the focus in previous studies involving pathologies of the vascular system. Even though this blood vessel is important, there is a need to explore the impact of disease on resistance arteries. Resistance arteries and arterioles are the primary vessels in regulating blood pressure and flow at/within an organ. They are located after small arteries but right before the capillaries (Figure 11). These resistance vessels further dampen the pulsatility of blood coming from the aorta. Once blood reaches the small arteries, there is a 50-70\% decrease in pressure (2). This dissertation will focus specifically on resistance arterioles within the skeletal muscle, and partially on the cerebral microvasculature.

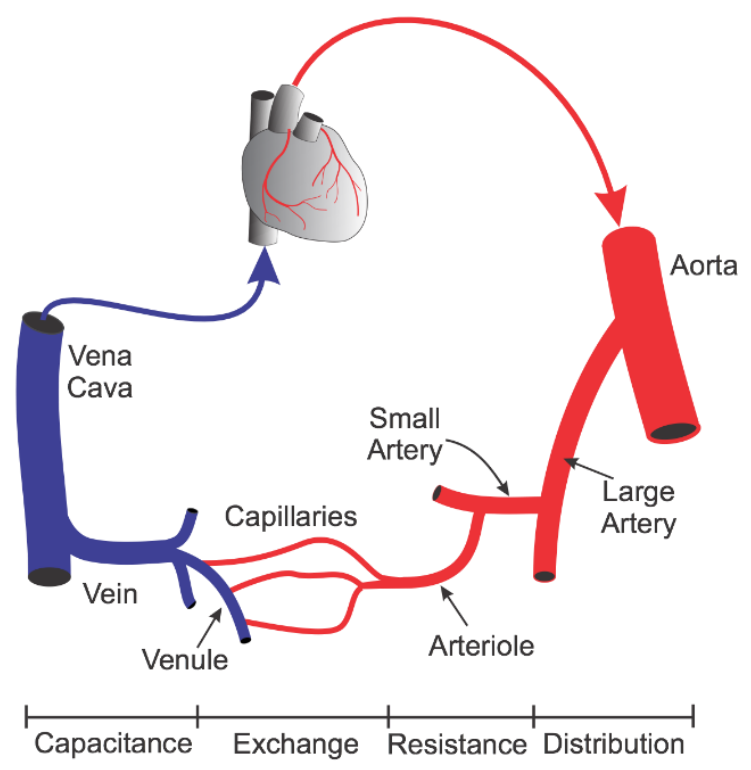

Figure 1-1 Cardiovascular Physiology Concepts. Klabunde 2016. 
The structure of an arteriole is optimized for its function. The diameter of the vessel is small, and the tunica media consists of fewer smooth muscle cell layers than what is seen in muscular and elastic arteries. These vascular smooth muscle cells keep the arteriole in a partially constricted state, called basal vascular or vasomotor tone (3). Central control processes and local regulatory mechanisms alter the contractile activity of the vascular smooth muscle $(2,4)$. On the smooth muscle, there are membrane receptors, ion channels, and mechanical sensors that respond to changes in blood flow, along with second messenger systems that are activated by gaseous signaling molecules. These factors illustrate the complexity of the regulation of vascular tone to control blood flow (4). Vasomotor control properties vary along the arteriolar branch but also among the different types of skeletal muscle fibers (5).

\section{Skeletal muscle arteriole function}

Resistance arteries and arterioles are highly innervated by the sympathetic nervous system (2). The sympathetic nervous system acts on peripheral arteries and arterioles during times of increased cardiac demand. Sympathetic input constricts these blood vessels to increase resistance and decrease distal blood flow. The downstream effect of resistance artery constriction is an increase in cardiac output, systemic vascular resistance, and arterial blood pressure. The main nerves innervating resistance arteries are sympathetic adrenergic nerves that release norepinephrine (NE) as a neurotransmitter. NE binds to $\alpha_{1}$-adrenoceptors to cause smooth muscle contraction, thus vasoconstriction. A common pharmaceutical drug that is used in studies because of its actions as a $\alpha_{1}$-adrenoceptor agonist is phenylephrine (PE). Vasodilation can be achieved by stimulation with epinephrine (EPI) which binds to $\beta_{2}$-adrenoceptors, but this is highly 
concentration dependent. Acetylcholine (Ach) is another neurotransmitter involved in vasodilation, where it binds to muscarinic receptors (specifically $\mathrm{M}_{3}$ ) on the endothelium to trigger the production of nitric oxide (NO) to prevent smooth muscle contraction (2).

There are several vascular signal transduction mechanisms including G-protein coupled and cGMP-coupled signaling. G-protein coupled signaling involves three different G-proteins: Gs, $\mathrm{Gi}$, and Gq. Gs-proteins stimulate adenylyl cyclase to catalyze the formation of cAMP. This causes relaxation of the smooth muscle because the increased cAMP inhibits myosin light chain kinase activity. The Gs-proteins are coupled to $\beta_{2}$-adrenoceptors (EPI and isoproterenol), $\alpha_{2}$-purinergic receptors (adenosine), and IP receptors (prostacyclin). $\alpha_{1}$-adrenoceptors are coupled to Gi-proteins and when NE binds, there is a reduction in cAMP leading to smooth muscle contraction (2).

Gq-proteins are coupled to three different receptors: $\alpha_{1}$-adrenoceptors (NE), $\mathrm{ET}_{\mathrm{A}}$ receptors (endothelin-1; ET-1), $\mathrm{AT}_{1}$ receptors (angiotensin II), and $\mathrm{V}_{1}$ receptors (vasopressin). Instead of stimulating adenylyl cyclase, Gq-proteins activate the phospholipase C pathway and the Rhokinase pathway to cause smooth muscle contraction (2).

Eighty percent of ET-1 is released towards the vascular smooth muscle cells where it binds to $\mathrm{ET}_{\mathrm{A}}$ receptors to cause vasoconstriction. Another isoform of the ET-1 receptor, $\mathrm{ET}_{\mathrm{B}}$, is expressed on both smooth muscle and endothelial cells (6). When ET-1 binds to this receptor on endothelial cells, it promotes the production of NO and prostacyclin which then diffuse into the smooth muscle to cause relaxation (4).

Under basal conditions, cyclooxygenase-1 (COX-1) is active in endothelial cells to convert arachidonic acid to prostaglandin $\mathrm{H} 2$ ( $\mathrm{PGH} 2)$. $\mathrm{PGH} 2$ is then converted to either prostacyclin 
(PGI2) or thromboxane A2 (TxA2) by their respective synthases. PGI2 causes vasodilation and TxA2 induces vasoconstriction (7).

$\mathrm{NO}$ is produced from the combination of L-arginine and molecular oxygen by the enzymatic activity of endothelial nitric oxide synthase (eNOS), inducible NOS (iNOS), and neuronal NOS (nNOS). cGMP-signaling within the vasculature involves the production of NO from eNOS, which diffuses into the smooth muscle to activate soluble guanylyl cyclase and increases cGMP formation to cause vasodilation (2) (Figure 1-2). Activation of eNOS is complicated and can be done through several different pathways. Adenosine, Ach, and NE can activate eNOS after binding to their respective receptors. During inflammatory conditions, bradykinin, calcitonin gene-related peptide, and substance $\mathrm{P}$ can also activate eNOS. Mechanical forces can activate eNOS, such as flow- or shear-dependent vasodilation. eNOS is also activated by the binding of calcium-calmodulin and post-translational control mechanisms including: phosphorylation of activation sites, fatty acid modification, and protein-protein interactions $(8,9)$. Treatment with $\mathrm{L}^{\mathrm{G}} \mathrm{N}^{\mathrm{G}}$-nitroarginine methyl ester (LNAME), a NOS inhibitor, abolishes

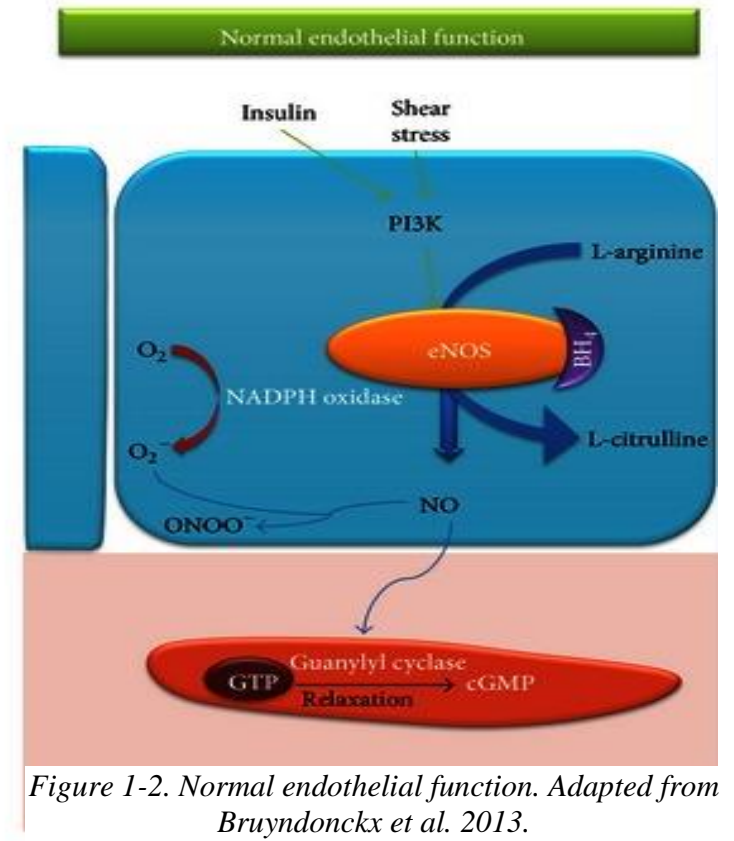


endothelium-dependent dilation and even causes significant vasoconstriction in a variety of vascular beds, providing evidence that NO is crucial to proper endothelial function (10-12).

\section{Myogenic Response}

Skeletal muscle arteriole smooth muscle responds to changes in transmural pressure, the difference between intravascular and extravascular pressure. When transmural pressure increases, smooth muscle contracts and luminal diameter is reduced to increase the resistance to blood flow. A decrease in transmural pressure causes an increase in luminal diameter. This reaction is called the myogenic response. The myogenic response keeps the arteriole in an intrinsic, steady-state of contraction, allowing it to change vessel diameter in either direction in response to stimuli $(3,13,14)$. Shear stress-induced vasodilation operates by mechanisms inherent to the blood vessel wall such that alterations in smooth muscle tone independent of changes in intravascular or transmural pressure can be produced in vessels isolated from the surrounding tissue and perfused in an ex vivo system (15-18).

\section{Autoregulation of blood flow}

The maintenance of relatively constant perfusion of an organ is essential to proper function. Most tissues, like skeletal muscle, are capable of autoregulating their blood flow in relation to changes in mean arterial pressure (MAP). If MAP is reduced, skeletal muscle blood flow falls, at least initially. Decreased blood flow increases the number of vasodilator metabolites within the tissue to cause vasodilation; blood flow is restored to near normal levels. The opposite is true when 
MAP increases. The increase in arterial pressure enhances vasodilator metabolite washout, leading to vasoconstriction and a restoration of blood flow toward normal levels $(19,20)$.

\section{Cerebral Microvascular Function}

The brain is the most perfused organ in the body, and obviously for important reason. In order for essential nutrient exchange to occur, the microcirculation of the brain must be highly regulated. Capillary density varies significantly within the brain, depending on region and energy needs. This density is influenced by pathological, physiological, and environmental factors (21). For example, hypertension affects brain capillary density the same way it affects peripheral microcirculation, causing rarefaction and impaired microvessel formation that leads to increased vascular resistance. The structure of brain capillaries is unique compared to their peripheral counterparts (Figure 1-3). Pericytes and astrocytes are crucial to cerebral capillary function by regulating cerebral blood flow, upregulating tight junction proteins, contributing to ion and water homeostasis, and interfacing directly with neurons (22-25).

Pericytes are adjacent to capillaries and share a common basement membrane with endothelial cells. In fact, the ratio of pericyte-to-endothelia is high compared to the vasculature of other organs (1:3 in brain vs 1:100 in skeletal muscle) (26). These cells are thought to have several roles in the brain such as contributing to the stability of the vessel, release of growth factors and matrix important for microvascular permeability, remodeling, and angiogenesis (27). Another essential structural component to the brain vasculature is collateral circulation. The collateral vascular network allows for maintenance of cerebral blood flow, if and when primary inflow fails 
due to occlusion or constriction. The circle of Willis provides low-resistance connections to the anterior and posterior circulations, allowing for reversal of blood flow if needed (28).

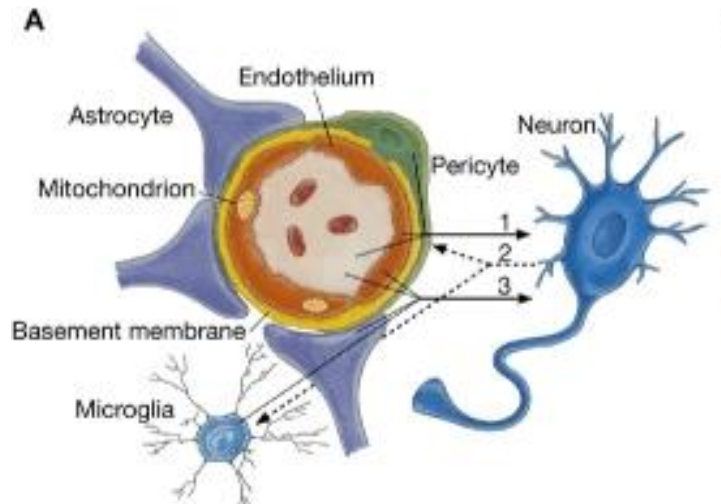

B

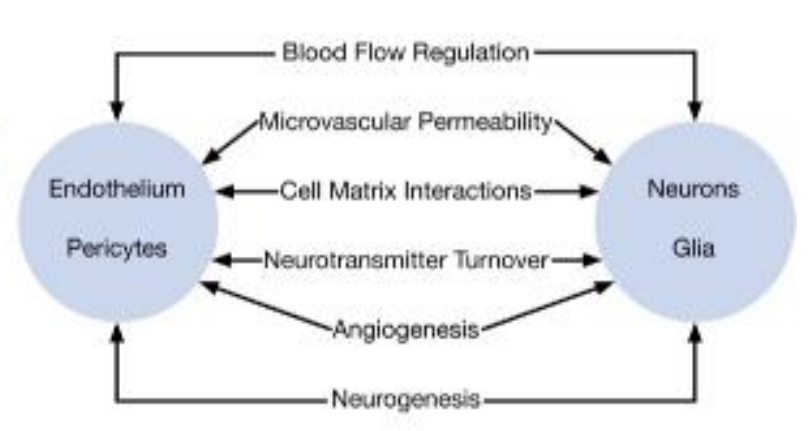

Figure 1-3. Schematic of the neurovascular unit. Neuron 2008;57:178-201

Autoregulation of the brain microvasculature is the most important mechanism to ensure constant and sufficient perfusion. The capillaries of the brain are perfused with blood at all times and each have their own neuron. When the resistance arteries and arterioles dilate, the microvascular pressure gradient increases, thus increasing capillary flow. Red blood cell velocity is high in the cerebral capillary microcirculation to provide efficient oxygen transport to the highly metabolic neuronal tissue (29). The microvessel innervation is intrinsic, meaning each vessel is innervated from within the brain tissue. The nerve terminals do not, however, contact the arteriole itself but rather targets astrocytes surrounding the vessel (30). Middle cerebral artery (MCA) smooth muscle cells are contracted by the binding of serotonin (5-HT) to $\alpha_{1}$-adrenoreceptors to cause activation of the phospholipase $\mathrm{C}$-protein kinase $\mathrm{C}$ pathway (31). Interestingly, sympathetic stimulation has little effect on resting cerebral blood flow under normotensive conditions. In contrast, parasympathetic stimulation has potent effects on cerebral arteries, and increases cerebral blood flow (32). Neuronal NO is important for modulating cerebral blood flow autoregulation. Other vasoactive substances such as $\mathrm{H}^{+}, \mathrm{K}^{+}, \mathrm{O}_{2}$, and adenosine are released to cause vasodilation 
when cerebral blood flow is reduced. When blood flow pressure is at the high end of the autoregulatory curve, regulation is probably due to the myogenic response of the cerebral smooth muscle to constrict in response to elevated pressure. Evidence for the crucial importance of autoregulation in normal brain function is provided by the fact that significant brain injury occurs when this autoregulatory mechanism is lost (33-35). Another protective mechanism for the cerebral circulation is segmental vascular resistance, meaning both large arteries and small arterioles contribute significantly to vascular resistance. This mechanism helps to provide constant blood flow in the brain to meet high metabolic demand, without pathologically increasing hydrostatic pressure $(36,37)$.

\section{Metabolic Syndrome (MetS)}

Thirty-five percent of all American adults and 50\% of those aged 60 years and older present with MetS (38). There is a 3-fold increased risk for CVD with MetS and the syndrome alone predicted $25 \%$ of all new-onset CVD (39). The conditions that underlie the metabolic syndrome, including most types of cardiovascular disease, have a cumulative cost of over $\$ 300$ billion in the US annually, which comprises the largest financial burden on the US healthcare system. For contrast, the annual cost of all types of cancer is just under $\$ 90$ billion $(38,40)$. MetS is defined by the co-occurrence of several cardiovascular risk factors including insulin resistance, obesity, atherogenic dyslipidemia, and hypertension. Previous research has shown that these risk factors are not independent of one another and they share underlying causes, mechanisms, and features $(41,42)$. The current definition of MetS is centered on insulin resistance and obesity. Insulin resistance is measured as impaired fasting glucose or glucose tolerance. An increased homeostatic 
model assessment of insulin resistance (HOMA-IR) is also indicative of insulin resistance. The diagnosis of MetS is contingent on the patient presenting with three or more of the criteria.

Insulin stimulates the synthesis of glycogen from glucose and inhibits glycogenolysis in the liver and skeletal muscle. Lipolysis is inhibited, and glucose uptake is stimulated by insulin in adipose tissue. Insulin signaling activates two pathways: the phosphoinositide 3-kinase (PI3K) and mitogen-activated protein kinase (MAPK) pathways. PI3K activates Akt kinase which phosphorylates and activates eNOS in vascular endothelial cells. Akt kinase also stimulates translocation of the insulin-responsive glucose transporter GLUT4 to the cell surface, leading to increased glucose uptake. Activation of the MAPK pathway mediates ET-1 production, leading to vasoconstriction; expression of the vascular cell adhesion molecules VCAM-1 and E-selectin, leading to more leukocytes-endothelial interactions; and growth and mitogenesis effects on vascular smooth muscle cells.

Low levels of ROS contribute to normal physiological cell signaling but when there is excessive production or impaired buffering of ROS, there can be deleterious effects. Many pathologies augment the production of ROS from nicotinamide adenine dinucleotide phosphate oxidase (NOX), xanthine oxidase (XO), cyclooxygenases (COX), and even eNOS. ROS, such as superoxide, degrades NO by binding to it to form peroxynitrite. Peroxynitrite is a highly unstable free radical that causes endothelial damage, and NO bioavailability is lowered. NOX is the predominant source of superoxide and is found in both endothelial and smooth muscle cells. Superoxide dismutase (SOD) usually breaks down superoxide anions into hydrogen peroxide but under pathological conditions, SOD function decreases and leads to an impaired buffering of ROS. Experimental inhibition of SOD results in impaired agonist-evoked endothelium-dependent, NOmediated dilation (43-46). 
Other endogenous antioxidant systems exist in the vasculature including glutathione and hydrogen peroxide-reducing enzymes, glutathione peroxidase and catalase. Supplemental treatment with antioxidants acutely improve endothelium-dependent relaxation in vitro and in vivo (47-50). 4-hydroxy-TEMPO (TEMPOL) is a common pharmaceutical agent used to scavenge free radicals. Previous studies have shown that both acute and chronic treatment with TEMPOL can increase NO bioavailability and improve endothelium-dependent dilation response $(51,52)$. ROS can effect eNOS directly through $S$-glutathionylation to inactivate the enzyme (53).

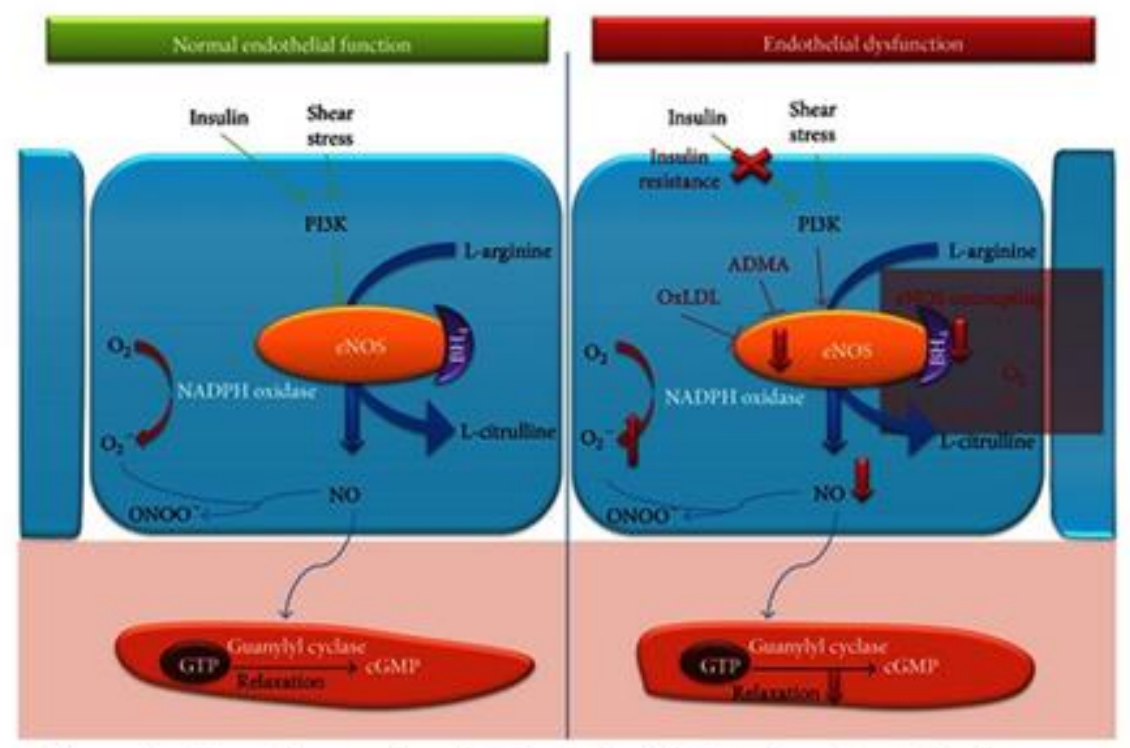

Figure 1-4. Normal versus impaired endothelial function. Bruyndonckx et al. 2013.

MetS encompasses a variety of different factors that contribute to endothelial dysfunction (Figure 1-4). Other contributors to endothelial dysfunction associated with MetS include: increased ROS production by oxidase complexes leading to damages of the insulin receptors; increased insulin receptor substrate (IRS)-1 phosphorylation at Ser307; induction of ET-1 expression in the endothelium; exaggerated activation of endothelial mineralocorticoid receptors by aldosterone; and increased production of tumor necrosis factor- $\alpha$ (TNF- $\alpha)$ (54). MetS alters arachidonic acid metabolism and shifts the pathway from mainly vasodilatory to vasoconstrictor 
metabolites $(55,56)$. Results from previous studies suggest that insulin resistance and increase oxidative stress contribute to enhanced TP activation which is independent of increased TxA2 or TP activity (57).

Blood flow must meet the metabolic demands of the tissue and where this is especially important is the skeletal muscle and brain. The microvascular network is optimized for meeting these demands but under pathological conditions, structural alterations to the network can elevate vascular resistance and impair functional hyperemic responses (58). This includes the loss of microvessels within the tissue, or microvascular rarefaction. Microvascular rarefaction can also decrease the ability of skeletal muscle to resist fatigue through impairments in the processes of mass transport and exchange $(59,60)$. The extent of rarefaction is correlated with a loss in NO bioavailability, suggested by previous studies that used physiological and pharmacological interventions to maintain NO levels and the severity of microvascular rarefaction was blunted (6165). Fluctuations in markers of inflammation and oxidative stress, such as TNF- $\alpha$, nitrotyrosine, and thromboxane, have been shown to be predictive of microvessel density changes (66).

Previous studies have provided evidence for a link between the balance of systemic vascular oxidant stress and endothelial function and progression/severity of microvascular rarefaction (66-68). This suggests that NO bioavailability is also linked to microvascular rarefaction because rarefaction followed the reduction in NO levels, and interventions aimed at improving NO bioavailability were the most effective in blunting the severity of rarefaction $(69,70)$. 


\section{Insulin Resistance}

Insulin resistance affects the PI3K-Akt pathway but not the MAPK pathway. This means NO production is reduced and ET-1 and expression of adhesion molecules are unaffected (71). During insulin resistance conditions, adipose, skeletal muscle, and liver cells do not respond appropriately to insulin, and circulating glucose levels remain high. Insulin resistance causes a reduction in eNOS phosphorylation; thus, the endothelium-dependent, NO-mediated relaxation response is blunted. As a common pathway in CVD and in the development of atherosclerosis, endothelial dysfunction is affected by each of the constituent risk factors of MetS. The major feature of endothelial dysfunction is a reduction in NO bioavailability. eNOS activation by phosphorylation at Ser-1177 is diminished by insulin resistance. Activation of eNOS is essential to the hemodynamic actions of insulin, thus during insulin resistance blood flow to skeletal muscle is reduced. ET-1 expression and vascular smooth muscle mitogenic effects are not affected by insulin resistance, therefore exacerbating endothelial dysfunction. TNF- $\alpha$ blocks IRS-1 activation and directly activates NOX to increase superoxide generation. This cytokine also stimulates lipolysis, resulting in FFA release (72).

\section{Visceral adiposity}

Obesity causes a reduction in NO-mediated, endothelium-dependent relaxation because of increased ROS production and decreased phosphorylation of eNOS $(73,74)$. The release of endothelium-derived vasoconstrictor prostanoids and ET-1 is also upregulated. Previous studies have found that caloric restriction, weight loss, and exercise training improve endotheliumdependent responses, which could partially be explained by deacetylation and activation of eNOS by SIRT1 (75). Free fatty acids diminish PI3K-Akt signaling, increase ROS, and increase ET-1 
production (71,76-78). As another major risk factor of MetS, visceral obesity causes a decrease in insulin-mediated glucose uptake through adipokine signaling including TNF- $\alpha$ and IL-6. Adiponectin is a protective adipokine that couples insulin sensitivity with energy metabolism but adiponectin levels are decreased in obesity and MetS. Adiponectin attenuates ET-1-induced vasoconstriction in normal, healthy conditions but with obesity, adiponectin levels are decreased and the imbalance of ET-1 vs. adiponectin could contribute to insulin resistance. Further, ET-1 stimulates reactive oxygen species (ROS) production by NAPDH oxidase, thus promoting oxidative stress-induced vascular dysfunction $(4,79)$.

\section{Atherogenic dyslipidemia}

Dyslipidemia is characterized by high plasma triglyceride levels, low HDL cholesterol levels, and an increase in small dense LDL. Insulin resistance and dyslipidemia are causative factors of one another. Insulin normally suppresses lipolysis in adipocytes, thus when insulin signaling is impaired there is an increase in lipolysis and increase of free fatty acid levels. apoB, the major lipoprotein of very-low-density lipoprotein (VLDL) particles, is stabilized by free fatty acids resulting in more VLDL production. Insulin also regulates the activity of lipoprotein lipase, the major mediator of VLDL clearance. If HDL is triglyceride-rich, hepatic lipase can rapidly clear it from the circulation to leave fewer HDL particles to participate in reverse cholesterol transport from the vasculature. This perpetuates the dyslipidemia associated with MetS $(39,71,80)$. 


\section{Hypertension}

The generally accepted view of hypertension is it causes premature aging of the vasculature because it is exposed to chronically increased arterial blood pressure. It has been shown that NO bioavailability is reduced, thus causing a reduction in endothelium-dependent dilation response. A variety of different mechanisms have been proposed as to why NO is decreased. Perticone et al, (81) attributed lower NO bioavailability in hypertension to higher circulating levels of asymmetric dimethylarginine (ADMA). High blood pressure can cause epigenomic DNA methylation and RNA processing changes which alter gene expressions, increase oxidative stress, and precipitate senescence of endothelial cells (82). Increased intraluminal pressure can also increase local angiotensin signaling and further augment oxidative stress (83). All of these factors lead to endothelial dysfunction. A chronic increase in perfusion pressure, in the case of hypertension, also causes microvascular rarefaction (84).

\section{Animal model of MetS}

Lois Zucker discovered the $f a$ mutation in a cross between Merck M-strain and Sherman rats, and rats that are homozygous for this allele present with a missense mutation in the leptin receptor (85). These rats are named obese Zucker rats (OZR). Leptin is released by adipose tissue in proportion to the amount of lipids stored and acts in the brain to determine a decrease in food intake and an increase in energy expenditure. By 3-5 weeks, the OZRs become noticeably obese as a result of hyperphagia, and develop defective non-shivering thermogenesis and preferential deposition of energy into adipose tissue. These animals also have elevated circulating leptin levels as compared to their lean counterparts. At 14 weeks, the body composition of the obese Zucker is 
approximately $40 \%$ lipid weight $(85,86)$. The OZRs also present with dyslipidemia, insulin resistance, and mild glucose intolerance.

Mesenteric arterial function is reduced in OZRs. Wu et al. (87), found the endotheliumdependent dilation response to Ach was significantly reduced and incubation with LNAME inhibited dilation even further. This study and others suggest endothelial dysfunction in OZRs, perhaps by a decrease in NO bioavailability (88-92). A study by Frisbee and Stepp (89) confirmed this finding, but in the cremaster muscle arteriole. Further, the study attributed the decrease in dilation response to increased levels of superoxide which in turn ameliorated NO levels.

MetS is associated with microvascular rarefaction along with endothelial dysfunction. Chantler et al. (70), showed a decrease in cerebral cortical MVD in OZRs by 12-13 weeks. Cerebral MVD was reduced by 20\% in 16-17-week-old OZRs as compared to LZR controls. This study used two pharmaceuticals prescribed for glycemic control and found they were effective in reducing plasma levels of nitrotyrosine (marker of oxidative stress) and blunting microvascular rarefaction (70). It is important to note that MetS-associated loss of MVD is not solely present in the brain, but also in the skeletal muscle.

Lash et al. (93), compared the capillary density (CD) and capillary basement membrane (CBM) thickness in the plantar muscle of sedentary and trained OZRs to those of lean Zucker rats (LZR). At 11 weeks of age, OZRs had lower CD and thicker CBM than LZRs. CD and CBM decreased proportionally greater in OZRs from 11 weeks to 18 weeks. Exercise training for 6 or 12 weeks significantly increased CD in 18-week OZRs. A study by Xiang et al. (94), showed exercise training could also improve skeletal muscle microvascular function, specifically by augmenting endothelium-dependent dilation. 
The collective factors of MetS cause direct endothelial injury, resulting in vascular remodeling. Lumen remodeling occurs in three ways: hypotrophic (thinned), eutrophic (invariant), or hypertrophic (thickened). Thickening of the vessel wall usually occurs by vascular smooth muscle cell proliferation and migration, impaired integrity of elastin fibers, and deposition of extracellular matrix (95).

MetS causes an increase in circumferential wall stress and flow-mediate shear stress, leading to vascular remodeling. Specifically, carotid wall thickness is increased as is lumen diameter (96-98). In OZRs, the microvasculature has been shown to undergo atrophic remodeling, a reduced lumen size and thinner vascular walls (99). The coronary resistance microvessels in a swine model of MetS demonstrated inward hypertrophic remodeling (100). Vascular remodeling is variable, possibly site- and animal-dependent (101). MetS causes arterial stiffening, which may be due to decreased NO bioavailability, smooth muscle cell proliferation, and increased synthesis of structural proteins including collagen. The chronic inflammation associated with MetS can also induce release of matrix metalloproteinases (MMPs). Leukocytes can facilitate outward remodeling, while macrophages can expedite inward remodeling (102). Further, local hormones such as angiotensin II induces hypertrophy of vascular smooth muscle cells and increases collagen production by fibroblasts (103).

A disease that is often underdiagnosed and undertreated is peripheral artery disease (PAD). PAD is associated with an elevated risk of poor cardiovascular outcomes such as myocardial infarction, stroke and even death. More than 200 million people have PAD worldwide. Pain related to PAD causes patient quality of life to diminish as mobility and independence are progressively reduced, often exceeding the loss of function seen in patients with other forms of cardiovascular 
disease (CVD) (104). The individuals most affected by PAD are those 50 years and older, with a sharp rise in prevalence around the age of 70 (105).

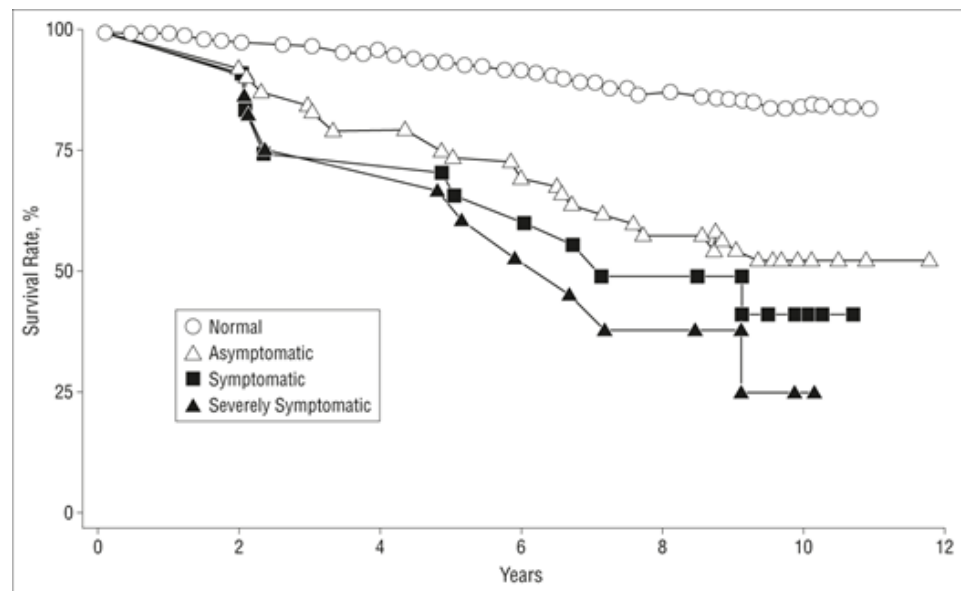

Figure 1-5. 10-year survival rate for patients with and without PAD. San Diego Artery Study, 1992.

The risk factors associated with PAD correlate with those of CVD. The first is diabetes mellitus which is estimated to attribute to PAD in $14 \%$ of patients (106). The duration of diabetes mellitus, level of glycemic control, and use of insulin are strongly correlated with the increased risk of PAD (107,108). Diabetic patients with PAD have worse outcomes such as an increased amputation risk and 3-times higher odds of mortality (109) (Figure 1-5).

Several other risk factors for PAD are hypertension, dyslipidemia, obesity, and increased C-reactive protein. These are not just risk factors for PAD, but also fall under the cluster of factors that constitute MetS. Hypertension and systolic blood pressure were found to be significantly and independently associated with PAD. The higher prevalence of PAD in elderly patients renders hypertension a major contributor to the total burden of PAD in the population (110). The ratio between total cholesterol and HDL-C is another measure for increased risk of PAD. The typical dyslipidemia seen in insulin-resistant individuals (low HDL-C and high triglycerides) is 
significantly associated with PAD (111). Although obesity has not been found to be independently associated with PAD, the factors linked to obesity, like the ones previously stated, contribute to PAD. A higher waist/hip ratio has been found to be significantly correlated with a higher risk of PAD even though BMI or body fat percentage were not (108). An increase in inflammatory markers, such as C-reactive protein, have also been shown to contribute to PAD risk (112).

\section{Chronic Stress and Depression}

Diagnosing depression is actually problematic because distinguishing mood changes between clinical and normally occurring is difficult. Depressive symptoms in and of themselves are complex, characterized by the absence of a positive effect (anhedonia), low mood, and a range of associated emotional, cognitive, physical and behavioral symptoms. Major depression is based on its severity, persistence, the presence of other symptoms, and the degree of functional and social impairment but there is no distinct 'cut-off' between 'major' and 'normal' degrees of depression $(113,114)$.

In major depressive disorder, mood remains low throughout the day and does not change with circumstance. Within other forms of depression, mood can be reactive to positive experiences and events, but depressive feelings return/reemerge quickly after the event is over (115). Physical and behavioral symptoms include tearfulness, irritability, social withdrawal, and exacerbation of pre-existing pains, pains secondary to increased muscle tension, a lack of libido, and fatigue and diminished activity. In some patients sleep and appetite are lowered but in others, sleep and appetite are increased. Other behavioral changes associated with depression include: loss of interest and enjoyment in everyday life, feelings of guilt, worthlessness and that one deserves punishment, lowered self-esteem, loss of confidence, and suicidal ideation. Poor concentration and 
reduced attention, pessimistic and recurrently negative thoughts about oneself, one's past and the future, and mental slowing are all cognitive changes that occur with depression $(116,117)$.

It used to be thought that depression was time-limited and although it is episodic, incomplete recovery and relapse are very common. Fifty percent of people will have at least one more episode after their first, and after the second and third episodes, the risk of further relapse rises to 70 and $90 \%$, respectively (118). As the most common mental disorder, depression is a major cause of disability across the world. There is a strong correlation between illness severity and the extent of disability (119). Depressive illness causes a greater decrement in health state than the major chronic physical illnesses such as angina, arthritis, asthma, and diabetes (120). The emotional and cognitive effects of depression substantially reduce a person's ability to work effectively, which increases dependence on welfare and benefits and reduces personal income. When coupled with pre-existing physical diseases, health is worsened as compared with physical disease alone and increases risk of death $(117,120)$.

The etiology of depression spans many different physiological processes and factors. Diabetes, cardiac disease, diseases of the thyroid, Cushing's syndrome, and Addison's disease have all been shown to increase the risk of depression (117). Interestingly, some psychological disorders have been found to be significantly correlated with PAD such as anxiety and depressive symptoms (121). The prevalence of depression in PAD is similar to that in CVD, which is from 210\%. Depression has been linked with certain risk factors for PAD including coronary artery disease, hypertension, and diabetes mellitus. Hippisley-Cox et al. (122), found that $20 \%$ of depressed patients also had coronary artery disease and Frasure-Smith et al. (123), showed a significant increased mortality in patients with comorbid depression and coronary artery disease. Patients with hypertension are three times as likely to have concurrent major depression (124). In 
individuals with diabetes mellitus, the mean prevalence of depression is $32 \%$ (125). The fact that PAD risk factors are significantly related to depression suggests there is a bi-directional causality between the two. Brostow et al. (126) examined the link between the physical dysfunction caused by PAD and the negative affect of depression on walking ability. The study made the connection that depressed PAD patients may experience a multifactorial burden of disease because PAD directly impacts patients' ability to walk and depression is also an independent predictor of disability and loss of mobility (126). Another study by Smolderen et al. (127) found that depressed PAD patients performed worse on the treadmill exercise test.

\section{Chronic Stress}

The state of threatened homeostasis, or stress, is caused by intrinsic and/or extrinsic adverse forces (stressors). The body then tries to counteract these stressors by activating physiologic and behavioral responses to reestablish equilibrium. Chronic stressors have the most detrimental effects on physiological functions including growth, reproduction, metabolism, immunocompetence, and behavior and personality development (128). In addition to these effects, chronic stress acts as a pre-disposing and participating factor in the onset of depression in humans (129-131).

Part of the stress response system includes the hypothalamic-pituitary-adrenal (HPA) axis. Corticotropin-releasing hormone $(\mathrm{CRH})$ acts to regulate the anterior pituitary adrenocorticotropic hormone (ACTH). Under normal, non-stressful conditions, $\mathrm{CRH}$ and vasopressin are secreted in a circadian fashion but also pulsatile with a pulse of production every 1-2 hours. The production of CRH and vasopressin increase in the early morning hours $(132,133)$. Acute stress augments CRH 
and vasopressin production and induces the production of Ang II and various cytokines and lipid mediators of inflammation, leading to further activation of the HPA axis (134).

ACTH targets the adrenal cortex to regulate glucocorticoid and adrenal androgen secretion. Cortisol secretion is increased during times of stress, and can be regulated by other hormones and cytokines coming from the adrenal medulla or systemic circulation (135). Glucocorticoids increase hepatic gluconeogenesis and glucose plasma levels, induce lipolysis, and cause protein degradation in multiple tissues. Therefore, chronic HPA axis activation can have detrimental effects including increased visceral adiposity, suppressed osteoblastic activity, decreased lean body mass, and insulin resistance (136-138). Previous studies have shown that chronic stressors increased the incidence of visceral obesity and MetS $(138,139)$. In addition to accumulation of visceral adipose tissue, chronic stress strongly correlates with behavioral changes that decrease physical activity and poor dietary habits, therefore leading to further weight gain and potentially to dysregulation of glucose and lipid metabolism $(140,141)$.

Under chronic systemic inflammation situations, such as in MetS, prolonged increased circulating levels of pro-inflammatory cytokines can lead to hyperactivation and derangement of the HPA axis (142). Adipocytes specifically release pro-inflammatory cytokines such as TNF- $\alpha$ and IL-6 that can chronically stimulate the HPA axis to induce a vicious cycle whereby hypercortisolemia contributes to adipocyte accumulation and vice versa $(80,143)$. After chronic exposure to high aldosterone levels NO-dependent relaxations are impaired, perhaps due to a reduction in $\mathrm{BH} 4$ production and an increase in oxidative stress, thus augmenting the release of vasoconstrictor prostaglandins (144). Endothelium-dependent reactivity is reduced under chronically high cortisol levels, probably due to a decrease in eNOS expression (145). 
Little is known about how chronic stress and depression directly impact vascular structure and cause remodeling. Aldosterone has been shown to decrease vascular integrity by disrupting endothelial remodeling, specifically by modifying the actin cytoskeleton assembly. Cortisol was found to partially mimic this effect by aldosterone where it significantly increased paracellular permeability and influenced distribution of junction-associated proteins (146).

\section{Unpredictable Chronic Mild Stress Model}

Unpredictable Chronic Mild Stress (UCMS) is a well-known, validated animal model using chronic stress to induce depressive symptoms. Most studies that use this model have documented physiological changes in the brains of rodents, mainly reflecting an elevated physiological stress response (147). The effects of UCMS have been attributed to its impact on the HPA axis, shown by the prevention of a depressive phenotype when glucocorticoid receptors are inhibited (148151) and development of depressive symptoms when exogenous corticosterone is given $(149,150,152)$.

Changes in NO levels have been discovered in chronic stress-induced depression patients but it is unclear in humans whether bioavailability is increased or decreased $(153,154)$. In animals, however, Gao et al. (155) have shown an increase in plasma NO levels and decrease in total NOS activity. Isingrini et al. (156), illustrated an overall decrease in endothelium-dependent dilation response of the aorta in UCMS. The maximum response was significantly lower in UCMS as compared to the control group (156). Oxidative stress associated with chronic stress and depression

directly decrease NO bioavailability. Zhou et al. (157), found that nNOS mRNA and protein 
content were elevated in the hippocampus. nNOS enzymatic activity was also enhanced, consistent with the increase in expression (157).

\section{Exercise}

\section{Acute Effects}

Initiation of exercise causes drastic changes in hemodynamics through different mechanisms. The sympathetic nervous system directs increased sympathetic outflow to the heart to increase cardiac output and evokes baroreflex-mediated vasoconstriction in peripheral organs to redirect blood flow to contracting skeletal muscles and maintain blood pressure $(158,159)$. This process is called functional hyperemia. Exercise creates a 'muscle-pump' to increase the blood flow to the active muscles.

Dilation of the arterioles is important to provide sufficient blood flow to meet the increased demand for oxygen. Vasoactive metabolites such as potassium ions, adenosine, and NO from the muscle, all generate vasodilation $(160,161)$. Through the production of adenosine and NO, sympathetic vasoconstrictor tone in exercising muscles is lessened, a process known as functional sympatholysis.

Exercise inherently increases shear stress within the lumen of blood vessels, which contributes to the regulation of vascular tone (162). The increase in shear stress acts to trigger vasodilation, mainly through NO release from endothelial cells, but also hydrogen peroxide, epoxyeicosatrienoic acids, and PGI2. ATP released from endothelial cells stimulates purinergic receptors to induce NO production from endothelial cells. It has also been shown that in response to laminar shear stress, eNOS mRNA expression is upregulated (163). All of these factors caused by shear stress aid in vasodilation to provide proper perfusion of active skeletal muscle. 
Sudden increases in shear stress induce bursts of PGI2, a vasodilator, to be released. In the skeletal muscle arterioles, PGI2 plays a larger role in flow-mediated vasodilation than it does in conduit arteries. After short-term daily exercise the gracilis muscle arteriole response to wall shear stress was upregulated and resulted in an augmented dilator response, perhaps due to increased NO and prostacyclin (164). Continuous release of NO and prostacyclin, enhanced by shear stress, can counteract neurogenic and myogenic vasoconstriction in vivo (165).

Previous studies have shown that short-term exercise increased endothelial NO synthesis in skeletal muscle arterioles and increased the vasodilator response to Ach. Endotheliumdependent dilation was improved in conduit arteries as well (166). These results suggest that shortterm exercise training enhances NO production and activity to buffer increased shear stress.

Active muscles release myokines such as IL-6 and IL-8. IL-6 is known to influence AMPactivated protein kinase (AMPK). It is thought that through this pathway, vasodilation is activated by AMPK phosphorylating eNOS to produce NO. Skeletal muscle also highly expresses neuronal NOS (nNOS), which enhances the production of IL-6 (167).

\section{Chronic Effects}

Adaptive changes in skeletal muscle circulation are found after chronic exercise training to improve blood flow capacity and oxygen diffusing capacity. Mainly this occurs through angiogenic adaptations and remodeling of the vasculature (160,168-170), but it also exerts beneficial effects on vascular reactivity.

The periodic increases in blood flow improve endothelium-dependent vasodilation by modulating the expression of NO synthase. The magnitude and nature of shear stress has influence 
on endothelial cell NO synthesis, where laminar shear stress dose dependently upregulates NO synthesis but turbulent shear stress has no effect on the NO synthase pathway (171). One mechanism by which flow augments NO synthase is through an increase in the involvement of shear stress responsive elements within the promoter region of the gene. The sequence for these shear stress responsive elements is also common in other endothelial genes that respond to shear stress including tissue plasminogen activator, intracellular adhesion molecule, TGF- $\beta$, PDGF- $\beta$, and ET-1 (172,173).

Flow-mediated vascular remodeling is endothelium-dependent. With chronic low flow, vessel diameter decreases but the opposite is true for a chronic increase in flow. It is proposed that the endothelium induces changes in vessel structure by producing vascular growth-mediators such as NO, TGF- $\beta$, PDGF- $\beta$, ET-1, PGI2, and tissue plasminogen activator $(15,164,174-178)$.

Exercise increases capillary density and arteriolar number. The stimulation of angiogenesis may be derived from perivascular or stromal cells responding to mediators and mechanical forces associated with exercise to release angiogenic factors such as vascular endothelial growth factor (VEGF) and NO, thus inducing vascular remodeling $(179,180)$. IL-8 seems to be involved with the angiogenic response to exercise. This particular myokine can affect pericyte function, which is essential for endothelial lumen formation during angiogenesis $(167,181,182)$.

\section{Protective Effects}

Dysfunction within the peripheral microcirculation contributes significantly to pathologic conditions but exercise can mitigate the pathologic consequences through its protective actions. 


\section{Major Depressive Disorder}

Using a chronic mild stress model, Watanasriyakul et al., (183) illustrated the beneficial effects of voluntary wheel running in the prairie vole. This study found that exercise trained voles had significantly lower depressive- and anxiety-behaviors, along with lower corticosterone levels as compared to sedentary voles. Four weeks of swimming exercise reversed UCMS-induced depression-like behaviors (184). Vancampfort et al. (185) through meta-analysis found a significant negative association between physical activity and suicide ideation (SI) levels. Further, "active" people were less likely to have SI but also were protected against SI.

\section{Ischemia}

Ischemia in any tissue can be deleterious to its function, and therefore, blood flow is of utmost importance. Exercise can precondition the heart and skeletal muscles to induce ischemic tolerance. The periods of increased blood flow and shear stress stimulate the release of substances such as NO and prostacyclin, which not only decrease the permeability of arterial walls to plasma lipoproteins, but also attenuate inflammatory processes $(186,187)$.

\section{Inflammation}

A general risk factor for poor cardiovascular outcomes is chronic inflammation. Diseases associated with this type of inflammatory state include MetS, PAD, depression, and CVD. The main target of the inflammatory response is the endothelium of both large and small blood vessels 
alike. This creates endothelial barrier dysfunction, expansion of proinflammatory stimuli, enhanced adhesion/leukocyte molecule expression, platelet recruitment, impaired vasomotor function, and vascular remodeling $(187,188)$. The proinflammatory response contributes to enhanced cell trafficking and to the translocation of large inflammatory molecules into the blood vessel due to increase permeability (189). Exercise can reduce the damaging effects of inflammation on the endothelium by downregulating transcription of proinflammatory and atherogenic genes.

\section{Oxidative Stress}

Endothelium-dependent dilation impairment is caused by increased ROS production by the vasculature and circulating immune cells, upregulated angiotensin II and ET-1 production, which in turn activate NADPH oxidase and can uncouple eNOS (190). There is a reduction in endothelialderived bioavailable NO, which is partially responsible for the diminished responses to Ach or increased shear stress. NO and superoxide interact to form peroxynitrite. Peroxynitrite is detrimental to NO production because it interacts with the eNOS cofactor, tetrahydrobiopterin, to cause eNOS uncoupling (191). The protective effect of exercise acts to decrease ROS production and increase eNOS function. 


\section{Microvascular Rarefaction}

Hypertension, diabetes, and obesity cause the skeletal muscle microcirculation to undergo significant degenerative remodeling, known as microvascular rarefaction (Figure 1-6). This results from an imbalance of pro- and anti-angiogenic factors, cleavage of vascular growth factor receptors by matrix metalloproteinases, oxidant-mediated inactivation of $\mathrm{NO}$, impaired angiogenic responses to growth factors, and alterations in adipokine expression (69). However, exercise can attenuate microvascular rarefaction by increasing $\mathrm{NO}$ bioavailability and decreasing inflammatory cytokines such as MCP-1 and IL-1 $\beta$ (69).

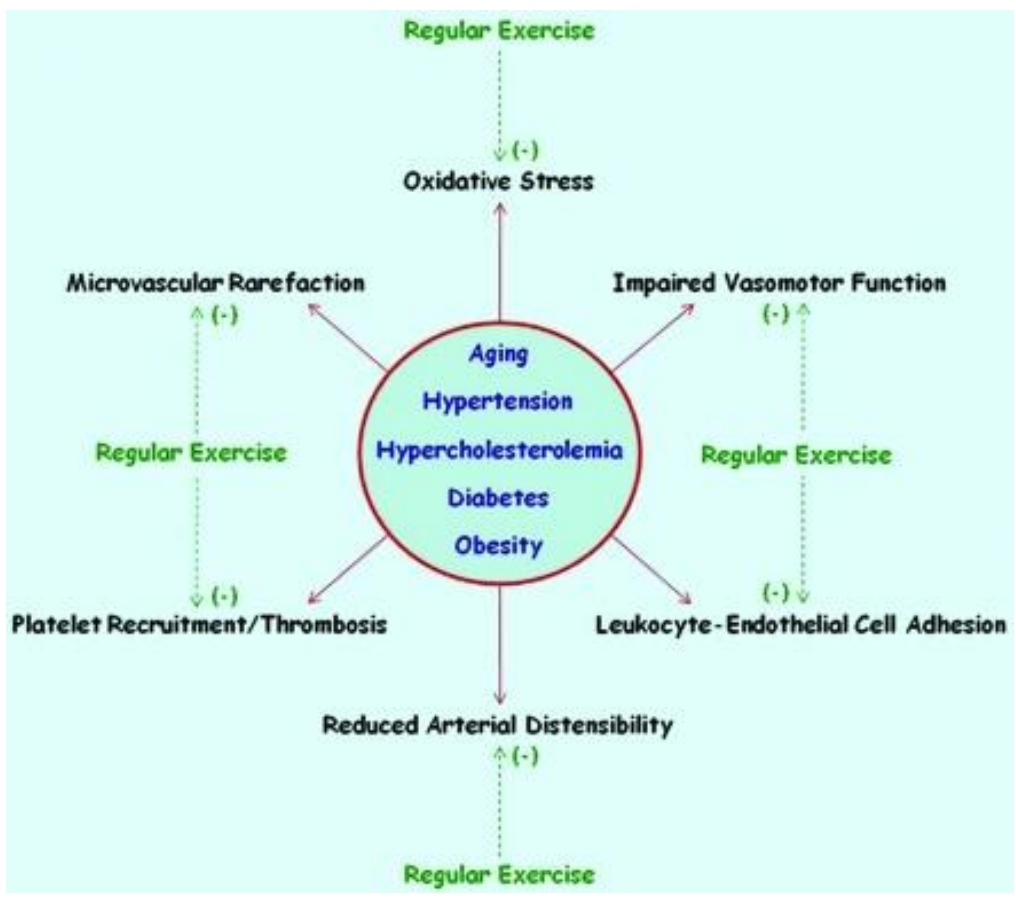

Figure 1-6. Protective effects of exercise. Korthius 2011. 


\section{Summary and Statement of Aims}

Previous studies have focused on the causative mechanisms of MetS and chronic stressinduced depression separately, however, there is a high prevalence of comorbidity between these two. The effects of this comorbidity on the peripheral microvasculature are unknown. There is a clear association between the vasculopathy present in each disorder and the effect of increased oxidative stress on vascular reactivity and MVD. The endothelial functional deficits, as well as the loss of MVD, seen in MetS and chronic stress-induced depression are causal to the poor cardiovascular outcomes correlated with the disorders. It is important to determine if chronic stress-induced depression exacerbates the vascular dysfunction present in MetS. Exercise has been shown in many previous studies to augment NO bioavailability, decrease ROS, and improve endothelium-dependent dilation response. This raises the question whether exercise can directly improve the vascular dysfunction associated with MetS and chronic stress-induced depression, and perhaps the exacerbated effects of the comorbidity. Further, exercise may attenuate loss of MVD and, in fact, stimulate angiogenesis.

Therefore, this dissertation aims to use a valid and reliable model of MetS to examine the hypothesis: 1) UCMS will cause peripheral microvascular dysfunction and microvascular dysfunction in LZRs similar to that seen in OZRs; 2) OZRs exposed to UCMS will have exacerbated peripheral microvascular dysfunction; 3) the peripheral microvascular dysfunction and loss of MVD are caused by reduced NO bioavailability and increase in oxidative stress; and 4) exercise can augment peripheral microvascular dysfunction and rarefaction by decreasing oxidative stress and improving endothelium-dependent dilation response. 


\section{References}

1. Golbidi S, Frisbee JC, Laher I. Chronic stress impacts the cardiovascular system: animal models and clinical outcomes. Am J Physiol - Hear Circ Physiol [Internet]. 2015;308(12):H1476-98. Available from:

http://ajpheart.physiology.org/lookup/doi/10.1152/ajpheart.00859.2014

2. Klabunde RE. Cardiovascular Physiology Concepts (2nd Ed.). Lippincott Williams \& Wilkins [Internet]. 2012;256. Available from: http://books.google.com/books?hl=en\&lr=\&id=Ns77UPURq30C\&pgis=1

3. Davis MJ, Hill MA. Signaling mechanisms underlying the vascular myogenic response. Physiol Rev. 1999;79(2):387-423.

4. Korthuis RJ. Skeletal Muscle Circulation [Internet]. Vol. 3, Colloquium Series on Integrated Systems Physiology: From Molecule to Function. 2011. 1-144 p. Available from:

http://www.ncbi.nlm.nih.gov/books/NBK57137/\%5Cnhttp://www.morganclaypool.com/d oi/abs/10.4199/C00035ED1V01Y201106ISP023

5. Laughlin MH, Pollock JS, Amann JF, Hollis ML, Woodman CR, Price EM. Training induces nonuniform increases in eNOS content along the coronary arterial tree. J Appl Physiol. 2001;90(2):501-10.

6. Masaki T, Yanagisawa M, Goto K. Physiology and pharmacology of endothelins. Med Res Rev. 1992;12(4):391-421.

7. Baber SR, Deng W, Rodriguez J, Master RG, Bivalacqua TJ, Hyman AL, et al. Vasoactive prostanoids are generated from arachidonic acid by COX-1 and COX-2 in the 
mouse. Am J Physiol Heart Circ Physiol [Internet]. 2005;289(4):H1476-87. Available from: http://www.ncbi.nlm.nih.gov/pubmed/15863457

8. Sessa WC. eNOS at a glance. J Cell Sci [Internet]. 2004;117(12):2427-9. Available from: http://jcs.biologists.org/cgi/doi/10.1242/jcs.01165

9. Sessa WC. Regulation of endothelial derived nitric oxide in health and disease. In: Memorias do Instituto Oswaldo Cruz. 2005. p. 15-8.

10. Pfeiffer S, Leopold E, Schmidt K, Brunner F, Mayer B. Inhibition of nitric oxide synthesis by NG-nitro-L-arginine methyl ester (L-NAME): requirement for bioactivation to the free acid, NG-nitro-L-arginine. Br J Pharmacol [Internet]. 1996;118(6):1433-40. Available from:

http://www.pubmedcentral.nih.gov/articlerender.fcgi?artid=1909689\&tool=pmcentrez\&re ndertype $=$ abstract

11. Amezcua JL, Palmer RM, de Souza BM, Moncada S. Nitric oxide synthesized from Larginine regulates vascular tone in the coronary circulation of the rabbit. Br J Pharmacol [Internet]. 1989;97(4):1119-24. Available from: http://www.ncbi.nlm.nih.gov/entrez/query.fcgi?cmd=Retrieve\&db=PubMed\&dopt=Citati on\&list_uids=2790378

12. Lahera V, Salom MG, Miranda-Guardiola F, Moncada S, Romero JC. Effects of NGnitro-L-arginine methyl ester on renal function and blood pressure. Am J Physiol. 1991;261(6 Pt 2):F1033-7.

13. Davis MJ. Myogenic response gradient in an arteriolar network. Am J Physiol [Internet]. 1993;264(6 Pt 2):H2168-79. Available from: papers://35bd2bc7-b5b1-49ed-bd73- 
ff0858dd5ce0/Paper/p6601

14. Davis MJ, Hill MA, Kuo L. Local Regulation of Microvascular Perfusion. In: Microcirculation. 2008. p. 161-284.

15. Koller A, Kaley G. Endothelial regulation of wall shear stress and blood flow in skeletal muscle microcirculation. Am J Physiol [Internet]. 1991;260(3 Pt 2):H862-8. Available from: http://www.ncbi.nlm.nih.gov/pubmed/2000980

16. Kuo L, Davis MJ, Chilian WM. Endothelium-dependent, flow-induced dilation of isolated coronary arterioles. Am J Physiol [Internet]. 1990;259(4 Pt 2):H1063-70. Available from: http://www.ncbi.nlm.nih.gov/pubmed/2221113

17. Smiesko V, Lang DJ, Johnson PC. Dilator response of rat mesenteric arcading arterioles to increased blood flow velocity. Am J Physiol. 1989;257(6 Pt 2):H1958-65.

18. Sinoway LI, Hendrickson C, Jr WRD, Prophet S, Zelis R. Characteristics of FlowMediated Brachial Artery Vasodilation in Human Subjects. Circ Res. 1988;64(1):32-43.

19. Hudlicka O. Microcirculation in skeletal muscle. Muscles Ligaments Tendons J [Internet]. 2011;1(1):3-11. Available from: http://www.pubmedcentral.nih.gov/articlerender.fcgi?artid=3666465\&tool=pmcentrez\&re ndertype $=$ abstract

20. Delp MD. Integrative control of the skeletal muscle microcirculation in the maintenance of arterial pressure during exercise. J Appl Physiol [Internet]. 2004;97(3):1112-8. Available from: http://jap.physiology.org/cgi/doi/10.1152/japplphysiol.00147.2003

21. Klein B, Kuschinsky W, Schröck H, Vetterlein F. Interdependency of local capillary 
density, blood flow, and metabolism in rat brains. Am J Physiol [Internet]. 1986;251(6 Pt

2):H1333-40. Available from: http://www.ncbi.nlm.nih.gov/pubmed/3098116

22. Lok J, Gupta P, Guo S, Kim WJ, Whalen MJ, Van Leyen K, et al. Cell-cell signaling in the neurovascular unit. Vol. 32, Neurochemical Research. 2007. p. 2032-45.

23. Rennels ML, Nelson E. Capillary innervation in the mammalian central nervous system: An electron microscopic demonstration. Am J Anat. 1975;144(2):233-41.

24. Zlokovic B V. The Blood-Brain Barrier in Health and Chronic Neurodegenerative Disorders. Vol. 57, Neuron. 2008. p. 178-201.

25. Hamel E. Perivascular nerves and the regulation of cerebrovascular tone. J Appl Physiol [Internet]. 2005;100(3):1059-64. Available from: http://jap.physiology.org/cgi/doi/10.1152/japplphysiol.00954.2005

26. Allt G, Lawrenson JG. Pericytes: Cell biology and pathology. Vol. 169, Cells Tissues Organs. 2001. p. 1-11.

27. Dore-Duffy P, LaManna JC. Physiologic angiodynamics in the brain. Antioxid Redox Signal [Internet]. 2007;9(9):1363-71. Available from: http://www.ncbi.nlm.nih.gov/pubmed/17627476

28. Liebeskind DS. Collateral circulation. Vol. 34, Stroke. 2003. p. 2279-84.

29. Cipolla MJ. The Cerebral Circulation. In: Colloquium Series on Integrated Systems Physiology: From Molecule to Function to Disease [Internet]. 2009. p. 1-59. Available from: http://bjarev.oxfordjournals.org/cgi/doi/10.1093/bjacepd/1.3.67\%5Cnhttp://www.morganc 
laypool.com/doi/abs/10.4199/C00005ED1V01Y200912ISP002

30. Cohen Z, Molinatti G, Hamel E. Astroglial and vascular interactions of noradrenaline terminals in the rat cerebral cortex. J Cereb Blood Flow Metab. 1997;17(8):894-904.

31. Alberts B, Johnson A, Lewis J. Signaling through G-Protein-Linked Cell-Surface Receptors. In: Molecular Biology of the Cell. 4th ed. New York: Garland Science; 2002. p. 1-17.

32. Goadsby PJ. Autonomic nervous system control of the cerebral circulation. Handb Clin Neurol. 2013;117:193-201.

33. Talman WT, Nitschke Dragon D. Neuronal nitric oxide mediates cerebral vasodilatation during acute hypertension. Brain Res. 2007;1139(1):126-32.

34. Strandgaard S, MacKenzie ET, Sengupta D, Rowan JO, Lassen NA, Harper AM. Upper limit of autoregulation of cerebral blood flow in the baboon. Circ Res [Internet]. 1974;34(4):435-40. Available from: http://www.ncbi.nlm.nih.gov/pubmed/4363762

35. Paulson OB, Strandgaard S, Edvinsson L. Cerebral autoregulation. Cerebrovasc Brain Metab Rev [Internet]. 1990;2(2):161-92. Available from: http://www.ncbi.nlm.nih.gov/pubmed/2201348

36. Heistad DD, Marcus ML, Abboud FM. Role of large arteries in regulation of cerebral blood flow in dogs. J Clin Invest. 1978;62(4):761-8.

37. Johnson PC. The Myogenic Response. Physiology. 1991;6(1):41-2.

38. Aguilar M, Bhuket T, Torres S, Liu B, Wong RJ. Prevalence of the Metabolic Syndrome in the United States, 2003-2012. JAMA [Internet]. 2015;313(19):1973. Available from: 
http://jama.jamanetwork.com/article.aspx?doi=10.1001/jama.2015.4260

39. Grundy SM, Brewer HB, Cleeman JI, Smith SC, Lenfant C. Definition of Metabolic Syndrome: Report of the National Heart, Lung, and Blood Institute/American Heart Association Conference on Scientific Issues Related to Definition. In: Circulation. 2004. p. 433-8.

40. Grundy SM. Metabolic syndrome pandemic. Vol. 28, Arteriosclerosis, Thrombosis, and Vascular Biology. 2008. p. 629-36.

41. Grundy SM, Cleeman JI, Daniels SR, Donato KA, Eckel RH, Franklin BA, et al. Diagnosis and management of the metabolic syndrome: An American Heart Association/National Heart, Lung, and Blood Institute scientific statement. Vol. 112, Circulation. 2005. p. 2735-52.

42. Kahn R, Buse J, Ferrannini E, Stern M. The metabolic syndrome: time for a critical appraisal: joint statement from the American Diabetes Association and the European Association for the Study of Diabetes. Diabetes Care [Internet]. 2005;28(9):2289-304. Available from: http://www.ncbi.nlm.nih.gov/pubmed/16123508

43. Carneado J, Alvarez de Sotomayor M, Perez-Guerrero C, Jimenez L, Herrera MD, Pamies E, et al. Simvastatin improves endothelial function in spontaneously hypertensive rats through a superoxide dismutase mediated antioxidant effect. J Hypertens [Internet]. 2002;20(3):429-37. Available from: http://www.ncbi.nlm.nih.gov/pubmed/11875310

44. Mugge A, Elwell JH, Peterson TE, Harrison DG. Release of intact endothelium-derived relaxing factor depends on endothelial superoxide dismutase activity. Am J Physiol. 1991;260(2 Pt 1):C219-25. 
45. Omar HA, Cherry PD, Mortelliti MP, Burke-Wolin T, Wolin MS. Inhibition of coronary artery superoxide dismutase attenuates endothelium-dependent and -independent nitrovasodilator relaxation. Circ Res [Internet]. 1991;69(3):601-8. Available from: http://www.ncbi.nlm.nih.gov/pubmed/1651814

46. Wambi-Kiéssé CO, Katusic ZS. Inhibition of copper/zinc superoxide dismutase impairs NO.-mediated endothelium-dependent relaxations. Am J Physiol. 1999;276(3 Pt 2):H1043-8.

47. Aubin MC, Carrier M, Shi YF, Tardif JC, Perrault LP. Role of probucol on endothelial dysfunction of epicardial coronary arteries associated with left ventricular hypertrophy. $\mathbf{J}$ Cardiovasc Pharmacol [Internet]. 2006;47(5):702-10. Available from: http://www.ncbi.nlm.nih.gov/pubmed/16775511

48. Liu Y-H, You Y, Song T, Wu S-J, Liu L-Y. Impairment of endothelium-dependent relaxation of rat aortas by homocysteine thiolactone and attenuation by captopril. $\mathrm{J}$ Cardiovasc Pharmacol [Internet]. 2007;50(2):155-61. Available from: http://www.ncbi.nlm.nih.gov/pubmed/17703131

49. Costa CA, Amaral TS, Carvalho LCRM, Ognibene DT, da Silva AFE, Moss MB, et al. Antioxidant treatment with tempol and apocynin prevents endothelial dysfunction and development of renovascular hypertension. Am J Hypertens [Internet]. 2009;22(12):12429. Available from: http://dx.doi.org/10.1038/ajh.2009.186

50. Dal-Ros S, Zoll J, Lang AL, Auger C, Keller N, Bronner C, et al. Chronic intake of red wine polyphenols by young rats prevents aging-induced endothelial dysfunction and decline in physical performance: Role of NADPH oxidase. Biochem Biophys Res 
Commun. 2011;404(2):743-9.

51. Chatterjee PK, Cuzzocrea S, Brown PJ, Zacharowski K, Stewart KN, Mota-Filipe H, et al. Tempol, a membrane-permeable radical scavenger, reduces oxidant stress-mediated renal dysfunction and injury in the rat. Kidney Int. 2000;58:658-73.

52. Banday AA, Marwaha A, Tallam LS, Lokhandwala MF. Tempol reduces oxidative stress, improves insulin sensitivity, decreases renal dopamine D1 receptor hyperphosphorylation, and restores D1 receptor-G-protein coupling and function in obese Zucker rats. Diabetes [Internet]. 2005;54(7):2219-26. Available from:

http://www.ncbi.nlm.nih.gov/entrez/query.fcgi?cmd=Retrieve\&db=PubMed\&dopt=Citati on\&list_uids=15983225

53. Chen C-A, Wang T-Y, Varadharaj S, Reyes LA, Hemann C, Talukder MAH, et al. Sglutathionylation uncouples eNOS and regulates its cellular and vascular function. Nature [Internet]. 2010;468(7327):1115-8. Available from:

http://www.nature.com/doifinder/10.1038/nature09599

54. Vanhoutte PM, Shimokawa H, Feletou M, Tang EHC. Endothelial dysfunction and vascular disease - a 30th anniversary update. Vol. 219, Acta Physiologica. 2017. p. $22-96$.

55. Traupe T, Lang M, Goettsch W, Münter K, Morawietz H, Vetter W, et al. Obesity increases prostanoid-mediated vasoconstriction and vascular thromboxane receptor gene expression. J Hypertens [Internet]. 2002;20(11):2239-45. Available from: http://www.ncbi.nlm.nih.gov/pubmed/12409963

56. Davi G, Guagnano MT, Ciabattoni G, Basili S, Falco A, Marinopiccoli M, et al. Platelet activation in obese women: role of inflammation and oxidant stress. Jama. 
2002;288(16):2008-14.

57. Xiang L, Dearman J, Abram SR, Carter C, Hester RL. Insulin resistance and impaired functional vasodilation in obese Zucker rats. Am J Physiol Heart Circ Physiol [Internet]. 2008;294(4):H1658-66. Available from: http://www.ncbi.nlm.nih.gov/pubmed/18296567

58. Frisbee JC. Reduced nitric oxide bioavailability contributes to skeletal muscle microvessel rarefaction in the metabolic syndrome. Am J Physiol Regul Integr Comp Physiol. 2005;289(2):R307-16.

59. McGuire BJ, Secomb TW. A theoretical model for oxygen transport in skeletal muscle under conditions of high oxygen demand. J Appl Physiol [Internet]. 2001;91(5):2255-65. Available from: http://www.ncbi.nlm.nih.gov/pubmed/11641369

60. McGuire BJ, Secomb TW. Estimation of capillary density in human skeletal muscle based on maximal oxygen consumption rates. Am J Physiol Hear Circ Physiol [Internet]. 2003;285(6):H2382--91. Available from: http://www.ncbi.nlm.nih.gov/entrez/query.fcgi?cmd=Retrieve \&db=PubMed\&dopt=Citati on\&list_uids=12893642

61. Dai X, Faber JE. Endothelial nitric oxide synthase deficiency causes collateral vessel rarefaction and impairs activation of a cell cycle gene network during arteriogenesis. Circ Res. 2010;106(12):1870-81.

62. Faber JE, Zhang H, Lassance-Soares RM, Prabhakar P, Najafi AH, Burnett MS, et al. Aging causes collateral rarefaction and increased severity of ischemic injury in multiple tissues. Arterioscler Thromb Vasc Biol. 2011;31(8):1748-56. 
63. Fernandes T, Nakamuta JS, Magalhães FC, Roque FR, Lavini-Ramos C, Schettert IT, et al. Exercise training restores the endothelial progenitor cells number and function in hypertension: implications for angiogenesis. J Hypertens [Internet]. 2012;30(11):2133-43. Available from: http://www.ncbi.nlm.nih.gov/pubmed/23052048

64. Goligorsky MS. Microvascular rarefaction: the decline and fall of blood vessels. Organogenesis [Internet]. 2010;6(1):1-10. Available from: http://www.pubmedcentral.nih.gov/articlerender.fcgi?artid=2861737\&tool=pmcentrez\&re ndertype $=$ abstract

65. Okutsu M, Call JA, Lira VA, Zhang M, Donet JA, French BA, et al. Extracellular superoxide dismutase ameliorates skeletal muscle abnormalities, cachexia, and exercise intolerance in mice with congestive heart failure. Circ Hear Fail. 2014;7(3):519-30.

66. Frisbee JC, Goodwill AG, Frisbee SJ, Butcher JT, Brock RW, Olfert IM, et al. Distinct temporal phases of microvascular rarefaction in skeletal muscle of obese Zucker rats. Am J Physiol Heart Circ Physiol. 2014;307(12):H1714-28.

67. Frisbee JC. Hypertension-independent microvascular rarefaction in the obese Zucker rat model of the metabolic syndrome. Microcirculation [Internet]. 2005;12(24):383-92. Available from: http://www.ncbi.nlm.nih.gov/pubmed/16020387

68. Gealekman O, Brodsky S V., Zhang F, Chander PN, Friedli C, Nasjletti A, et al. Endothelial dysfunction as a modifier of angiogenic response in Zucker diabetic fat rat: Amelioration with Ebselen. Kidney Int. 2004;66(6):2337-47.

69. Frisbee JC, Samora JB, Peterson J, Bryner R. Exercise training blunts microvascular rarefaction in the metabolic syndrome. Am J Physiol Heart Circ Physiol. 
2006;291(5):H2483-92.

70. Chantler PD, Shrader CD, Tabone LE, d'Audiffret AC, Huseynova K, Brooks SD, et al. Cerebral Cortical Microvascular Rarefaction in Metabolic Syndrome is Dependent on Insulin Resistance and Loss of Nitric Oxide Bioavailability. Microcirculation [Internet]. 2015;22(6):435-45. Available from: http://doi.wiley.com/10.1111/micc.12209

71. Huang PL. A comprehensive definition for metabolic syndrome. Dis Model Mech. 2009;2(5-6):231-7.

72. Eckel RH, Grundy SM, Zimmet PZ. The metabolic syndrome. In: Lancet. 2005. p. 141528.

73. Van Guilder GP, Stauffer BL, Greiner JJ, DeSouza CA. Impaired endothelium-dependent vasodilation in overweight and obese adult humans is not limited to muscarinic receptor agonists. AJP Hear Circ Physiol [Internet]. 2008;294(4):H1685-92. Available from: http://ajpheart.physiology.org/cgi/doi/10.1152/ajpheart.01281.2007

74. Karagiannis J, Reid JJ, Darby I, Roche P, Rand MJ, Li CG. Impaired nitric oxide function in the basilar artery of the obese Zucker rat. J Cardiovasc Pharmacol. 2003;42(4):497505.

75. Mattagajasingh I, Kim C-S, Naqvi A, Yamamori T, Hoffman TA, Jung S-B, et al. SIRT1 promotes endothelium-dependent vascular relaxation by activating endothelial nitric oxide synthase. Proc Natl Acad Sci U S A [Internet]. 2007;104(37):14855-60. Available from: http://www.pubmedcentral.nih.gov/articlerender.fcgi?artid=1976244\&tool=pmcentrez\&re ndertype $=$ abstract 
76. Huang PL. Unraveling the links between diabetes, obesity, and cardiovascular disease. Circulation Research. 2005;96(11):1129-31.

77. Atochin DN, Wang A, Liu VWT, Critchlow JD, Dantas AP V, Looft-Wilson R, et al. The phosphorylation state of eNOS modulates vascular reactivity and outcome of cerebral ischemia in vivo. J Clin Invest. 2007;117(7):1961-7.

78. Kershaw EE, Flier JS. Adipose tissue as an endocrine organ. J Clin Endocrinol Metab [Internet]. 2004;89(6):2548-56. Available from: http://www.ncbi.nlm.nih.gov/pubmed/15181022

79. Randall MD. Vascular activities of the endothelins. Vol. 50, Pharmacology and Therapeutics. 1991. p. 73-93.

80. Kyrou I, Chrousos GP, Tsigos C. Stress, visceral obesity, and metabolic complications. In: Annals of the New York Academy of Sciences. 2006. p. 77-110.

81. Perticone F, Sciacqua A, Maio R, Perticone M, Maas R, Boger RH, et al. Asymmetric dimethylarginine, L-arginine, and endothelial dysfunction in essential hypertension. J Am Coll Cardiol. 2005;46(3):518-23.

82. Chiu J-J, Chien S. Effects of Disturbed Flow on Vascular Endothelium: Pathophysiological Basis and Clinical Perspectives. Physiol Rev [Internet]. 2011;91(1):327-87. Available from: http://physrev.physiology.org/cgi/doi/10.1152/physrev.00047.2009

83. Zhao Y, Flavahan S, Leung SW, Xu A, Vanhoutte PM, Flavahan NA. Elevated pressure causes endothelial dysfunction in mouse carotid arteries by increasing local angiotensin 
signaling. Am J Physiol - Hear Circ Physiol [Internet]. 2015;308(4):H358-63. Available from: http://ajpheart.physiology.org/lookup/doi/10.1152/ajpheart.00775.2014

84. Greene AS, Tonellato PJ, Zhang Z, Lombard JH, Cowley AW. Effect of microvascular rarefaction on tissue oxygen delivery in hypertension. Am J Physiol Hear Circ Physiol. 1992;262(5):H1486-93.

85. Zucker LM, Antoniades HN. Insulin and obesity in the zucker genetically obese rat “Fatty.” Endocrinology. 1972;90(5):1320-30.

86. Zucker LM. Hereditary obesity in the rat associated with hyperlipemia. Ann N Y Acad Sci. $1965 ; 131(1): 447-58$.

87. Wu X, Makynen H, Kahonen M, Arvola P, Porsti I. Mesenteric arterial function in vitro in three models of experimental hypertension. J Hypertens [Internet]. 1996;14(3):365-72. Available from: http://www.ncbi.nlm.nih.gov/entrez/query.fcgi?cmd=Retrieve\&db=PubMed\&dopt=Citati on\&list_uids=8723991

88. Johnson FK, Johnson RA, Durante W, Jackson KE, Stevenson BK, Peyton KJ. Metabolic syndrome increases endogenous carbon monoxide production to promote hypertension and endothelial dysfunction in obese Zucker rats. Am J Physiol Regul Integr Comp Physiol. 2006;290(3):R601-8.

89. Frisbee JC, Stepp DW. Impaired NO-dependent dilation of skeletal muscle arterioles in hypertensive diabetic obese Zucker rats. Am J Physiol Heart Circ Physiol. 2001;281(3):H1304-11. 
90. Xiang L, Naik JS, Hodnett BL, Hester RL. Altered arachidonic acid metabolism impairs functional vasodilation in metabolic syndrome. Am J Physiol Regul Integr Comp Physiol [Internet]. 2006;290(1):R134-138. Available from:

http://ajpregu.physiology.org/cgi/content/abstract/290/1/R134

91. Frisbee JC. Enhanced arteriolar alpha-adrenergic constriction impairs dilator responses and skeletal muscle perfusion in obese Zucker rats. J Appl Physiol (Bethesda, Md 1985) [Internet]. 2004;97(2):764-72. Available from:

http://www.ncbi.nlm.nih.gov/pubmed/15075303

92. Phillips SA, Sylvester FA, Frisbee JC. Oxidant stress and constrictor reactivity impair cerebral artery dilation in obese Zucker rats. Am J Physiol Regul Integr Comp Physiol [Internet]. 2005;288(2):R522-30. Available from:

http://www.ncbi.nlm.nih.gov/pubmed/15514104

93. Lash JM, Sherman WM, Hamlin RL. Capillary basement membrane thickness and capillary density in sedentary and trained obese Zucker rats. Diabetes. 1989;38(7):854-60.

94. Xiang L, Naik J, Hester RL. Exercise-induced increase in skeletal muscle vasodilatory responses in obese Zucker rats. Am J Physiol Regul Integr Comp Physiol [Internet]. 2005;288(4):R987-91. Available from: http://www.ncbi.nlm.nih.gov/pubmed/15604297

95. Xu X, Wang B, Ren C, Hu J, Greenberg DA, Chen T, et al. Age-related Impairment of Vascular Structure and Functions. Aging Dis [Internet]. 2017;8(5):590-610. Available from:

http://www.ncbi.nlm.nih.gov/pubmed/28966804\%0Ahttp://www.pubmedcentral.nih.gov/a rticlerender.fcgi?artid=PMC5614324 
96. Fournier SB, Reger BL, Donley DA, Bonner DE, Warden BE, Gharib W, et al. Exercise reveals impairments in left ventricular systolic function in patients with metabolic syndrome. Exp Physiol [Internet]. 2014;99(1):149-63. Available from:

http://www.ncbi.nlm.nih.gov/pubmed/24036595

97. Scuteri A, Najjar SS, Muller DC, Andres R, Hougaku H, Metter EJ, et al. Metabolic syndrome amplifies the age-associated increases in vascular thickness and stiffness. J Am Coll Cardiol. 2004;43(8):1388-95.

98. Ferreira I, Beijers HJ, Schouten F, Smulders YM, Twisk JW, Stehouwer CD. Clustering of metabolic syndrome traits is associated with maladaptive carotid remodeling and stiffening: A 6-year longitudinal study. In: Hypertension. 2012. p. 542-9.

99. Stepp DW, Pollock DM, Frisbee JC. Low-flow vascular remodeling in the metabolic syndrome X. Am J Physiol Heart Circ Physiol. 2004;286(3):H964-70.

100. Trask AJ, Katz PS, Kelly AP, Galantowicz ML, Cismowski MJ, West TA, et al. Dynamic micro- and macrovascular remodeling in coronary circulation of obese Ossabaw pigs with metabolic syndrome. J Appl Physiol [Internet]. 2012;113(7):1128-40. Available from: http://jap.physiology.org/cgi/doi/10.1152/japplphysiol.00604.2012

101. Chantler PD, Frisbee JC. Arterial Function in Cardio-Metabolic Diseases: From the Microcirculation to the Large Conduits. Prog Cardiovasc Dis [Internet]. 2015;57(5):48996. Available from: http://linkinghub.elsevier.com/retrieve/pii/S0033062014001376

102. Bakker ENTP, Pistea A, Spaan JAE, Rolf T, De Vries CJ, Van Rooijen N, et al. Flowdependent remodeling of small arteries in mice deficient for tissue-type transglutaminase: Possible compensation by macrophage-derived factor XIII. Circ Res. 2006;99(1):86-92. 
103. Williams B. Angiotensin II and the pathophysiology of cardiovascular remodeling. Am J Cardiol. 2001;87(8A):10C-17C.

104. Belch JJF, Topol EJ, Agnelli G, Bertrand M, Califf RM, Clement DL, et al. Critical issues in peripheral arterial disease detection and management: a call to action. Arch Intern Med [Internet]. 2003;163(8):884-92. Available from:

http://www.ncbi.nlm.nih.gov/pubmed/12719196

105. Allison MA, Ho E, Denenberg JO, Langer RD, Newman AB, Fabsitz RR, et al. EthnicSpecific Prevalence of Peripheral Arterial Disease in the United States. Am J Prev Med. 2007;32(4):328-33.

106. Joosten MM, Pai JK, Bertoia ML, Rimm EB, Spiegelman D, Mittleman MA, et al. Associations Between Conventional Cardiovascular Risk Factors and Risk of Peripheral Artery Disease in Men. JAMA [Internet]. 2012;308(16):1660. Available from: http://jama.jamanetwork.com/article.aspx?doi=10.1001/jama.2012.13415

107. Althouse AD, Abbott JD, Forker AD, Bertolet M, Barinas-Mitchell E, Thurston RC, et al. Risk factors for incident peripheral arterial disease in type 2 diabetes: Results from the bypass angioplasty revascularization investigation in type 2 diabetes (BARI 2D) trial. Diabetes Care. 2014;37(5):1346-52.

108. Katsilambros NL, Tsapogas PC, Arvanitis MP, Tritos NA, Alexiou ZP, Rigas KL. Risk Factors for Lower Extremity Arterial Disease in Non-Insulin-Dependent Diabetic Persons. Vol. 13, Diabetic Medicine. 1996. p. 243-6.

109. Jude EB, Oyibo SO, Chalmers N, Boulton a J. Peripheral arterial disease in diabetic and nondiabetic patients: a comparison of severity and outcome. Diabetes Care. 
2001;24(8):1433-7.

110. Hooi JD, Kester AD, Stoffers HE, Overdijk MM, van Ree JW, Knottnerus JA. Incidence of and risk factors for asymptomatic peripheral arterial occlusive disease: a longitudinal study. Am J Epidemiol [Internet]. 2001;153(7):666-72. Available from:

http://www.ncbi.nlm.nih.gov/pubmed/11282794

111. Mowat BF, Skinner ER, Wilson HM, Leng GC, Fowkes FG, Horrobin D. Alterations in plasma lipids, lipoproteins and high density lipoprotein subfractions in peripheral arterial disease. Atherosclerosis [Internet]. 1997;131(2):161-6. Available from: http://www.ncbi.nlm.nih.gov/pubmed/9199268

112. Bloemenkamp DGM, Van Den Bosch MAAJ, Mali WPTM, Tanis BC, Rosendaal FR, Kemmeren JM, et al. Novel risk factors for peripheral arterial disease in young women. Am J Med [Internet]. 2002;113(6):462-7. Available from: https://www.scopus.com/inward/record.uri?eid=2-s2.00037109529\&partnerID=40\&md5=eb4bceda70eeacf07cdc7fbcfc5551cc

113. Lewinsohn PM, Solomon A, Seeley JR, Zeiss A. Clinical implications of "subthreshold" depressive symptoms. J Abnorm Psychol. 2000;109(2):345-51.

114. Kessing L V. Epidemiology of subtypes of depression. In: Acta Psychiatrica Scandinavica. 2007. p. 85-9.

115. American Psychiatric Association. Diagnostic and statistical manual of mental disorders (5th ed.). American Journal of Psychiatry. 2013. 991 p.

116. Gerber PD, Barrett JE, Barrett JA, Oxman TE, Manheimer E, Smith R, et al. The 
relationship of presenting physical complaints to depressive symptoms in primary care patients. J Gen Intern Med. 1992;7(2):170-3.

117. Cassano P, Fava M. Depression and public health: An overview. In: Journal of Psychosomatic Research. 2002. p. 849-57.

118. Kupfer DJ. Long-term treatment of depression. J Clin Psychiatry [Internet]. 1991;52 Suppl:28-34. Available from: http://www.ncbi.nlm.nih.gov/pubmed/1903134

119. Ormel J, VonKorff M, Ustun TB, Pini S, Korten A, Oldehinkel T. Common mental disorders and disability across cultures. Results from the WHO Collaborative Study on Psychological Problems in General Health Care. Jama [Internet]. 1994;272(22):1741-8. Available from: http://www.ncbi.nlm.nih.gov/pubmed/7966922

120. Moussavi S, Chatterji S. Depression, chronic diseases, and decrements in health: results from the World Health Surveys. Lancet. 2007;370:851-8.

121. McDermott MM, Greenland P, Guralnik JM, Liu K, Criqui MH, Pearce WH, et al. Depressive symptoms and lower extremity functioning in men and women with peripheral arterial disease. J Gen Intern Med [Internet]. 2003;18(6):461-7. Available from: http://www.ncbi.nlm.nih.gov/entrez/query.fcgi?cmd=Retrieve\&db=PubMed\&dopt=Citati on\&list_uids=12823653\%5Cnhttp://pubmedcentralcanada.ca/picrender.cgi?accid=PMC14 94875\&blobtype $=$ pdf

122. Hippisley-Cox J, Fielding K, Pringle M. Depression as a risk factor for ischaemic heart disease in men: population based case-control study. Bmj. 1998;316(7146):1714-9.

123. Frasuresmith N, Lesperance F, Talajic M. depression following myocardial-infarction - 
impact on 6-month survival. jama-journal Am Med Assoc. 1993;270(15):1819-25.

124. Rabkin JG, Charles E, Kass F. Hypertension and DSM-III depression in psychiatric outpatients. Am J Psychiatry. 1983;140(8):1072-4.

125. Gavard JA, Lustman PJ, Clouse RE. Prevalence of depression in adults with diabetes: An epidemiological evaluation. Diabetes Care. 1993;16(8):1167-78.

126. Brostow DP, Petrik ML, Starosta AJ, Waldo SW. Depression in patients with peripheral arterial disease: A systematic review. Eur J Cardiovasc Nurs [Internet]. 2017 [cited 2017 Jul 10];16(3):147451511668722. Available from:

https://doi.org/10.1177/1474515116687222

127. Smolderen KGE, Aquarius AE, De Vries J, Smith ORF, Hamming JF, Denollet J, et al. Depressive symptoms in peripheral arterial disease: A follow-up study on prevalence, stability, and risk factors. J Affect Disord [Internet]. 2008 [cited 2017 Jul 10];110:27-35. Available from: www.elsevier.com/locate/jad

128. Tsigos C, Kyrou I, Chrousos G. Stress, endocrine physiology and pathophysiology. J Psychosom Res [Internet]. 2002;53(4):865-71. Available from: http://www.ncbi.nlm.nih.gov/pubmed/25905226

129. Willner P, Towell A, Sampson D, Sophokleous S, Muscat R. Reduction of sucrose preference by chronic unpredictable mild stress, and its restoration by a tricyclic antidepressant. Psychopharmacology (Berl). 1987;93(3):358-64.

130. Anisman H, Zacharko RM. Depression as a consequence of inadequate neurochemical adaptation in response to stressors. In: British Journal of Psychiatry. 1992. p. 36-43. 
131. D'Aquila PS, Brain P, Willner P. Effects of chronic mild stress on performance in behavioural tests relevant to anxiety and depression. Physiol Behav. 1994;56(5):861-7.

132. Young EA, Abelson J, Lightman SL. Cortisol pulsatility and its role in stress regulation and health. Vol. 25, Frontiers in Neuroendocrinology. 2004. p. 69-76.

133. Horrocks PM, Jones AF, Ratcliffe WA, Holder G, White A, Holder R, et al. patterns of acth and cortisol pulsatility over twenty-four hours in normal males and females. Clin Endocrinol (Oxf). 1990;32(1):127-34.

134. Veldhuis JD, Iranmanesh A, Johnson ML, Lizarralde G. Amplitude, but not frequency, modulation of adrenocorticotropin secretory bursts gives rise to the nyctohemeral rhythm of the corticotropic axis in man. J Clin Endocrinol Metab. 1990;71(2):452-63.

135. Aguilera G. Factors controlling steroid biosynthesis in the zona glomerulosa of the adrenal. J Steroid Biochem Mol Biol. 1993;45(1-3):147-51.

136. Chrousos GP. Stress and disorders of the stress system. Nat Rev Endocrinol [Internet]. 2009;5(7):374-81. Available from: http://www.nature.com/doifinder/10.1038/nrendo.2009.106

137. Smith SM, Vale WW. The role of the hypothalamic-pituitary-adrenal axis in neuroendocrine responses to stress. Vol. 8, Dialogues in Clinical Neuroscience. 2006. p. 383-95.

138. Kyrou I, Tsigos C. Stress mechanisms and metabolic complications. In: Hormone and Metabolic Research. 2007. p. 430-8.

139. Chandola T, Brunner E, Marmot M. Chronic stress at work and the metabolic syndrome: 
prospective study. Bmj [Internet]. 2006;332(7540):521-4. Available from:

http://www.ncbi.nlm.nih.gov/entrez/query.fcgi?cmd=Retrieve \&db=PubMed\&dopt=Citati on\&list_uids=16428252\%5Cnhttp://pubmedcentralcanada.ca/picrender.cgi?accid=PMC13 88129\&blobtype $=$ pdf

140. Kyrou I, Tsigos C. Stress hormones: physiological stress and regulation of metabolism. Vol. 9, Current Opinion in Pharmacology. 2009. p. 787-93.

141. Adam TC, Epel ES. Stress, eating and the reward system. Physiol Behav. 2007;91(4):44958.

142. Tsigos C, Papanicolaou D a, Defensor R, Mitsiadis CS, Kyrou I, Chrousos GP. Dose effects of recombinant human interleukin-6 on pituitary hormone secretion and energy expenditure. Neuroendocrinology. 1997;66(1):54-62.

143. Chrousos GP. The role of stress and the hypothalamic-pituitary-adrenal axis in the pathogenesis of the metabolic syndrome: neuro-endocrine and target tissue-related causes. Int J Obes Relat Metab Disord. 2000;24 Suppl 2:S50-5.

144. Schäfer N, Lohmann C, Winnik S, van Tits LJ, Miranda MX, Vergopoulos A, et al. Endothelial mineralocorticoid receptor activation mediates endothelial dysfunction in dietinduced obesity. Eur Heart J [Internet]. 2013;34:3515-24. Available from: http://www.pubmedcentral.nih.gov/articlerender.fcgi?artid=3844149\&tool=pmcentrez\&re ndertype $=$ abstract

145. Li F, Wood CE, Keller-Wood M. Adrenalectomy alters regulation of blood pressure and endothelial nitric oxide synthase in sheep: modulation by estradiol. Am J Physiol Regul Integr Comp Physiol. 2007;293:R257-66. 
146. Kirsch T, Beese M, Wyss K, Klinge U, Haller H, Haubitz M, et al. Aldosterone modulates endothelial permeability and endothelial nitric oxide synthase activity by rearrangement of the actin cytoskeleton. Hypertension. 2013;61(2):501-8.

147. Willner P. Neurobiology of Stress The chronic mild stress ( CMS ) model of depression : History, evaluation and usage. Neurobiol Stress [Internet]. 2017;6:78-93. Available from: http://dx.doi.org/10.1016/j.ynstr.2016.08.002

148. Wu L-M, Han H, Wang Q-N, Hou H-L, Tong H, Yan X-B, et al. Mifepristone Repairs Region-Dependent Alteration of Synapsin I in Hippocampus in Rat Model of Depression. Neuropsychopharmacology [Internet]. 2007;32(12):2500-10. Available from: http://www.nature.com/doifinder/10.1038/sj.npp.1301386

149. Kvarta MD, Bradbrook KE, Dantrassy HM, Bailey AM, Thompson SM. Corticosterone mediates the synaptic and behavioral effects of chronic stress at rat hippocampal temporoammonic synapses. J Neurophysiol [Internet]. 2015;114(3):1713-24. Available from: http://jn.physiology.org/lookup/doi/10.1152/jn.00359.2015

150. Goshen I, Kreisel T, Ben-Menachem-Zidon O, Licht T, Weidenfeld J, Ben-Hur T, et al. Brain interleukin-1 mediates chronic stress-induced depression in mice via adrenocortical activation and hippocampal neurogenesis suppression. Mol Psychiatry [Internet]. 2008;13(7):717-28. Available from: http://www.nature.com/doifinder/10.1038/sj.mp.4002055

151. Chen J, Wang Z zhen, Zuo W, Zhang S, Chu S feng, Chen N hong. Effects of chronic mild stress on behavioral and neurobiological parameters - Role of glucocorticoid. Horm Behav. 2016;78:150-9. 
152. Gourley SL, Taylor JR. Recapitulation and reversal of a persistent depression-like syndrome in rodents. Current Protocols in Neuroscience. 2009.

153. Lee BH, Lee SW, Yoon D, Lee HJ, Yang JC, Shim SH, et al. Increased plasma nitric oxide metabolites in suicide attempters. Neuropsychobiology [Internet]. 2006;53(3):12732. Available from:

http://www.ncbi.nlm.nih.gov/entrez/query.fcgi?cmd=Retrieve \&db=PubMed\&dopt=Citati on\&list_uids=16601363

154. Chrapko WE, Jurasz P, Radomski MW, Lara N, Archer SL, Le Mellédo J-M. Decreased platelet nitric oxide synthase activity and plasma nitric oxide metabolites in major depressive disorder. Biol Psychiatry [Internet]. 2004;56(2):129-34. Available from: http://www.ncbi.nlm.nih.gov/pubmed/15231445

155. Gao S-F, Lu Y-R, Shi L-G, Wu X-Y, Sun B, Fu X-Y, et al. ScienceDirect Nitric oxide synthase and nitric oxide alterations in chronically stressed rats: A model for nitric oxide in major depressive disorder. Psychoneuroendocrinology [Internet]. 2014 [cited 2017 Jul 30];47:136-40. Available from: http://dx.doi.org/10.1016/j.psyneuen.2014.05.009

156. Isingrini E, Surget A, Belzung C, Freslon JL, Frisbee J, O’Donnell J, et al. Altered aortic vascular reactivity in the unpredictable chronic mild stress model of depression in mice. UCMS causes relaxation impairment to ACh. Physiol Behav [Internet]. 2011;103(5):5406. Available from: http://dx.doi.org/10.1016/j.physbeh.2011.04.002

157. Zhou QG, Hu Y, Hua Y, Hu M, Luo CX, Han X, et al. Neuronal nitric oxide synthase contributes to chronic stress-induced depression by suppressing hippocampal neurogenesis. J Neurochem. 2007;103(5):1843-54. 
158. Dela F, Mohr T, Jensen CMR, Haahr HL, Secher NH, Biering-Sørensen F, et al. Cardiovascular control during exercise: Insights from spinal cord-injured humans. Circulation. 2003;107(16):2127-33.

159. Delius W, Hagbarth K -E, Hongell A, Wallin BG. General Characteristics of Sympathetic Activity in Human Muscle Nerves. Acta Physiol Scand. 1972;84(1):65-81.

160. Blomqvist CG, Saltin B. CARDIOVASCULAR ADAPTATIONS TO PHYSICAL TRAINING. Ann Rev Physiol. 1983;4:169-89.

161. Bockman EL. Blood flow and oxygen consumption in active soleus and gracilis muscles in cats. AmJ Physiol. 1983;244:H546-51.

162. Niebauer J, Cooke JP. Cardiovascular effects of exercise: role of endothelial shear stress. J Am Coll Cardiol [Internet]. 1996;28(7):1652-60. Available from: http://www.ncbi.nlm.nih.gov/pubmed/8962548

163. Green DJ, Maiorana A, O’Driscoll G, Taylor R. Effect of exercise training on endothelium-derived nitric oxide function in humans. J Physiol. 2004;561(Pt 1):1-25.

164. Koller A, Huang A, Sun D, Kaley G. Exercise training augments flow-dependent dilation in rat skeletal muscle arterioles. Role of endothelial nitric oxide and prostaglandins. Circ Res [Internet]. 1995;76(4):544-50. Available from: http://www.ncbi.nlm.nih.gov/pubmed/7534658

165. Hecker M, Mülsch a, Bassenge E, Busse R. Vasoconstriction and increased flow: two principal mechanisms of shear stress-dependent endothelial autacoid release. Am J Physiol [Internet]. 1993;265(3 Pt 2):H828-33. Available from: 
http://www.ncbi.nlm.nih.gov/pubmed/8105699

166. Sun D, Huang A, Koller A, Kaley G. Short-term daily exercise activity enhances endothelial NO synthesis in skeletal muscle arterioles of rats. J Appl Physiol. 1994;76(5):2241-7.

167. Sarelius I, Pohl U. Control of muscle blood flow during exercise: Local factors and integrative mechanisms. Vol. 199, Acta Physiologica. 2010. p. 349-65.

168. Bowles DK, Woodman CR, Laughlin MH. Coronary smooth muscle and endothelial adaptations to exercise training. Exerc Sport Sci Rev. 2000;28(2):57-62.

169. Calbet JAL, Joyner MJ. Disparity in regional and systemic circulatory capacities: Do they affect the regulation of the circulation? Vol. 199, Acta Physiologica. 2010. p. 393-406.

170. Clarkson P, Montgomery HE, Mullen MJ, Donald a E, Powe a J, Bull T, et al. Exercise training enhances endothelial function in young men. J Am Coll Cardiol [Internet]. 1999;33(5):1379-85. Available from: http://www.ncbi.nlm.nih.gov/pubmed/10193742

171. Noris M, Morigi M, Donadelli R, Aiello S, Foppolo M, Todeschini M, et al. Nitric oxide synthesis by cultured endothelial cells is modulated by flow conditions. Circ Res. 1995;76(4):536-43.

172. Resnick N, Gimbrone Jr. MA. Hemodynamic forces are complex regulators of endothelial gene expression. FASEB J [Internet]. 1995;9(10):874-82. Available from: http://www.ncbi.nlm.nih.gov/pubmed/7615157

173. Resnick N, Collins T, Atkinson W, Bonthront DT, Dewey CF, Gimbrone MA. Plateletderived growth factor B chain promoter contains a cis-acting fluid shear-stress-responsive 
element. Proc Natl Acad Sci U S A. 1993;90:4591-5.

174. Cooke JP, Stamler J, Andon N, Davies PF, McKinley G, Loscalzo J. Flow stimulates endothelial cells to release a nitrovasodilator that is potentiated by reduced thiol. Am J Physiol [Internet]. 1990;259(3 Pt 2):H804-12. Available from: http://www.ncbi.nlm.nih.gov/pubmed/2396689

175. Grabowski EF, Jaffe EA, Weksler BB. Prostacyclin production by cultured endothelial cell monolayers exposed to step increases in shear stress. J Lab Clin Med [Internet]. 1985;105(1):36-43. Available from: http://www.ncbi.nlm.nih.gov/pubmed/3918129

176. Kuchan MJ, Frangos JA. Shear stress regulates endothelin-1 release via protein kinase C and cGMP in cultured endothelial cells. Am J Physiol [Internet]. 1993;264(1 Pt 2):H1506. Available from: http://www.ncbi.nlm.nih.gov/pubmed/8381608

177. Yoshizumi M, Kurihara H, Sugiyama T, Takaku F, Yanagisawa M, Masaki T, et al. Hemodynamic shear stress stimulates endothelin production by cultured endothelial cells. Biochem Biophys Res Commun. 1989;161(2):859-64.

178. Ohno M, Cooke JP, Dzau VJ, Gibbons GH. Fluid shear stress induces endothelial transforming growth factor beta- 1 transcription and production. Modulation by potassium channel blockade. J Clin Invest [Internet]. 1995;95(3):1363-9. Available from: http://www.pubmedcentral.nih.gov/articlerender.fcgi?artid=441476\&tool=pmcentrez\&ren dertype $=$ abstract

179. Newcomer SC, Thijssen DHJ, Green DJ. Effects of exercise on endothelium and endothelium/smooth muscle cross talk: role of exercise-induced hemodynamics. J Appl Physiol. 2011;111(March 2011):311-20. 
180. Sessa WC. Molecular control of blood flow and angiogenesis: role of nitric oxide. J Thromb Haemost [Internet]. 2009;7 Suppl 1:35-7. Available from: http://www.ncbi.nlm.nih.gov/pubmed/19630764

181. Li A, Dubey S, Varney ML, Dave BJ, Singh RK. IL-8 Directly Enhanced Endothelial Cell Survival, Proliferation, and Matrix Metalloproteinases Production and Regulated Angiogenesis. J Immunol [Internet]. 2003;170(6):3369-76. Available from: http://www.jimmunol.org/cgi/doi/10.4049/jimmunol.170.6.3369

182. Pedersen BK. Edward F. Adolph distinguished lecture: muscle as an endocrine organ: IL6 and other myokines. J Appl Physiol. 2009;107(4):1006-14.

183. Watanasriyakul WT, Wardwell J, McNeal N, Schultz R, Woodbury M, Dagner A, et al. Voluntary physical exercise protects against behavioral and endocrine reactivity to social and environmental stressors in the prairie vole. Social Neuroscience. $2017 ; 1-14$.

184. Liu W, Sheng H, Xu Y, Liu Y, Lu J, Ni X. Swimming exercise ameliorates depressionlike behavior in chronically stressed rats: Relevant to proinflammatory cytokines and IDO activation. Behav Brain Res. 2013;242(1):110-6.

185. Vancampfort D, Hallgren M, Firth J, Rosenbaum S, Schuch FB, Mugisha J, et al. Physical activity and suicidal ideation: a systematic review and meta-analysis. J Affect Disord [Internet]. 2017; Available from: http://linkinghub.elsevier.com/retrieve/pii/S0165032717313745

186. Brown DA, Moore RL. Perspectives in innate and acquired cardioprotection: cardioprotection acquired through exercise. J Appl Physiol [Internet]. 2007;103(5):18949. Available from: http://jap.physiology.org/content/103/5/1894.abstract 
187. Kalogeris T, Baines CP, Krenz M, Korthuis RJ. Cell Biology of Ischemia/Reperfusion Injury. Int Rev Cell Mol Biol. 2012;298:229-317.

188. Datla SR, Griendling KK. Reactive oxygen species, NADPH oxidases, and hypertension. Vol. 56, Hypertension. 2010. p. 325-30.

189. Prewitt R, Chen I, Dowell R. Development of microvascular rarefaction in the spontaneously hypertensive rat. Am J Physiol Hear Circ Physiol [Internet]. 1982;243(2):243-51. Available from: http://ajpheart.physiology.org/content/243/2/H243.short

190. Caballero AE. Endothelial Dysfunction in Obesity and Insulin Resistance: A Road to Diabetes and Heart Disease. Obes Res [Internet]. 2003;11(11):1278-89. Available from: http://doi.wiley.com/10.1038/oby.2003.174

191. Schwartz LM, Mckenzie JE. Adenosine and active hyperemia and gracilis muscle of cats in soleus. 1990; 


\section{CHAPTER 2 : Role of Chronic Stress and Exercise on Microvascular Function in Metabolic Syndrome}

Kayla W. Branyan ${ }^{1}$, Evan R. DeVallance ${ }^{1}$, Kent A. Lemaster $^{3}$, R. Christopher Skinner ${ }^{1}$, Randy

Bryner $^{1}$, I. Mark Olfert ${ }^{1}$, Eric E. Kelley ${ }^{2}$, Jefferson C. Frisbee ${ }^{3}$, Paul D. Chantler ${ }^{1}$

${ }^{1}$ Division of Exercise Physiology, School of Medicine, West Virginia University, Morgantown, WV; ${ }^{2}$ Department of Physiology and Pharmacology, West Virginia University, Morgantown, WV;

${ }^{3}$ Department of Medical Biophysics, Transdisciplinary Program in Vascular Health, Schulich School of Medicine and Dentistry, University of Western Ontario, London, Ontario, Canada.

Corresponding Author:

Paul D. Chantler

1 Medical Center Drive, P.O. Box 9227

Morgantown, WV 26506

pchantler@hsc.wvu.edu

Tel: 304-293-0646

Fax: 304-293-7105 


\begin{abstract}
Purpose: The present study examined the effect of unpredictable chronic mild stress (UCMS) on peripheral microvessel function in healthy and metabolic syndrome (MetS) rodents, and whether exercise training could prevent the vascular dysfunction associated with UCMS.
\end{abstract}

Methods: Lean and obese (model of MetS) Zucker rats (LZR; OZR) were exposed to 8 weeks of UCMS, exercise (Ex), UCMS+Ex, or control conditions. At the end of the intervention, gracilis arterioles (GAs) were isolated and hung in a pressurized myobath to assess endothelium-dependent (EDD) and -independent (EID) dilation. Levels of nitric oxide (NO) and reactive oxygen species (ROS) were measured through DAF-FM and DHE staining, respectively.

Results: Compared to LZR controls, EDD and EID was lower $(p=0.0001)$ in LZR-UCMS. The OZR-Ex group had a higher EDD ( $\mathrm{p}=0.0001)$ and EID ( $\mathrm{p}=0.003)$, compared to OZR-Controls; whereas only a difference in EDD ( $\mathrm{p}=0.01)$ was noted between LZR-Control and LZR-Ex groups. Importantly, EDD and EID were higher in the LZR $(p=0.0001 ; p=0.02)$ and OZR $(p=0.0001$; $\mathrm{p}=0.02) \mathrm{UCMS}+\mathrm{Ex}$ groups compared to UCMS alone. Lower NO bioavailability and higher ROS were noted in the LZR-UCMS group ( $\mathrm{p}=0.0001$ ), but not OZR-UCMS, compared to controls. Ex and UCMS-Ex groups had higher NO bioavailability $(\mathrm{p}=0.0001)$ compared to control and UCMS groups, but ROS levels remained high.

Conclusions: The comorbidity between UCMS and MetS does not exacerbate the effects of one another on GA EDD responses, but does lead to the development of other vasculopathy adaptations, which can be partially explained by alterations in NO and ROS production. Importantly, exercise training alleviates most of the negative effects of UCMS on GA function.

Key words: obesity, UCMS, skeletal muscle arteriole, endothelial dysfunction 


\section{Introduction}

Fifty-six million American adults are diagnosed with the metabolic syndrome (MetS) (14), which significantly increases an individual's risk of peripheral vascular disease (PVD). Indeed, Maksimovic et al. (5) showed that around $60 \%$ of patients with PVD also manifested with MetS. Our group, and others, have shown in a model of MetS (obese Zucker rat) there is a global reduction in vascular-derived nitric oxide (NO) bioavailability, leading to significant peripheral vascular dysfunction associated with PVD (6-9).

Depression is independent risk factor for PVD (10). Previous studies have shown that chronic stress is a major contributor to depressive illness and may be the link between depression and PVD (11-15). Stress-induced depression causes vascular dysfunction, in part, by impairing the bioavailability of dilator metabolites such as NO (16-18). Furthermore, it has been postulated that exposure to chronic psychosocial stress is a significant risk factor for the development of MetS. Indeed, approximately $43 \%$ of MetS patients present with depression (20, 23). Given that both MetS and depression result in significant vasculopathies, it remains unknown whether MetS exposed to chronic stress results in more severe vasculopathies thereby significantly increasing the risk of PVD events (myocardial infarction, heart failure, stroke, and/or limb ischemia).

Exercise, when used as an intervention, reduces the risk of PVD associated with MetS and depression, separately $(19,20)$. Previous studies have shown that chronic exercise training can increase the expression of endothelial NO synthase (NOS) and its activity (21-24). Exercise also upregulates antioxidant activity which leads to an attenuation of reactive oxygen species (ROS) production, and therefore, decreases oxidative stress $(25,26)$. Through these two mechanisms, aerobic exercise can increase NO bioavailability, improving vascular endothelial function (27) and perhaps reduce the risk of PVD associated with MetS and depression. However, it is unknown 
whether chronic exercise can limit or restore the vasculopathies involving MetS exposed to chronic stress.

The current study used the obese $(f a / f a)$ Zucker rat, a translational model of MetS that develops significant PVD risk (in the absence of significant atherosclerosis) that can impair skeletal muscle perfusion and performance, and its lean controls (LZR) to explore the role of unpredictable chronic mild stress (UCMS), exercise (Ex), and a combination of each on peripheral microvascular function $(8,28)$. UCMS is a protocol used to induce depressive-like symptoms by exposing animal models to daily, mild stressors (29-31). The UCMS protocol is accepted as a relevant rodent model of depression that has been shown to reproduce clinical symptoms of depression, including anhedonia and increased anxiety-like behavior (32). Our initial hypothesis was that: 1) LZRs exposed to UCMS would have peripheral microvascular dysfunction similar to that evident in the OZRs controls due to a reduction in NO bioavailability and an increase in ROS production; 2) the comorbidity between MetS exposed to UCMS would exacerbate the already existing peripheral microvascular dysfunction; and 3) exercise could limit the peripheral microvascular dysfunction by decreasing oxidative stress and improving vasodilation associated with MetS exposed to chronic stress.

\section{Materials and Methods}

\section{Animals}

Male LZR and OZRs (Harlan) arrived at the West Virginia University Health Sciences Center (WVUHSC) animal facility at 7-8 weeks of age. After 1 week of acclimation to the local environment, LZRs ( $n=8$ per protocol) and OZRs ( $n=8$ per protocol) were randomly assigned to 
a specific protocol group for the subsequent 8-9 weeks including: 1) sedentary controls, 2) UCMS, 3) exercise (Ex), and 4) a combination of UCMS+Ex, resulting in 8 groups in total. All animals were fed standard chow and tap water ad libitum for all experiments. Protocols received prior approval from the WVUHSC Animal Care and Use Committee.

\section{UCMS Protocol}

Previous investigators developed the UCMS model for developing depression-like behaviors in rodents (212-215). The UCMS model is considered to be the most appropriate rodent model for clinical depression, based on its ability to reproduce the development of many clinical human depressive symptoms, including anhedonia and learned helplessness (147).

All rats were singly housed. In UCMS groups, rats were exposed to the following mild environmental stressors in randomly chosen sequences for 8 hours each day, 5 days/week, over the course of 8 weeks:

1. Damp bedding - $10 \mathrm{oz}$. of water was added to each standard cage

2. Bath - all bedding was removed and $\sim 0.5$ inches of water was added to empty cage. Water temperature was room temperature, $\sim 24^{\circ} \mathrm{C}$

3. Cage Tilt - cage was tilted to 45 degrees without bedding

4. Social stress - each rat was switched into a cage of a neighboring rat

5. No bedding - all bedding was removed from the cage

6. Alteration of light/dark cycles -turning lights off/on in random increments for scheduled period.

\section{Exercise Training Protocol}


LZR and OZR underwent 8 weeks of treadmill running, either concurrent with UCMS or as a standalone treatment. Animals ran 5 days/week on multi-lane motor driven treadmills set at a $5 \%$ grade. During the first week, animals were acclimatized to the treadmill by running for $20 \mathrm{~min}$, then increasing by $10 \mathrm{~min} /$ day until sustainable duration of 60 minutes daily was achieved. A maximum speed test was performed on each animal and target-running speed was set for $60-70 \%$ of that maximum. After acclimatization, the first 15 minutes of the total 60 minutes consisted of a gradual increase until reaching target-running speed. Rats ran at this speed for the remaining 45 minutes. Mild electrical stimulus $(\leq 0.3 \mathrm{~mA})$ was used at the rear of the treadmill to discourage rats from stopping. There was a 48-hour wash out period between the last Ex bout and the terminal surgery at the end of 8-week treatment.

\section{UCMS and Exercise Combination Protocol}

OZRs and LZRs assigned to this group performed treadmill running first thing in the morning (8-9am) and then were immediately subjected to the UCMS protocol as described previously.

\section{Coat Score}

The rodents coats were evaluated throughout the duration of the 8-week protocol. Each week, the rats were weighed and inspected for grooming habits (216). The total cumulative coat score was computed by giving an individual score of 0 (clean) or 1 (dirty) to eight different body parts (i.e. head, neck, back, forelimbs, stomach, hindlimbs, tail, genitals).

\section{Circulating Cortisol}


Corticosterone is a glucocorticoid produced by the adrenal cortex in response to ACTH (corticotropic hormone) and is the precursor to aldosterone. Corticosterone is the main glucocorticoid in rodents as cortisol is in humans. The production of glucorcorticoids is increased by stress. Using a commercially available ELISA Kit (Cayman Chemical, Item \#501320) serum samples, collected at time of terminal surgery, were examined for corticosterone levels in duplicate accordingly to the manufacturer's instructions

\section{Plasma Clinical Markers}

Fasting blood was drawn intravenously from anesthetized rats into lithium-heparin coated blood tubes and transported immediately to the laboratory for analysis. Levels of triglycerides (TG), total cholesterol (TC), high-density lipoprotein (HDL) were measured by the clinical laboratory service at Ruby Memorial Hospital (Morgantown, WV). Blood glucose was measured using a commercially available glucometer (FreeStyle, Abbott), and insulin was measured using a rat ELISA kit (Cayman Chemical, item \#589501).

\section{Isolation of the Gracilis Arteriole}

After completion of the treatment period and at 17-18 weeks of age, each rat was anesthetized with pentobarbital sodium (50 mg/kg ip) and was intubated via the trachea to facilitate maintenance of a patent airway. In all rats, a carotid artery and an external jugular vein were cannulated for determination of arterial pressure and for infusion of heparin. Under anesthesia, an aliquot of blood was drawn from the inferior vena cava to be used for further analysis. 
With specific attention to the skeletal muscle circulation and its role in the development of PVD we selected the gracilis arterioles (GA) to determine the effects of MetS and UCMS on peripheral vascular function. Under deep anesthesia, both right and left gracilis arterioles (GA) were isolated from their origin in the skeletal muscle of the thigh then placed in cold $\left(4^{\circ} \mathrm{C}\right)$ physiological salt solution (PSS; in mM: $119 \mathrm{NaCL}, 1.17 \mathrm{MgSO}_{4}, 1.6 \mathrm{CaCl}_{2}, 1.18 \mathrm{NaH}_{2} \mathrm{PO}_{4}, 24$ $\mathrm{NaHCO}_{3}, 0.026$ EDTA, and 5.5 glucose). Each GA was doubly cannulated in a heated $\left(37^{\circ} \mathrm{C}\right)$ chamber that allowed perfusion and superfusion of the lumen and exterior of the vessel, respectively, with PSS from separate reservoirs. The PSS was equilibrated with a $21 \% \mathrm{O}_{2}-5 \%$ $\mathrm{CO}_{2}-74 \% \mathrm{~N}_{2}$ gas mixture. Vessel diameter was measured using microscopy and an on-screen video micrometer.

\section{Measurements of vascular reactivity in isolated $G A$}

After cannulation, GAs were extended to their in-situ length and equilibrated at $80 \%$ of the animal's mean arterial pressure (MAP) to approximate in vivo perfusion pressure. Active tone at the equilibration pressure was calculated as $\left(\Delta D / D_{\max }\right) \times 100$, where $\Delta D$ is the diameter increase from rest in response to $\mathrm{Ca}^{2+}$-free PSS and $D_{\max }$ is the maximum diameter measured at the equilibration pressure in $\mathrm{Ca}^{2+}$-free PSS.

After equilibration, the dilator reactivity of GA was assessed in response to increasing concentrations $\left(10^{-10}-10^{-6} \mathrm{M}\right)$ of acetylcholine $(\mathrm{ACh})$ to determine endothelium-dependent dilation (EDD) and sodium nitroprusside (SNP, $\left.10^{-10}-10^{-6} \mathrm{M}\right)$ to determine endothelium-independent dilation (EID). Constriction was assessed by exposing the GA to increasing doses of phenylephrine (PE, $\left.10^{-10}-10^{-7} \mathrm{M}\right)$. Vascular responses to ACh were also measured following acute (45-60 min) 
incubation with nitro-L- arginine methyl ester (L-NAME, a NO synthase inhibitor, Sigma-Aldrich N5751) $\left(10^{-4} \mathrm{M}\right)$ and 4-Hydroxy-TEMPO (TEMPOL, Sigma-Aldrich 176141$)\left(10^{-4} \mathrm{M}\right)$ to assess the contributions of NO and oxidative stress, respectively, to modulation of vascular reactivity.

Following the experimental procedures for measuring ex-vivo reactivity, the perfusate and superfusate PSS were replaced with $\mathrm{Ca}^{2+}$-free PSS containing the metal chelators EDTA (0.03 $\mathrm{mM})$ and EGTA $(2.0 \mathrm{mM})$. Vessels were stimulated with $10^{-7} \mathrm{M}(\mathrm{PE})$ to facilitate $\mathrm{Ca}^{2+}$ release and eliminate active tone. Subsequently, intraluminal pressure within the isolated vessel was altered, in $20 \mathrm{mmHg}$ increments, between 0 and $160 \mathrm{mmHg}$. To ensure that a negative intraluminal pressure was not exerted on the vessel, $5 \mathrm{mmHg}$ was used as the " $0 \mathrm{mmHg}$ " intraluminal pressure point. After 7 mins at each intraluminal pressure, the inner and outer diameters of the passive GA were determined.

\section{Measurement of Reactive Oxygen Species}

Dihydroethidium (DHE, Invitrogen D1168) assays were performed on unfixed femoral arteries to evaluate superoxide and hydrogen peroxide levels in situ. Femoral artery was used rather than GAs because the entire section of isolated GA was used for reactivity. Femoral arteries were placed in individual wells of a 96 well plate containing $200 \mu$ l of HEPES buffer. Femoral artery was incubated in control/drug treatment for 30 minutes at $37^{\circ} \mathrm{C}$. Following incubation, $2 \mu$ l of stock DHE solution was added to each well to a concentration of $10 \mu \mathrm{M}$ and incubated at $37^{\circ} \mathrm{C}$ for another 30 minutes. After completion of DHE incubation, arteries were washed in HEPES buffer, placed separately in Optimal Cutting Temperature compound (OCT, Fisher Healthcare ${ }^{\mathrm{TM}}$ Tissue-Plus $^{\mathrm{TM}}$ O.C.T Compound), and flash frozen in liquid nitrogen to be stored at $-80^{\circ} \mathrm{C}$. DHE OCT blocks 
were then cut into $8 \mu \mathrm{m}$ slices using a cryostat at $-22^{\circ} \mathrm{C}$ and transferred to charged slides (Fisherbrand ${ }^{\circledR}$ Superfrost ${ }^{\circledR}$ plus microscope slides) and stained/mounted with DAPI mounting media (VECTORSHEILD antifade mounting media with DAPI, Vector laboratories). Four slices per animal were imaged with an EVOS fluorescent microscope (Invitrogen EVOS FL Auto Cell Imaging System) and then analyzed in ImageJ as fluorescent density/nucleus.

\section{Measurement of NO Bioavailability}

Aortic NO levels were measured by 4-Amino-5-Methylamino-2', $7^{\prime}$ - Difluorofluorescein Diacetate (DAF-FM-DA, Invitrogen) according to manufacturer's instructions. As stated previously, aortas were used because GA reactivity required the entire section of vessel. $3 \mathrm{~mm}$ aortic rings were placed in individual wells of a 96 well plate containing $200 \mu 1$ of HEPES buffer

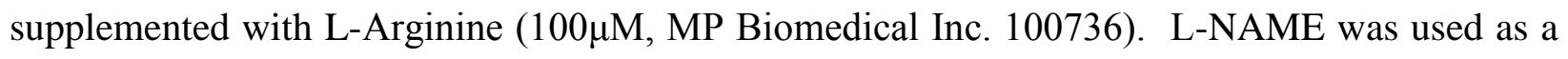
negative control. After 30-minutes incubation with treatment, DAF-FM $10 \mu \mathrm{M}$ was added to each well and the vessel was stimulated with Acetyl- $\beta$-methylcholine chloride (methacholine (MCh), $1 \mathrm{X} 10^{-6}$, Sigma-Aldrich A2251). After 10 minutes, the aorta was removed and the conditioned solution was read in a plate reader excitation/emission at 495/515nm wavelength (BioTek Synergy HT). Fluorescence was normalized to aorta length and the L-NAME value to account for the reaction of the DAF assay with other molecules (i.e., hydrogen peroxide).

\section{Data and Statistical Analyses}

Data are presented as mean \pm SD. Normality was evaluated by the Kolmogorov-Smirnov test. The maximal reactivity or the remodeling of the GA due to the experimental conditions were 
analyzed by a multifactorial analysis of variance (ANOVA) [ i.e., species (i.e., LZR vs. OZR), and experimental condition (i.e., Control, UCMS, Ex, and UCMS+Ex)] with an interaction term (species-by-group), and a Tukey post-hoc test was performed to determine differences between groups. The effects of TEMPOL and L-NAME on the maximal dilation of the GA was examined with a repeated measures ANOVA. Clinical characteristics between the animals were compared with a One-Way ANOVA with Tukey post-hoc test, as appropriate. DHE, was examined using Kruskal Wallis test, with within group comparisons examined using the Mann-Whitney test. In all cases, $\mathrm{p}<0.05$ was taken to reflect statistical significance.

\section{Results}

\section{Animal Characteristics}

The baseline characteristics of the animals used in the present study are summarized in Table 2-1. In comparison to LZR and OZR controls, the intervention groups had a lower body mass at the end of the intervention. Mean arterial pressure did not differ between UCMS or Ex groups. Higher fasting glucose concentrations were noted in the LZR and OZR UCMS group compared to their respective controls. Further, glucose concentrations were lower in the OZR-Ex

group, but higher in the OZR-UCMS+Ex compared to OZR-controls. Markers and symptoms of stress were elevated in both LZRs and OZRs using the UCMS protocol as seen by an increase in corticosterone and coat scores in both LZR and OZR-UCMS, and UCMS+Ex groups compared to controls. Also, there was an increase in adrenal weights with UCMS in LZRs, from $16.7 \mathrm{~g}$ to $25.1 \mathrm{~g}$ $(\mathrm{p}=0.0001)$ and in OZRs, from $27.2 \mathrm{~g}$ to $32.7 \mathrm{~g}(\mathrm{p}=0.0001)$ (data not shown). Adrenal weight did not significantly change in LZR- or OZR-UCMS+Ex as compared to their respective controls. 


\section{Effects of Experimental Conditions on GA Reactivity}

Figure 2-1 illustrates the EDD, EID, and constriction responses of the GA for each treatment group. After 8 weeks of UCMS in LZRs, there was a significant impairment in EDD (73\%, $\mathrm{p}=0.0001)$ compared to LZR-Controls. EDD was higher in LZR-Ex (41\%, $\mathrm{p}=0.009)$ compared to LZR-Controls, and EDD was also higher in the LZR-UCMS+Ex $(209 \%$, p=0.0001) vs. LZR-UCMS. Importantly, now EDD in the LZR-UCMS+Ex group did not statistically differ compared to LZR-Control. In the OZR groups, UCMS did not attenuate EDD further (Fig 2-1A); however, in the OZR-Ex group, EDD was higher $(141 \%, \mathrm{p}=0.0001)$ compared to OZR-Controls. When Ex was combined with UCMS, the EDD was higher $(174 \%, \mathrm{p}=0.0001)$ vs. OZR-UCMS, and EDD in the OZR-UCMS+Ex group was also higher $(83 \%, \mathrm{p}=0.02)$ than OZR-Controls (Fig. 2-1A). Of note, there was a significant ( $\mathrm{p}=0.0006)$ species (LZR vs. OZR) by group (Con, UCMS, Ex, UCMS+Ex) interaction for the GA EDD response.

Next, we examined EID of the GA, and found that EID was lower $(53 \%, p=0.001)$ in LZRUCMS compared to LZR-Controls (Fig. 2-1B), but no differences were noted in EID between LZR-Ex and LZR-Control groups. Importantly, the concurrent exposure of LZR to UCMS and Ex resulted in a higher EID (56\%, p=0.02) compared to LZR-UCMS, and made EID similar between LZR-UCMS+Ex and LZR-Control groups. As for the OZR groups, no significant differences in EID were noted between OZR-UCMS and OZR-Controls; however, EID was higher in the OZREx $(88 \%, p=0.003)$ vs. OZR-Controls (Fig. 2-1B). Further, EID in OZR-UCMS+Ex was higher (17\%, $\mathrm{p}=0.02)$ compared to OZR-UCMS (Fig. 2-1B). We also noted a close to significant $(p=0.054)$ species-by-group interaction for the GA EID response.

The GA constriction response was evaluated by stimulating the GA with increasing doses of PE (Fig. 2-1C). In LZR, UCMS resulted in a smaller constriction response $(57 \%, \mathrm{p}=0.002)$ 
compared to LZR-Controls. The GA constriction response was similar between LZR-Ex, LZRUCMS+Ex, and LZR-Control groups. In the OZR, the GA constriction response was similar between all groups. As such, a significant ( $\mathrm{p}=0.001)$ species-by-group interaction was noted for the GA constriction response.

Effect of Acute TEMPOL or L-NAME on GA

To examine whether the impairment in the GA EDD was a reflection of increased oxidative stress and reduced NO bioavailability, the GA was acutely incubated with TEMPOL and L-NAME (Fig. 2-2). Of note, all comparisons here are compared to within the experimental group without the TEMPOL, or L-NAME incubation (i.e., LZR control-TEMPOL vs. LZR control). Acute TEMPOL incubation did not significantly impact EDD in LZR-Control, LZR+Ex, and LZRUCMS+Ex (Fig. 2-2A); however, in the LZR-UCMS group, TEMPOL significantly increased EDD $(81 \%, p=0.009)$, suggesting a role of oxidative stress on the impaired EDD with UCMS in LZRs. Acute TEMPOL incubation significantly increased EDD in OZR-Control $(76 \%, \mathrm{p}=0.01)$ and OZR-UCMS (149\%, p=0.03) (Fig. 2-2B). Neither OZR-Ex nor OZR-UCMS+Ex had any improvements in EDD with acute TEMPOL incubation. A significant $(\mathrm{p}=0.0012)$ species-bygroup interaction was noted for the EDD-TEMPOL response.

As with TEMPOL, we also incubated the GA with L-NAME to examine the role of NO. Acute L-NAME incubation severely blunted the EDD in LZR-Control (75\%, p=0.0001), LZR-Ex $(76 \%, \mathrm{p}=0.0001)$, and LZR-UCMS+Ex $(64 \%, \mathrm{p}=0.0001)$ groups but had minimal effect on EDD in the LZR-UCMS group (9\%, p=0.99) (Fig. 2-2C). In the OZR groups, acute L-NAME incubation only significantly blunted EDD in OZR-Ex $(71 \%, \mathrm{p}=0.0001)$ and OZR-UCMS+Ex 
$(65 \%, \mathrm{p}=0.0001)$, with no significant effects in the OZR-Controls, and OZR-UCMS groups (Fig. 2-2D). We also noted a significant $(\mathrm{p}=0.0001)$ species by group interaction for the EDD-L-NAME response.

Effects of Experimental Conditions on GA Remodeling

Following assessment of vessel reactivity in our experimental groups, we then examined, under passive conditions, the GA remodeling. There were minimal changes in ID, OD, and WT in the LZR-UCMS vs. LZR-Control groups (Table 2-2); however, an increase in the 3 -slope of the GA stress-strain relationship ( $\mathrm{p}=0.05$ ) was noted in LZR-UCMS vs. LZR-Control. In contrast, no differences were noted between LZR-Ex, LZR-UCMS+Ex, or LZR-Control groups for ID, OD, WT, or B-slope, suggesting that Ex limited the increased GA stiffness noted with UCMS alone in LZRs. As for the effects of the experimental conditions in OZR, we noted a significantly lower ID and OD in OZR-UCMS vs. OZR-Controls ( $\mathrm{p}=0.01$ ), and as such WT did not differ between OZRUCMS vs. OZR-Controls (Table 2-2). Further, an increase in the $ß$-slope of the GA stress-strain relationship ( $\mathrm{p}=0.01$ ) was noted in the OZR-UCMS vs. OZR-Controls (Table 2-2). No significant differences were noted in ID, OD, WT, and the B-slope of the stress-strain relationship between OZR-Ex and OZR-Control groups. However, when Ex was combined with UCMS, the ID and OD were reduced $(16 \%-18 \%, \mathrm{p}<0.05)$ and the $B$-slope was increased $(80 \%, \mathrm{p}=0.001)$ in OZRUCMS+Ex vs. OZR-Controls, as such the effects of UCMS+Ex on GA remodeling was similar to that noted with UCMS alone in OZRs (Table 2-2). No significant species-by-group interactions were identified for GA remodeling. 
NO and ROS Levels

The improvement in EDD with acute TEMPOL or Ex suggested that the endothelial dysfunction in MetS with and without UCMS was in part, mediated by changes in ROS and NO levels. We therefore, examined NO levels in the aorta as determined by DAF-FM diacetate assay. NO bioavailability was lower in LZR-UCMS $(68 \%, \mathrm{p}=0.0001)$ compared to LZR-Controls, but higher in LZR-Ex (15\%, p=0.001) vs. LZR-Control, and NO bioavailability was higher (25\%, $\mathrm{p}=0.0001$ ) in the LZR-UCMS+Ex vs. LZR-UCMS group. As for the OZR groups, NO bioavailability was similar between OZR-UCMS and OZR-Controls; however, NO bioavailability was higher $(146 \%, \mathrm{p}=0.0001)$ in OZR-Ex vs. OZR-Controls, and slightly higher $(14 \%, \mathrm{p}=0.057)$ in OZR-UCMS+Ex vs. OZR-UCMS group (Fig. 2-3A).

Figure 2-3B illustrates ROS levels in the femoral artery. Levels of ROS were higher in LZR-UCMS (99\%, p=0.0001), LZR-Ex (99\%, p=0.003), and LZR-UCMS+Ex (100\%, p=0.0001) vs. LZR-Controls. Further, the ROS levels were higher in LZR-UCMS+Ex vs. LZR-Ex (130\%, $\mathrm{p}=0.0001)$, and LZR-UCMS (101\%, p=0.04). In the OZR groups, as with NO bioavailability, ROS levels did not differ between OZR-UCMS and OZR-Controls. No differences in ROS levels were noted between the OZR-UCMS+Ex vs. OZR-Controls, or OZR-UCMS groups.

\section{Discussion}

The present study is the first to look at the comorbidity between MetS undergoing chronic stress and the effects of Ex on limiting the peripheral vascular effects associated MetS and UCMS. Our results suggest that: 1) exposure to UCMS in LZR resulted in vascular pathologies similar to that evidence in OZR-Controls without the major changes in body mass, glucose or lipid profiles; 
2) exposure to UCMS in OZR did not further affect EDD; and 3) Ex combined with UCMS improved peripheral microvascular dysfunction associated with UCMS.

\section{The Impact of UCMS on the GA}

Chronic psychosocial stress has been proposed as a risk factor for the development of the MetS $(35,36)$. Thus, we were interested in understanding to what extent exposing a healthy rat (LZR) to the UCMS protocol would result in a MetS phenotype. The UCMS protocol resulted in some mild changes in fasting glucose, with a slight, but non-significant increase in triglycerides and MAP, and an actual reduction in BM in the LZR. Thus, one cannot say that the LZR now resembles a MetS phenotype based on the classification of MetS (i.e., BM, blood pressure, glucose, cholesterol); however, the LZR established substantial peripheral microvascular dysfunction that would represent the vasculopathies noted in an OZR. Indeed, the UCMS protocol severely blunted EDD and EID in LZR-Control. We have shown that UCMS significantly decreased NO and increased ROS production, which is the most likely cause of the impairment of EDD in LZRs. These results were also supported by the fact that acute incubation with the ROS scavenger, TEMPOL, improved EDD in LZR-UCMS, likely allowing NO levels to rise. Further, we also noted an increased production of ROS and a corresponding decrease in NO-bioavailability in the LZR-UCMS group. The UCMS-induced impairment of EID found in the present study is contrary to a similar study using UCMS in mice (37), but is in concurrence with a study using chronic social isolation in prairie voles (38). Factors that may have contributed to the smooth muscle damage include dysfunction of certain secondary messengers and their receptors, and increased cyclooxygenase signaling. One such secondary messenger is soluble guanylyl cyclase, which can be inhibited by increased levels of ROS. Inhibition of cyclic adenosine monophosphate expression 
by overproduction of cortisol could also influence smooth muscle function (39-41). Furthermore, an increase in thromboxane production can lead to smooth muscle cell dysfunction, thus creating chronic vasoconstriction $(42,43)$. However, further research is needed to address the potential reasons for the impaired EID with UCMS.

Previous studies by our group and others have examined the effects of MetS and UCMS on microvascular function separately $(5,6,11,37,44,45)$ but to what extent the development of vascular pathologies occurs with the progression of MetS undergoing UCMS remained unclear. The condition of MetS already has significant microvascular dysfunction, therefore, it was important to examine the vascular pathologies during comorbidity. The UCMS protocol did not have a significant impact on EDD or EID in the OZR. The lack of UCMS effect on EDD in OZR may be due to the fact OZR-Controls demonstrate elevated ROS levels, and thus diminished bioavailable NO, unlike LZR-Control. Our group has previously shown in the GA that NO levels in OZR-Control are substantially lower than LZR-Control, as well as in other models of disease states such as hypertension, high-fructose diet, and high-salt diet (9). Therefore, the severity of impairment in OZRs may make them less susceptible to the effects of UCMS than in LZRs. TEMPOL increased EDD in OZR-Control and OZR-UCMS, suggesting that ROS scavenging can recover the reduction in NO caused by UCMS and MetS. These data were confirmed by the effect of acute incubation with L-NAME, which blunted dilation response in the Ex and UCMS+Ex groups.

There are various other mechanisms that could be affecting the microvasculature during the comorbidity between UCMS and MetS. For example, with chronic stress and depression there is an increase in cortisol/corticosterone levels as we have seen here in our LZR- and OZR-UCMS groups. Chronically elevated cortisol results in overproduction of angiotensin II (Ang II), which 
causes vasoconstriction. Ang II has also been shown to cause an increase in endothelim-1, thromboxane, and ROS through activation of $\mathrm{AT}_{1}$ type receptors (46). Thus, the increase in circulating Ang II in vivo causes changes in the smooth muscle and endothelium, possible contributing to the impairment in EDD seen in vitro in LZR- and OZR-UCMS groups.

Peripheral microvascular wall dimensions were not affected by UCMS in LZRs but the stress-strain relationship was shifted to the left, suggesting an increase in stiffness. This response could reflect changes in the collagen deposition and elastin fractionation in the LZR GA $(47,48)$. In contrast, UCMS significantly decreased both inner and outer diameters in OZRs as compared to their controls, indicating eutrophic inward remodeling. Eutrophic inward remodeling could be caused by repositioning of vascular smooth muscle cells to adapt to the chronic circumferential stress (49). OZR-UCMS also had a significant leftward shift in the stress-strain relationship, implying a stiffening of the vessels. Physical inactivity, a by-product of depression and a cause of MetS, produces oxidative stress and inflammation (50). Therefore, Ex is the logical intervention to augment the deleterious effects of MetS and depression.

Exercise Can Improve Aspects of the Comorbidity of MetS and UCMS

Exercise increased LZR EDD but Ex had a much greater effect on OZR EDD response overall. Exercise significantly enhanced NO bioavailability in LZRs and OZRs, which could explain why there was a greater improvement in dilation in LZR- and OZR-Ex. An earlier study found NO production and arginine conversion (indicating eNOS activity) were both increased with Ex (20). Following Ex, EDD was unaffected by the ROS levels as supported by the lack of TEMPOL effect in both LZR- and OZR-Ex groups. The specific cause of the elevation of ROS 
levels is unclear given Ex has been shown to have antioxidant effects itself $(25,26)$. However, corticosterone levels were elevated in the Ex and UCMS+Ex groups vs. the controls which may, in part, reflect the slight stress induced by use of the forced treadmill Ex protocol. It has been shown that glucocorticoids can increase ROS directly, including superoxide, hydrogen peroxide, and peroxynitrite (12). Given that DHE can interact with these oxidants, it could be speculated the higher ROS levels seen in LZR-Ex and UCMS+Ex are a byproduct of increased corticosterone. The fact that in Ex and UCMS+Ex EDD was improved despite elevated corticosterone levels, suggests EDD augmentation was likely mediated from non-corticosterone pathways. L-NAME blunted maximum dilation back down to LZR- and OZR-Control+LNAME values, suggesting the Ex augmentation of EDD may be solely through a NO-dependent pathway. The expression and function of eNOS is upregulated after Ex training due to increased shear stress $(23,51)$, thus could explain why EDD in LZR- and OZR-Ex was improved in the skeletal muscle arterioles. Ex did not change EID response in LZRs or OZRs as compared to their respective controls, which was supported by a previous study from our group also showing no change in EID in LZRs and OZRs (20).

Ex did not result in GA structure remodeling in either the LZRs or OZRs, but Ex was able to prevent the level of impairment in EDD seen in LZR- and OZR-UCMS. Perhaps the increase in NO bioavailability in the UCMS+Ex groups, relative to the UCMS groups, limited the GA structure remodeling. LZR- and OZR-UCMS+Ex did not show an increase in EDD of the GA when incubated with TEMPOL as compared to their respective Control+TEMPOL values, which would suggest that TEMPOL did not have an additive effect when paired with exercise. EID was also increased with exercise in LZR- and OZR-UCMS+Ex. Furthermore, in the LZR, the combination of Ex with UCMS prevented the leftward shift (and increase GA stiffness) in the 
stress strain relationship as evident in the LZR-UCMS group, suggesting a global improvement in microvascular function (i.e., EDD, EID with reduced arterial stiffness). However, the combination of Ex with UCMS in OZR was unable to prevent the increase in GA arterial stiffness. Perhaps here the comorbidity of MetS and UCMS was too much of stressful stimulus for 8 weeks of Ex to prevent. Further, research is needed to identify whether longer periods of Ex or a combination of Ex with 'destiffening' agents (i.e., ALT-711) could be used to prevent the increase in arterial stiffness with UCMS in the OZR.

\section{Limitations}

The present study is not without limitations. We realize the limitation associated with measuring tissue superoxide levels by fluorescence-based assessment of DHE oxidation. While our excitation/emission gating does detect signals produced by oxidation products that may originate from reactions independent of superoxides, the spectral overlap does not exclude considerable contributions from 2-hydroxyethidium $\left(2-\mathrm{OH}-\mathrm{E}^{+}\right)$, the superoxide-specific oxidation product of DHE (232). The possible explanation for the higher ROS levels in LZR-Ex and LZRUCMS+Ex is the generation of hydrogen peroxide by Ex. Hydrogen peroxide has been shown to be a vasodilator and produced during Ex (233). Further, it was interesting to note that corticosterone levels were elevated in the Ex and UCMS+Ex groups vs. the controls, which could also have contributed to more hydrogen peroxide production, thus increasing fluorescence intensity in the Ex and UCMS+Ex groups. Future research should use HPLC to look for superoxide and $2-\mathrm{OH}-\mathrm{E}^{+}$levels to obtain a more quantitative indicator of these products. 
Another limitation that may, in part, affect the translational relevance of our study was that we deployed a forced treadmill running protocol as opposed to voluntary wheel running, which in itself can cause stress. However, given the sedentary nature of the OZR, we wanted to ensure that all rats were exposed to a similar Ex stimulus. In addition, given the size of the OZRs (by 12-15 weeks), it would be difficult for them to fit into a running wheel. Thus, although voluntary Ex would be more translationally relevant, unfortunately, in the OZR rats forced treadmill exercise was the most feasible option, we believe the benefits of forced Ex outweighed the stress the rats might undergo.

\section{Conclusions}

The data presented here shows that the chronic exposure to stressful conditions in healthy rats leads to substantial vasculopathies similar to that in an OZR. Further, the comorbidity between chronic stress and MetS, does not exacerbate the effects of one another on skeletal muscle arteriole EDD response. It does, however, lead to the development of other vasculopathy adaptations in relation to constriction response. We have found that Ex can improve these pathological maladaptations and that the NO pathway has the potential to be a therapeutic target in clinical settings.

\section{Acknowledgements}

This work was supported by the American Heart Association grants IRG 14330015 and predoctoral fellowship AHA 14PRE 20380386, and the National Institute of General Medical 
Sciences of the National Institutes of Health under award numbers U54GM104942 and 5P20GM109098.

The authors would like to thank Chris Pitzer, Stuart Clayton, Colton Allen, and all other undergraduate interns who helped with the exercise and depression protocol. Thank you to Christa Lilly for statistical consultation. We are grateful to the WVU Office of Laboratory Animal Resources husbandry and veterinary staff for their continued assistance.

\section{Conflict of Interest}

The authors declare no conflicts of interest. The results of the present study do not constitute endorsement by the American College of Sports Medicine and are presented clearly, honestly, and without fabrication, falsification, or inappropriate data manipulation. 


\section{References}

1. Ogden CL, Carroll MD, Kit BK, Flegal KM. Prevalence of childhood and adult obesity in the United States, 2011-2012. JAMA [Internet]. 2014;311(8):806-14. Available from: http://www.ncbi.nlm.nih.gov/pubmed/24570244\%5Cnhttp://jama.jamanetwork.com/articl e.aspx articleid $=1832542$

2. Malik S, Wong ND, Franklin SS, Kamath T V., L'Italien GJ, Pio JR, et al. Impact of the metabolic syndrome on mortality from coronary heart disease, cardiovascular disease, and all causes in United States adults. Circulation. 2004;110:1245-50.

3. Ervin RB. Prevalence of metabolic syndrome among adults 20 years of age and over, by sex, age, race and ethnicity, and body mass index: United States, 2003-2006. Natl Health Stat Report. 2009;(13):1-7.

4. Falkner B, Cossrow NDFH. Prevalence of metabolic syndrome and obesity-associated hypertension in the racial ethnic minorities of the United States. Vol. 16, Current Hypertension Reports. 2014.

5. Maksimovic M, Vlajinac H, Radak D, Marinkovic J, Jorga J. Relationship between peripheral arterial disease and metabolic syndrome. Angiology [Internet]. 2009;60:54653. Available from: http://www.ncbi.nlm.nih.gov/pubmed/19147526

6. Frisbee JC, Delp MD. Vascular function in the metabolic syndrome and the effects on skeletal muscle perfusion: lessons from the obese Zucker rat. Essays Biochem [Internet]. 2006;42:145-61. Available from:

http://www.ncbi.nlm.nih.gov/sites/entrez?db=PubMed\&cmd=retrieve \&dopt=AbstractPlus \&list_uids=17144886\%5Cnpapers2://publication/doi/10.1042/bse0420145 
7. Frisbee JC. Reduced nitric oxide bioavailability contributes to skeletal muscle microvessel rarefaction in the metabolic syndrome. Am J Physiol Regul Integr Comp Physiol. 2005;289(2):R307-16.

8. Russell JC, Proctor SD. Small animal models of cardiovascular disease: tools for the study of the roles of metabolic syndrome, dyslipidemia, and atherosclerosis. Cardiovasc Pathol. 2006;15(6):318-30.

9. Frisbee JC, Butcher JT, Frisbee SJ, Olfert IM, Chantler PD, Tabone LE, et al. Increased peripheral vascular disease risk progressively constrains perfusion adaptability in the skeletal muscle microcirculation. Am J Physiol - Hear Circ Physiol [Internet]. 2016;310(4):H488-504. Available from: http://ajpheart.physiology.org/lookup/doi/10.1152/ajpheart.00790.2015

10. Pratt AG, Norris ER, Kaufmann M. Peripheral vascular disease and depression. J Vasc Nurs [Internet]. 2005;23(4):123-7-9. Available from:

http://www.ncbi.nlm.nih.gov/pubmed/16326330

11. d'Audiffret AC, Frisbee SJ, Stapleton P a, Goodwill AG, Isingrini E, Frisbee JC. Depressive behavior and vascular dysfunction: a link between clinical depression and vascular disease? J Appl Physiol. 2010;108(5):1041-51.

12. Golbidi S, Frisbee JC, Laher I. Chronic stress impacts the cardiovascular system: animal models and clinical outcomes. Am J Physiol - Hear Circ Physiol [Internet]. 2015;308(12):H1476-98. Available from: http://ajpheart.physiology.org/lookup/doi/10.1152/ajpheart.00859.2014

13. Brostow DP, Petrik ML, Starosta AJ, Waldo SW. Depression in patients with peripheral 
arterial disease: A systematic review. Eur J Cardiovasc Nurs [Internet]. 2017 [cited 2017 Jul 10];16(3):147451511668722. Available from: https://doi.org/10.1177/1474515116687222

14. Smolderen KGE, Aquarius AE, De Vries J, Smith ORF, Hamming JF, Denollet J, et al. Depressive symptoms in peripheral arterial disease: A follow-up study on prevalence, stability, and risk factors. J Affect Disord [Internet]. 2008 [cited 2017 Jul 10];110:27-35. Available from: www.elsevier.com/locate/jad

15. Wong SYS, Woo J, Hong AWL, Leung JCS, Leung PC. Clinically relevant depressive symptoms and peripheral arterial disease in elderly men and women. Results from a large cohort study in Southern China. [cited 2017 Jul 10]; Available from: http://ac.elscdn.com/S0022399907002528/1-s2.0-S0022399907002528-main.pdf?_tid=715d6850659d-11e7-bc6600000aab0f01\&acdnat=1499711435_226b53fcef62a45ec6e902b8596ad84c

16. Chrapko WE, Jurasz P, Radomski MW, Lara N, Archer SL, Le Mellédo J-M. Decreased platelet nitric oxide synthase activity and plasma nitric oxide metabolites in major depressive disorder. Biol Psychiatry [Internet]. 2004;56(2):129-34. Available from: http://www.ncbi.nlm.nih.gov/pubmed/15231445

17. Dhir A, Kulkarni SK. Nitric oxide and major depression. Nitric Oxide [Internet]. 2011;24(3):125-31. Available from: http://dx.doi.org/10.1016/j.niox.2011.02.002

18. Isingrini E, Surget A, Belzung C, Freslon J-L, Frisbee J, O’Donnell J, et al. Altered aortic vascular reactivity in the unpredictable chronic mild stress model of depression in mice: UCMS causes relaxation impairment to ACh. Physiol Behav [Internet]. 2011;103(5):540- 


\section{Available from:}

http://www.ncbi.nlm.nih.gov/pubmed/21504753\%5Cnhttp://dx.doi.org/10.1016/j.physbeh. 2011.04 .002

19. Donley D a, Fournier SB, Reger BL, DeVallance E, Bonner DE, Olfert IM, et al. Aerobic exercise training reduces arterial stiffness in metabolic syndrome. J Appl Physiol [Internet]. 2014;116(April):1396-404. Available from:

http://www.ncbi.nlm.nih.gov/pubmed/24744384

20. Frisbee JC, Samora JB, Peterson J, Bryner R. Exercise training blunts microvascular rarefaction in the metabolic syndrome. Am J Physiol Heart Circ Physiol. 2006;291(5):H2483-92.

21. Bowles DK, Woodman CR, Laughlin MH. Coronary smooth muscle and endothelial adaptations to exercise training. Exerc Sport Sci Rev. 2000;28(2):57-62.

22. Green DJ, Maiorana A, O’Driscoll G, Taylor R. Effect of exercise training on endothelium-derived nitric oxide function in humans. J Physiol [Internet]. 2004;561(Pt 1):1-25. Available from: http://www.pubmedcentral.nih.gov/articlerender.fcgi?artid=1665322\&tool=pmcentrez\&re ndertype $=$ abstract

23. Kingwell B a. Nitric oxide-mediated metabolic regulation during exercise: effects of training in health and cardiovascular disease. Faseb J [Internet]. 2000;14(12):1685-96. Available from: http://www.ncbi.nlm.nih.gov/pubmed/10973917

24. Walther C, Gielen S, Hambrecht R. The effect of exercise training on endothelial function in cardiovascular disease in humans. Exerc Sport Sci Rev. 2004;32(4):129-34. 
25. Banerjee AK, Mandal A, Chanda D, Chakraborti S. Oxidant, antioxidant and physical exercise. Vol. 253, Molecular and Cellular Biochemistry. 2003. p. 307-12.

26. Gomez-Cabrera MC, Domenech E, Viña J. Moderate exercise is an antioxidant: Upregulation of antioxidant genes by training. Free Radic Biol Med. 2008;44(2):126-31.

27. Green DJ, Maiorana A, O’Driscoll G, Taylor R. Effect of exercise training on endothelium-derived nitric oxide function in humans. J Physiol. 2004;561(Pt 1):1-25.

28. Aleixandre de Artiñano A, Miguel Castro M. Experimental rat models to study the metabolic syndrome. Br J Nutr. 2009;102(9):1246-53.

29. Willner P, Muscat R, Papp M. Chronic mild stress-induced anhedonia: A realistic animal model of depression. Neurosci Biobehav Rev. 1992;16(4):525-34.

30. Willner P. Validity, reliability and utility of the chronic mild stress model of depression: a 10-year review and evaluation. Psychopharmacology (Berl) [Internet]. 1997;134(4):31929. Available from: http://www.ncbi.nlm.nih.gov/pubmed/9452163

31. Vollmayr B, Henn FA. Stress models of depression. Vol. 3, Clinical Neuroscience Research. 2003. p. 245-51.

32. Willner P. Neurobiology of Stress The chronic mild stress ( CMS ) model of depression : History , evaluation and usage. Neurobiol Stress [Internet]. 2017;6:78-93. Available from: http://dx.doi.org/10.1016/j.ynstr.2016.08.002

33. Frisbee JC, Brooks SD, Stanley SC, d'Audiffret AC. An Unpredictable Chronic Mild Stress Protocol for Instigating Depressive Symptoms, Behavioral Changes and Negative Health Outcomes in Rodents. J Vis Exp [Internet]. 2015;(106):1-8. Available from: 
http://www.ncbi.nlm.nih.gov/pubmed/26650668

34. Yalcin I, Aksu F, Belzung C. Effects of desipramine and tramadol in a chronic mild stress model in mice are altered by yohimbine but not by pindolol. Eur J Pharmacol. 2005;514(2-3):165-74.

35. Chandola T, Brunner E, Marmot M. Chronic stress at work and the metabolic syndrome: prospective study. Bmj [Internet]. 2006;332(7540):521-4. Available from: http://www.ncbi.nlm.nih.gov/entrez/query.fcgi?cmd=Retrieve\&db=PubMed\&dopt=Citati on\&list_uids=16428252\%5Cnhttp://pubmedcentralcanada.ca/picrender.cgi?accid=PMC13 88129\&blobtype $=$ pdf

36. Bergmann N, Gyntelberg F, Faber J. The appraisal of chronic stress and the development of the metabolic syndrome: a systematic review of prospective cohort studies. Endocr Connect [Internet]. 2014;3(2):R55-80. Available from: http://www.endocrineconnections.com/cgi/doi/10.1530/EC-14-0031

37. Stanley SC, Brooks SD, Butcher JT, d'Audiffret a. C, Frisbee SJ, Frisbee JC. Protective effect of sex on chronic stress- and depressive behavior-induced vascular dysfunction in BALB/cJ mice. J Appl Physiol [Internet]. 2014;117(9):959-70. Available from: http://jap.physiology.org/cgi/doi/10.1152/japplphysiol.00537.2014

38. Peuler JD, Scotti M-AL, Phelps LE, McNeal N, Grippo AJ. Chronic social isolation in the prairie vole induces endothelial dysfunction: implications for depression and cardiovascular disease. Physiol Behav [Internet]. 2012 Jun 25 [cited 2017 Jul 8];106(4):476-84. Available from: http://www.ncbi.nlm.nih.gov/pubmed/22469565

39. BRÜNE B, SCHMIDT K -U, ULLRICH V. Activation of soluble guanylate cyclase by 
carbon monoxide and inhibition by superoxide anion. Eur J Biochem. 1990;192(3):683-8.

40. Weber M, Lauer N, Mülsch A, Kojda G. The effect of peroxynitrite on the catalytic activity of soluble guanylyl cyclase. Free Radic Biol Med. 2001;31(11):1360-7.

41. Burgoyne JR, Madhani M, Cuello F, Charles RL, Brennan JP, Schroder E, et al. Cysteine Redox Sensor in PKGIa Enables Oxidant-Induced Activation. Science (80- ) [Internet]. 2007;317(5843):1393-7. Available from: http://www.sciencemag.org/cgi/doi/10.1126/science.1144318

42. Sparks MA, Makhanova NA, Griffiths RC, Snouwaert JN, Koller BH, Coffman TM. Thromboxane receptors in smooth muscle promote hypertension, vascular remodeling, and sudden death. Hypertension. 2013;61(1):166-73.

43. Dorn GW 2nd, Becker MW. Thromboxane A2 stimulated signal transduction in vascular smooth muscle. J Pharmacol Exp Ther. 1993;265(1):447-56.

44. Brooks SD, DeVallance E, d'Audiffret AC, Frisbee SJ, Tabone LE, Shrader CD, et al. Metabolic syndrome impairs reactivity and wall mechanics of cerebral resistance arteries in obese Zucker rats. Am J Physiol Heart Circ Physiol [Internet]. 2015 Dec 1 [cited 2015 Dec 11];309(11):H1846-59. Available from: http://ajpheart.physiology.org/content/309/11/H1846.full-text.pdf+html

45. Isingrini E, Surget A, Belzung C, Freslon JL, Frisbee J, O’Donnell J, et al. Altered aortic vascular reactivity in the unpredictable chronic mild stress model of depression in mice. UCMS causes relaxation impairment to ACh. Physiol Behav [Internet]. 2011;103(5):5406. Available from: http://dx.doi.org/10.1016/j.physbeh.2011.04.002 
46. Carey RM. The intrarenal renin-angiotensin system in hypertension. Adv Chronic Kidney Dis. 2015;22(3):204-10.

47. Cattell MA, Anderson JC, Hasleton PS. Age-related changes in amounts and concentrations of collagen and elastin in normotensive human thoracic aorta. Clin Chim Acta. 1996;245(1):73-84.

48. Venkataraman L, Ramamurthi A. Induced Elastic Matrix Deposition Within ThreeDimensional Collagen Scaffolds. Tissue Eng Part A [Internet]. 2011;17(21-22):2879-89. Available from: http://www.liebertonline.com/doi/abs/10.1089/ten.tea.2010.0749

49. Castorena-Gonzalez JA, Staiculescu MC, Foote C, Martinez-Lemus LA. Mechanisms of the inward remodeling process in resistance vessels: Is the actin cytoskeleton involved? Microcirculation. 2014;21(3):219-29.

50. ann het Rot M, Collins KA, Fitterling HL. Physical exercise and depression. Mt Sinai J Med. 2009;76(2):204-14.

51. Sindler AL, Delp MD, Reyes R, Wu G, Muller-Delp JM. Effects of ageing and exercise training on eNOS uncoupling in skeletal muscle resistance arterioles. J Physiol. 2009;587(Pt 15):3885-97.

52. Zielonka J, Kalyanaraman B. Hydroethidine- and MitoSOX-derived red fluorescence is not a reliable indicator of intracellular superoxide formation: Another inconvenient truth. Vol. 48, Free Radical Biology and Medicine. 2010. p. 983-1001.

53. Robinson AT, Franklin NC, Norkeviciute E, Bian JT, Babana JC, Szczurek MR, et al. Improved arterial flow-mediated dilation after exertion involves hydrogen peroxide in 
overweight and obese adults following aerobic exercise training. J Hypertens [Internet].

2016;34(7):1309-16. Available from:

http://www.ncbi.nlm.nih.gov/pubmed/27137176\%5Cnhttp://content.wkhealth.com/linkbac

k/openurl?sid=WKPTLP:landingpage $\& a n=00004872-201607000-00012$ 
Table 2-1. Baseline characteristics of animal groups.

\begin{tabular}{|c|c|c|c|c|c|c|c|c|}
\hline & \multicolumn{4}{|c|}{ LZR } & \multicolumn{4}{|c|}{ OZR } \\
\hline & Con & UCMS & $E x$ & $U C M S+E x$ & Con & UCMS & $E x$ & $U C M S+E x$ \\
\hline BM, $\mathbf{g}$ & $400 \pm 36$ & $361 \pm 25^{*}$ & $358 \pm 28^{*}$ & $343 \pm 21^{*}$ & $641 \pm 54$ & $585 \pm 39^{*}$ & $599 \pm 53^{*}$ & $567 \pm 46^{*}$ \\
\hline MAP, mmHg & $112 \pm 8$ & $122 \pm 13$ & $120 \pm 15$ & $120 \pm 11$ & $139 \pm 14$ & $142 \pm 16$ & $140 \pm 14$ & $132 \pm 13$ \\
\hline Glucose, mg/dl & $98 \pm 15$ & $124 \pm 17^{*}$ & $101 \pm 20$ & $115 \pm 15$ & $184 \pm 29$ & $230 \pm 34^{* \wedge}$ & $154 \pm 29$ & $219 \pm 36^{* \wedge}$ \\
\hline Insulin, mg/dl & $1.2 \pm 0.9$ & $2.1 \pm 0.9$ & $1.4 \pm 0.7$ & $1.8 \pm 0.9$ & $6.6 \pm 2.6$ & $7.8 \pm 3.7$ & $4.6 \pm 2.4$ & $6.2 \pm 2.4$ \\
\hline TG, mg/dl & $25 \pm 7$ & $54 \pm 40$ & $31 \pm 8$ & $36 \pm 8$ & $124 \pm 19$ & $114 \pm 35$ & $82 \pm 38$ & $103 \pm 40$ \\
\hline $\mathrm{TC}, \mathrm{mg} / \mathrm{dl}$ & $86 \pm 11$ & $87 \pm 12$ & $95 \pm 15$ & $88 \pm 4$ & $256 \pm 63$ & $213 \pm 42$ & $181 \pm 20^{*}$ & $187 \pm 27^{*}$ \\
\hline Corticosterone, $\mathrm{ng} / \mathrm{ml}$ & $7.0 \pm 0.4$ & $8.8 \pm 1.7^{*}$ & $9.4 \pm 2.9$ & $10.7 \pm 4.0$ & $13.8 \pm 1.4$ & $17.3 \pm 5.2^{*}$ & $10.6 \pm 2.9^{*}$ & $15.8 \pm 4.0^{*}$ \\
\hline Coat Scores, AU & $0.6 \pm 0.4$ & $1.5 \pm 0.4^{*}$ & $0.6 \pm 0.5$ & $1.8 \pm 0.8^{*}$ & $2.4 \pm 0.4$ & $4.8 \pm 0.8^{*}$ & $3.2 \pm 0.6$ & $4.5 \pm 0.4^{* \wedge}$ \\
\hline
\end{tabular}

Con, control; UCMS, Unpredictable Mild Chronic Stress; Ex, exercise; BM, body mass; MAP, mean arterial pressure; TG, triglycerides; TC, total cholesterol. ${ }^{*} \mathrm{p}<0.05$ vs. control, ${ }^{\wedge} \mathrm{p}<0.05$ vs. Ex. Mean $\pm \mathrm{SD}$. $\mathrm{n}=6-8$ per group. 
Table 2-2. Gracilis arteriole remodeling due to MetS and UCMS in the GA.

\begin{tabular}{|c|c|c|c|c|c|c|c|c|}
\hline & \multicolumn{4}{|c|}{ LZR } & \multicolumn{4}{|c|}{ OZR } \\
\hline & Con & UCMS & $E x$ & $U C M S+E x$ & Con & $U C M S$ & $E x$ & $U C M S+E x$ \\
\hline ID $(\mu \mathrm{m})$ & $210 \pm 8$ & $204 \pm 50$ & $194 \pm 11$ & $192 \pm 15$ & $184 \pm 31$ & $151 \pm 5^{*}$ & $189 \pm 31$ & $168 \pm 24^{*}$ \\
\hline OD $(\mu \mathrm{m})$ & $306 \pm 4$ & $294 \pm 38$ & $294 \pm 24$ & $292 \pm 28$ & $273 \pm 28$ & $230 \pm 5^{*}$ & $281 \pm 28$ & $258 \pm 31$ *\# \\
\hline WT $(\mu \mathrm{m})$ & $48 \pm 2$ & $45 \pm 11$ & $50 \pm 6$ & $50 \pm 6$ & $45 \pm 3$ & $40 \pm 2$ & $46 \pm 2$ & $45 \pm 6$ \\
\hline $\begin{array}{c}\text { Wall:Lumen } \\
\text { Ratio }\end{array}$ & $0.5 \pm 0.04$ & $0.5 \pm 0.19$ & $0.5 \pm 0.04$ & $0.5 \pm 0.03$ & $0.5 \pm 0.11$ & $0.5 \pm 0.03$ & $0.5 \pm 0.11$ & $0.5 \pm 0.09$ \\
\hline $\begin{array}{c}\beta \text {-Slope } \\
\text { Coefficient } \\
\end{array}$ & $4.5 \pm 0.9$ & $6.0 \pm 0.9^{*}$ & $3.5 \pm 0.7$ & $4.3 \pm 1.0$ & $4.5 \pm 1.3$ & $8.1 \pm 3.4^{*}$ & $4.6 \pm 1.2$ & $8.7 \pm 5.0^{*}$ \\
\hline
\end{tabular}

Con, control; UCMS, Unpredictable Mild Chronic Stress; Ex, exercise; ID, inner GA diameter; OD, outer GA diameter; WT, wall thickness. ${ }^{*} \mathrm{p}<0.05$ vs. control, ${ }^{*} \mathrm{p}<0.05$ vs. UCMS. Mean \pm SD. $\mathrm{n}=6-8$ per group. 
A

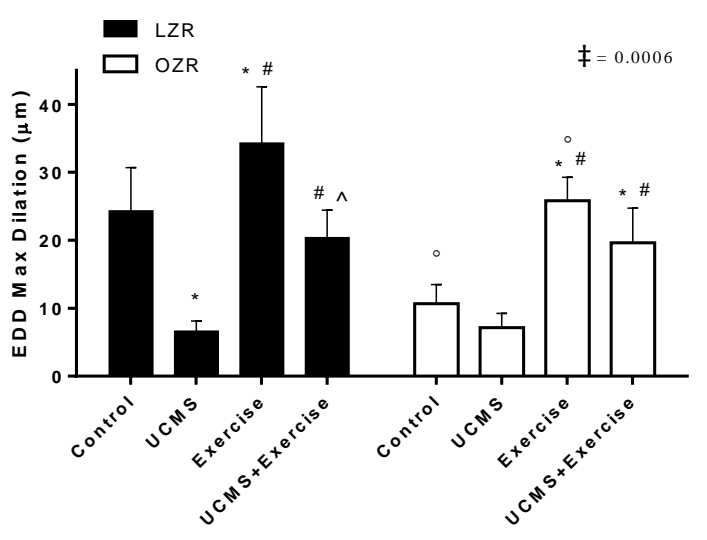

C

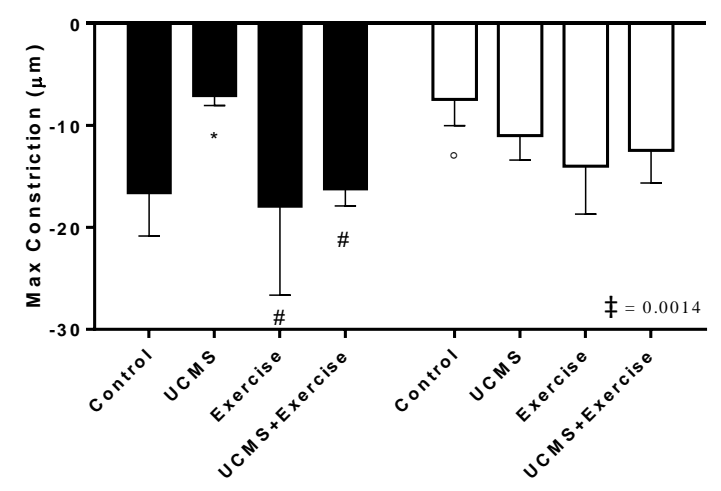

B

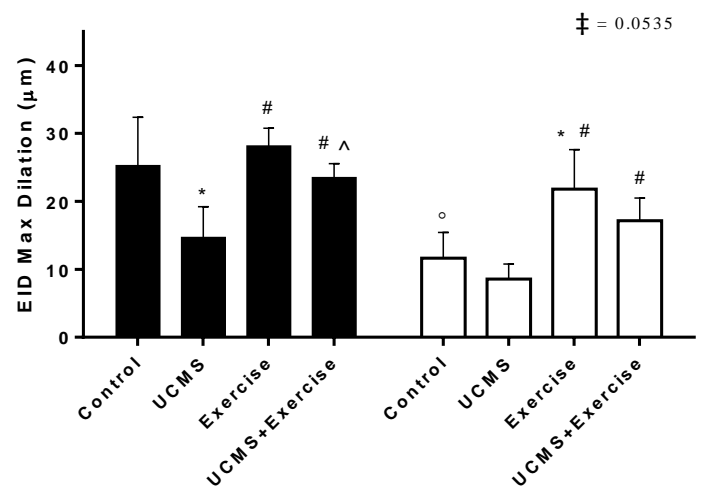

Figure 2-1. The effects of UCMS and Ex on GA reactivity. A) Assessment of endothelium-dependent dilation (EDD) to a maximal does of Ach $\left.\left(10^{-6} \mathrm{M}\right) ; \mathrm{B}\right)$ endothelium-independent dilation (EID) to a maximal does of SNP $\left(10^{-6} \mathrm{M}\right)$; and C) GA constriction to a maximal does of $\mathrm{PE}\left(10^{-7} \mathrm{M}\right) . n=6$-8/group. Mean $\pm \mathrm{SD} .{ }^{*} \mathrm{p}<0.05$ vs. control, ${ }^{\#} \mathrm{p}<0.05$ vs. UCMS, ${ }^{\wedge} \mathrm{p}<0.05$ vs. Ex, ${ }^{\circ} \mathrm{p}<0.05$ vs. matched treatment group in opposite species (i.e., LZR vs. OZR), ${ }^{\ddagger} \mathrm{p}<0.05$ species (LZR vs. OZR) by group (Con, UCMS, Ex, UCMS+Ex) interaction. Con=control, UCMS=Unpredictable Mild Chronic Stress, Ex=exercise. 
A

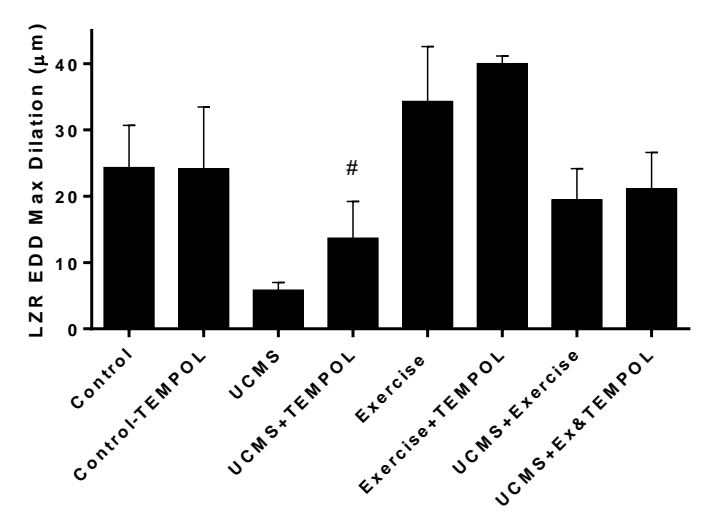

C

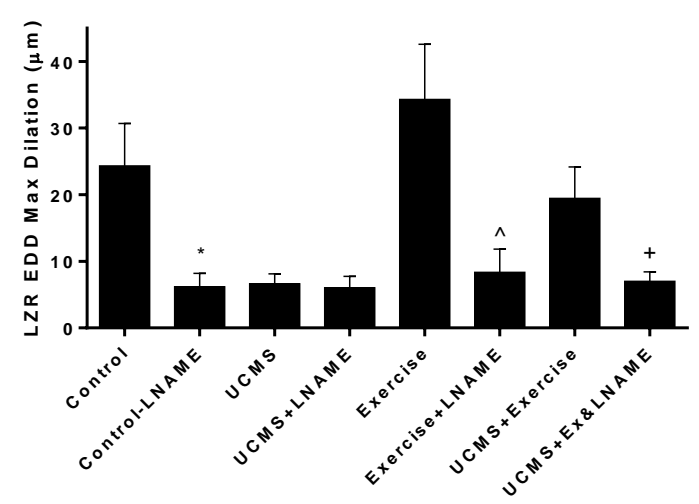

B

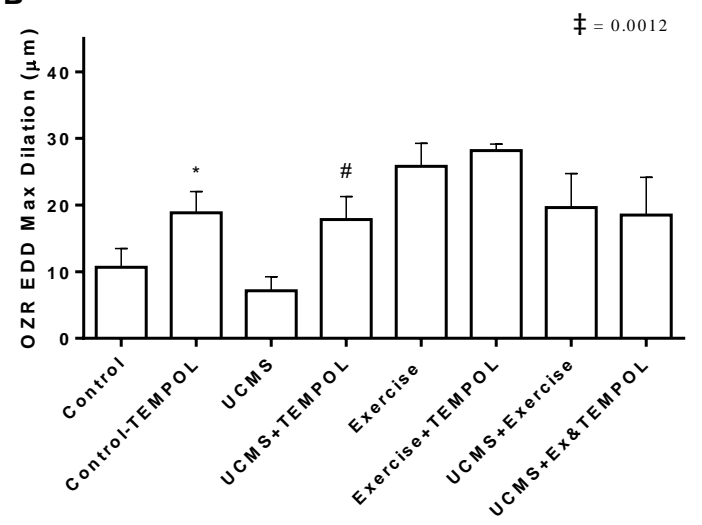

D

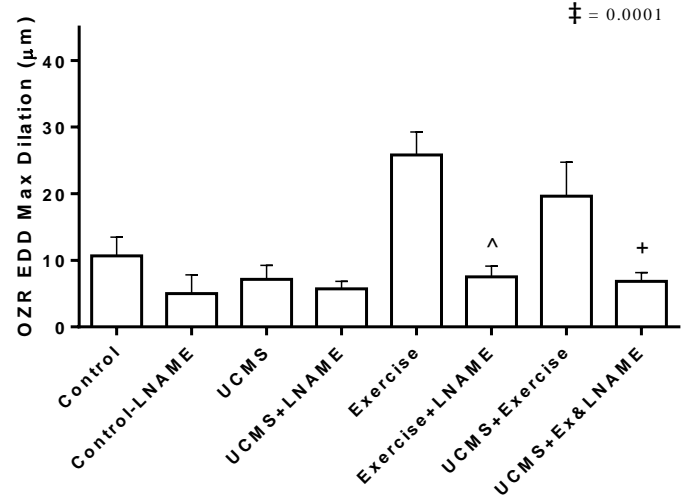

Figure 2-2. The effects of acute TEMPOL or L-NAME incubation on GA reactivity. The effects of acute TEMPOL incubation on EDD reactivity in LZR (A) and OZR (B). The effects of acute L-NAME incubation on EDD reactivity in LZR (C) and OZR (D). $n=6-8 /$ group. Mean \pm SD. ${ }^{*} \mathrm{p}<0.01$ vs. control, ${ }^{*} \mathrm{p}<0.01$ vs. UCMS, ${ }^{\wedge} \mathrm{p}<0.05$ vs. exercise, ${ }^{+} \mathrm{p}<0.05$ within group comparison for change in TEMPOL or L-NAME. ${ }^{\star} \mathrm{p}<0.05$ species (LZR vs. OZR) by group (Con, UCMS, Ex, UCMS+Ex) interaction. Con=control, UCMS=Unpredictable Mild Chronic Stress, $E x=$ exercise. 
A

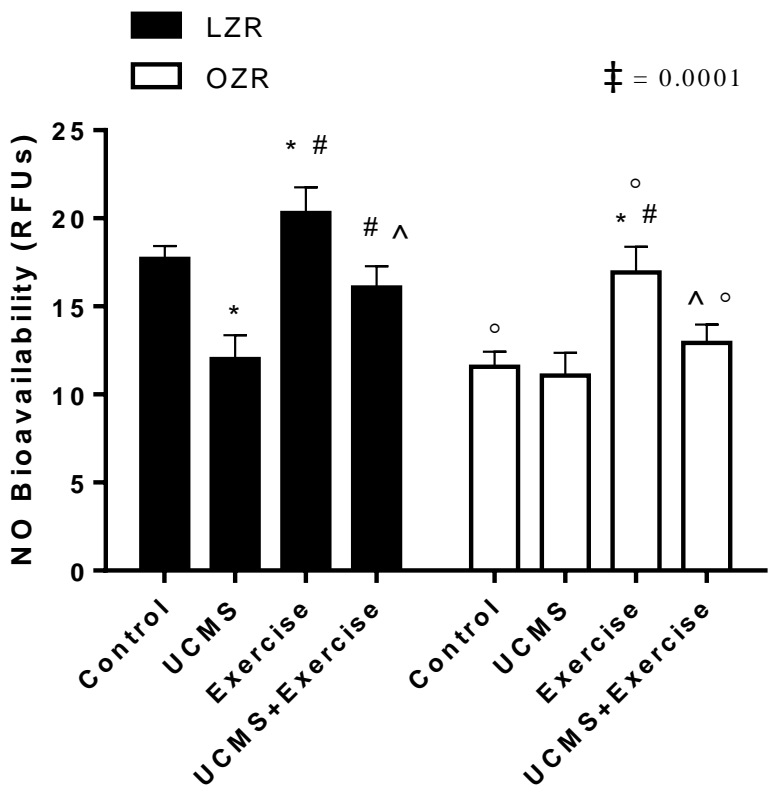

B

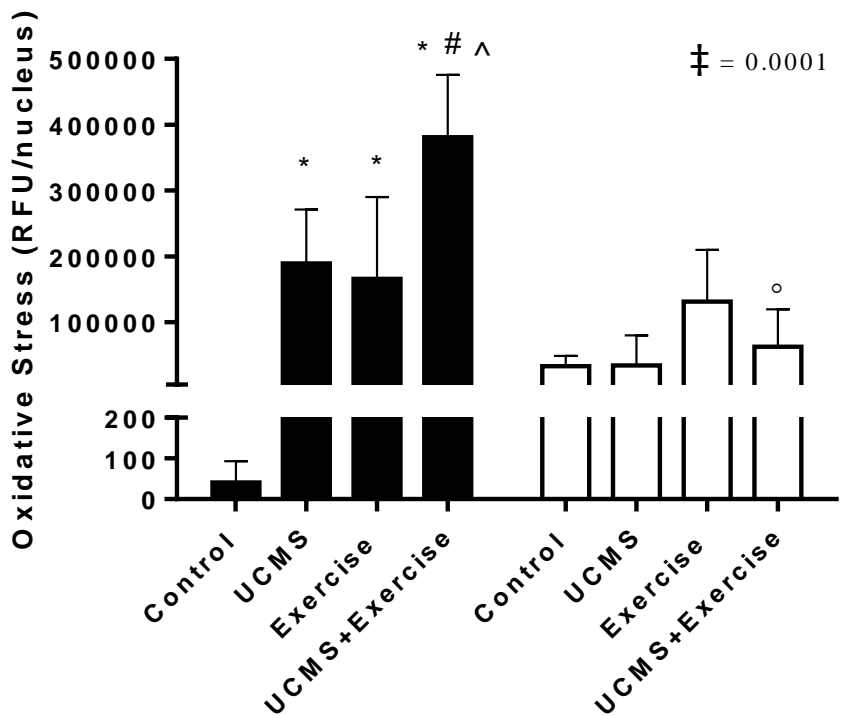

Figure 2-3. The effects of UCMS and Ex on NO and ROS levels. A) NO levels in the aorta as determined by DAF-FM diacetate assay; and B) DHE staining indicating ROS levels in the aortas of each group. Mean \pm SD. ${ }^{*} \mathrm{p}<0.05$ vs. control, ${ }^{\#} \mathrm{p}<0.05$ vs. UCMS, ${ }^{\wedge} \mathrm{p}<0.05$ vs. exercise, ${ }^{\circ} \mathrm{p}<0.05$ vs. matched treatment group in opposite species. ${ }^{\star} \mathrm{p}<0.05$ species (LZR vs. OZR) by group (Con, UCMS, Ex, UCMS+Ex) interaction. Con=control, UCMS=Unpredictable Mild Chronic Stress, $\mathrm{Ex}=$ exercise 
Supplemental Data for Chapter 2 


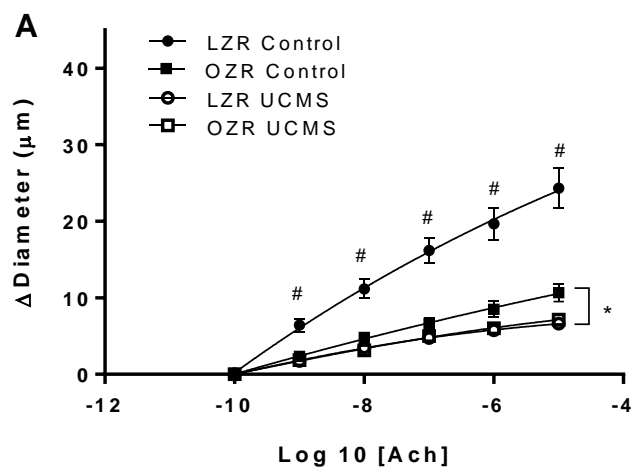

B

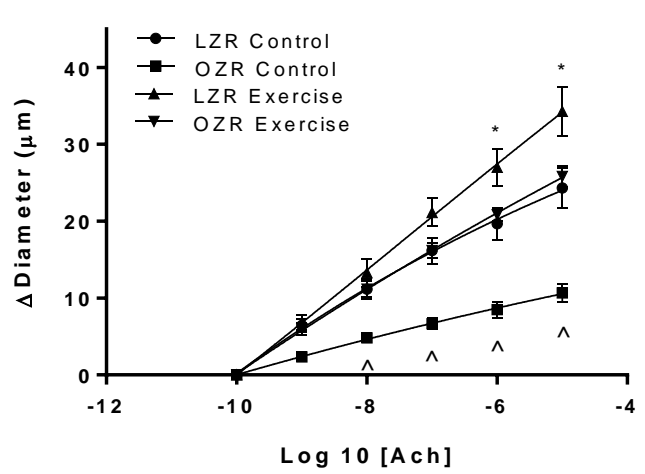

C

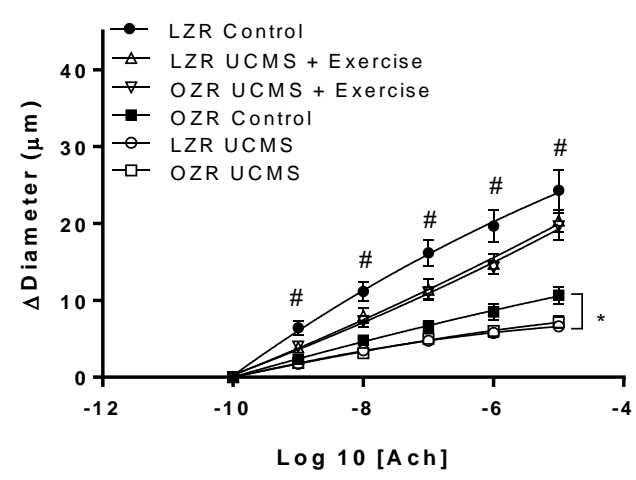

Figure S-1. The Effect of UCMS and Exercise on EDD in LZRs and OZRs. A) Assessment of endothelium-dependent dilation by exposure to increasing doses of Ach $\left(10^{-10}-10^{-6} \mathrm{M}\right)$ in control vs. UCMS, B) in control vs. exercise, C) in control vs. UCMS+Exercise. $n=6$-8/group. Mean \pm SEM. ${ }^{*} \mathrm{p}<0.01$ vs. control, ${ }^{*} \mathrm{p}<0.01$ vs. UCMS, ${ }^{\wedge} \mathrm{p}<0.01$ vs. exercise. 

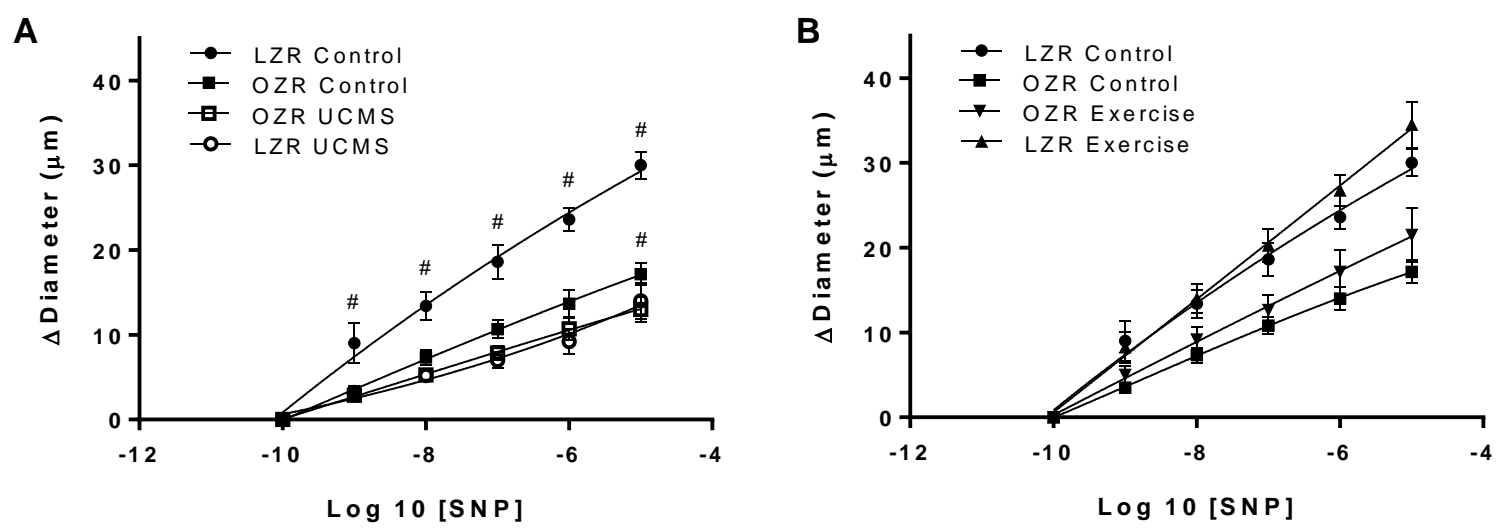

C

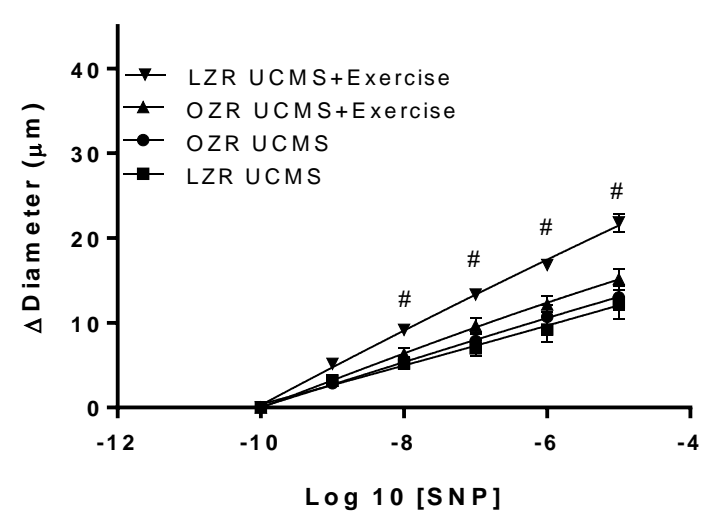

Figure S-2. The Effect of UCMS and Exercise on EID in LZRs and OZRs. A) Assessment of endothelium-independent dilation by exposure to increasing doses of SNP $\left(10^{-10}-10^{-6} \mathrm{M}\right)$ in control vs. UCMS, B) in control vs. exercise, C) in control vs. UCMS+Exercise. $n=6-8$ /group. Mean \pm SEM. ${ }^{*} \mathrm{p}<0.01$ vs. control, ${ }^{\#} \mathrm{p}<0.01$ vs. $\mathrm{UCMS}^{\wedge}{ }^{\wedge} \mathrm{p}<0.01$ vs. exercise. 
A

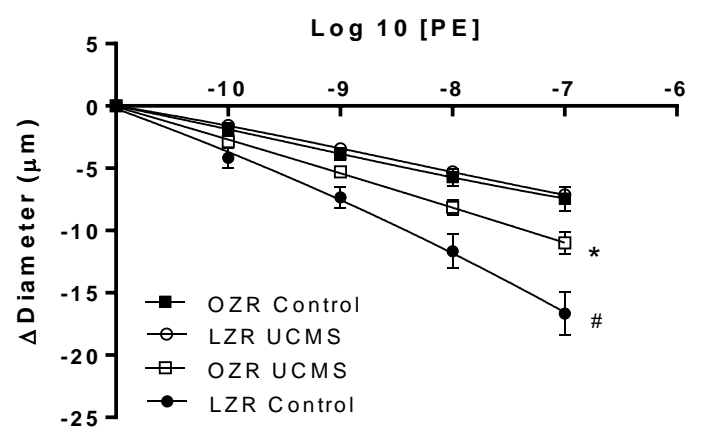

C

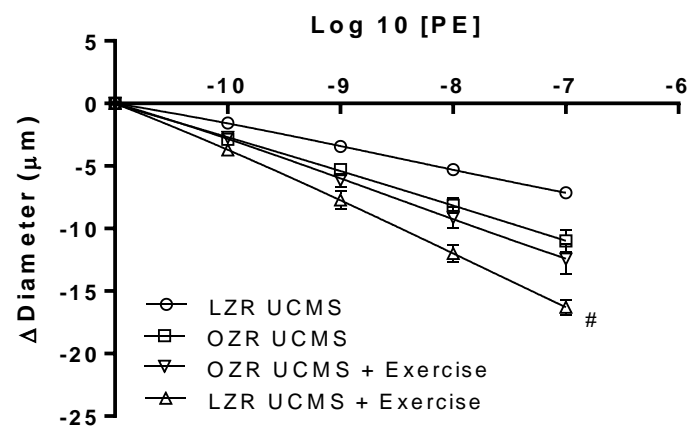

B

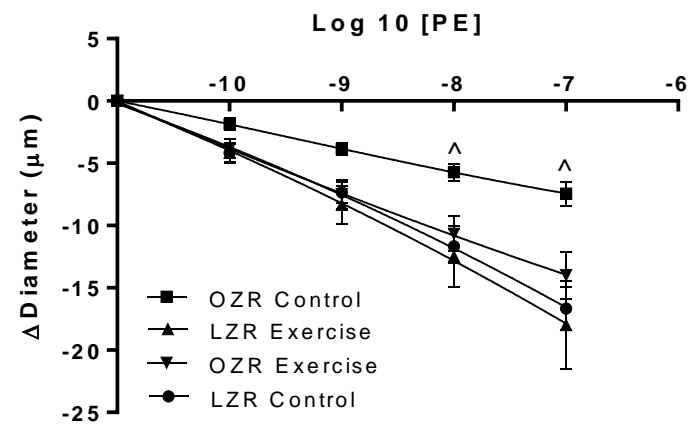

Figure S-2. The Effect of UCMS and Exercise on Constriction in LZRs and OZRs. A) Assessment of endothelium-independent dilation by exposure to increasing doses of PE $\left(10^{-10}\right.$ $10^{-7} \mathrm{M}$ ) in control vs. UCMS, B) in control vs. exercise, C) in control vs. UCMS+Exercise. $\mathrm{n}=$ 6-8/group. Mean \pm SEM. ${ }^{*} \mathrm{p}<0.01$ vs. control, ${ }^{\#} \mathrm{p}<0.01$ vs. $\mathrm{UCMS},{ }^{\wedge} \mathrm{p}<0.01$ vs. exercise. 


\section{CHAPTER 3 : Microvessel Density in the Brain is Attenuated with MetS and Depression but Improved with Exercise: A Preliminary Study}

Kayla W. Branyan ${ }^{1}$, Evan R. DeVallance ${ }^{1}$, Shinichi Asano ${ }^{1}$, Whitney Sheets ${ }^{1}$, Mariah Dawson ${ }^{1}$, Randy Bryner ${ }^{1}$, I. Mark Olfert ${ }^{1}$, Jefferson C. Frisbee ${ }^{2}$, Paul D. Chantler ${ }^{1}$

${ }^{1}$ Division of Exercise Physiology, School of Medicine, West Virginia University, Morgantown, WV; ${ }^{2}$ Department of Medical Biophysics, Transdisciplinary Program in Vascular Health, Schulich School of Medicine and Dentistry, University of Western Ontario, London, Ontario, Canada. 


\section{Introduction}

Endothelial cells play a primary role in maintaining microvascular function in the brain. These cells produce metabolic factors in response to stimuli and induce vasodilation or constriction. Proper endothelial function is essential to blood perfusion in any tissue, but especially in the most perfused organ in the body, the brain (1). In the cerebral vasculature, pericytes are adjacent to capillaries and share a common basement membrane with endothelial cells. Pericytes are important in cerebral capillary function by regulating cerebral blood flow, upregulating tight junction proteins, contributing to ion and water homeostasis, and interfacing directly with neurons (2-5). Further, pericytes also have several roles in regards to the cerebrovasculature such as contributing to the stability of the vessel, release of growth factors and matrix important for microvascular permeability, remodeling, and angiogenesis (6).

Metabolic syndrome (MetS), which is a collection of risk factors including hypertension, dyslipidemia, abdominal obesity, and high blood sugar (7), affects 56 million American adults (8). Through the collaborative deleterious effects of the MetS pathophysiologies, the vascular system is severely impacted including impairments in endothelial function and microvessel density. MetS has been found to reduce capillary-to-fiber ratio and microvessel density (MVD) in both the skeletal muscle and heart (9). In addition, MetS has also been shown to decrease functional brain capillary density and microvascular blood perfusion (10). A reduction of MVD in any vascular bed can cause disruption in patterns of blood flow and increased peripheral vascular resistance leading to an elevated risk of poor cardiovascular outcomes (11-13).

It has been postulated that exposure to chronic psychosocial stress is a significant risk factor for the development of MetS (14-16). Indeed, approximately 43\% of MetS patients present with depression (17). Unpredictable Chronic Mild Stress (UCMS) is a validated animal model 
using chronic stress to induce depressive symptoms $(18,19)$. Most studies that use this model have documented physiological changes in the brains of rodents, mainly reflecting an elevated physiological stress response (19). An elevated stress response can lead to vascular impairments due to increased cortisol levels and oxidative stress (20-22). Isingrini et al. (23), illustrated an overall decrease in endothelium-dependent dilation response of the aorta in UCMS-exposed mice as a result of decreased nitric oxide (NO) bioavailability. Although not much is known about the direct effect of chronic stress on cerebral microvascular rarefaction, an increase in cortisol has been shown to inhibit endothelial cell proliferation and induce apoptosis in pericytes in the brain (21,24). As with MetS, the chronic stress-induced loss in MVD can significantly increase an individual's risk of stroke or myocardial infarction $(11,25)$.

Exercise is often used to reduce the risk factors of MetS through lifestyle changes and has also proven to have beneficial effects on depression (26-30). One of these health benefits is an augmentation of microvascular rarefaction in pathological states. In a study by Machado et al. (31), two and a half hours of exercise per week resulted in an increase in capillary density in skeletal muscle, but only ninety minutes per week was required to reverse the microvascular rarefaction caused by a high fat diet in the left ventricle. Four weeks of aerobic exercise has been shown to increase both capillary density and surface area within the white matter of the brain (32). Further, previous studies have found that exercise by downregulating TNF- $\alpha$ and IL-1 $\beta$ could perhaps protect pericytes from apoptosis and enhance angiogenesis through upregulation of VEGF (33). These results suggest exercise could be a candidate therapeutic in individuals with comorbid MetS and depression to improve MVD.

The present study used the obese Zucker rat (OZR), an accepted, translational model of MetS, and induced depressive symptoms in these rats using the UCMS protocol. We hypothesized 
that: 1) cerebral MVD, along with pericyte number, would be reduced in rats exposed to UCMS; 2) cerebral MVD and pericytes would be increased with exercise; 3) exercise could mitigate the loss of cerebral MVD caused by the comorbidity between MetS and depression; and 4) the increase in MVD and number of pericytes would be reflected by an increase in VEGF and decrease in oxidative stress markers.

\section{Materials and Methods}

\section{Animals}

Male LZR and OZRs (Harlan) arrived at the West Virginia University Health Sciences Center (WVUHSC) animal facility at 7-8 weeks of age. After 1 week of acclimation to the local environment, LZRs ( $n=8$ per protocol) and OZRs ( $n=8$ per protocol) were randomly assigned to sedentary control or UCMS for the subsequent 8-9 weeks. All animals were fed standard chow and tap water ad libitum for all experiments. Protocols received prior approval from the WVUHSC Animal Care and Use Committee.

\section{UCMS Protocol}

Previous investigators developed the UCMS model for developing depression-like behaviors in rodents (34-37). The UCMS model is considered to be the most appropriate rodent model for clinical depression, based on its ability to reproduce the development of many clinical human depressive symptoms, including anhedonia and learned helplessness (19).

All rats were singly housed. In UCMS groups, rats were exposed to the following mild environmental stressors in randomly chosen sequences for 8 hours each day, 5 days/week, over the course of 8 weeks: 
7. Damp bedding - $10 \mathrm{oz}$. of water was added to each standard cage

8. Bath - all bedding was removed and $\sim 0.5$ inches of water was added to empty cage. Water temperature was room temperature, $\sim 24^{\circ} \mathrm{C}$

9. Cage Tilt - cage was tilted to 45 degrees without bedding

10. Social stress - each rat was switched into a cage of a neighboring rat

11. No bedding - all bedding was removed from the cage

12. Alteration of light/dark cycles -turning lights off/on in random increments for scheduled period.

\section{Coat Score}

Coat score evaluation was done for every group throughout the duration of the 8-week protocol. Each week, the rats were weighed and inspected for grooming habits (38). The total cumulative score was computed by giving an individual score of 0 (clean) or 1 (dirty) to eight different body parts (i.e. head, neck, back, forelimbs, stomach, hindlimbs, tail, genitals).

\section{Surgical Procedures}

After completion of the treatment period and at 17-18 weeks of age, each rat was anesthetized with pentobarbital sodium (50 mg/kg ip) and was intubated via the trachea to facilitate maintenance of a patent airway. In all rats, a carotid artery and an external jugular vein were cannulated for determination of arterial pressure and for infusion of heparin. Under anesthesia, an aliquot of blood was drawn from the inferior vena cava. Tissues of interest were isolated from each animal for further analysis. 


\section{Immunohistochemistry}

After rats were euthanized, surface cerebral blood vessels were removed for further analysis and the brain was placed in a matrix to cut $2 \mathrm{~mm}$ coronal slices. These slices were then flash-frozen in liquid nitrogen-cooled isopentane and store at $-80^{\circ} \mathrm{C}$ for later use. Brain slices were sectioned into $8 \mu \mathrm{m}$ slices using a cryostat at $-24^{\circ} \mathrm{C}$ and transferred to positively charged microscope slides (Fisherbrand ${ }^{\circledR}$ Superfrost ${ }^{\circledR}$ plus microscope slides).

Cerebral microvessel and capillary density was evaluated by fluorescence immunohistochemistry using purified rat anti-mouse CD31 antibody (BD Biosciences, San Diego, CA) and rat anti-rabbit desmin antibody (Abcam, Cambridge, MA). Briefly, brain sections were fixed with $10 \%$ formalin, permeabilized with $0.2 \%$ Triton $\mathrm{X}-100$, and blocked with blocking solution (5\% BSA in PBS) and then incubated with anti-CD31 (1:100) and anti-desmin (1:200) overnight in a humidified chamber at $4^{\circ} \mathrm{C}$. Following three washes with PBS, cells were incubated with AlexaFluor 555-conjugated anti-mouse IgG (1:1000; Invitrogen) and AlexaFluor 488conjugated anti-rabbit IgG (1:1000; Invitrogen) for $2 \mathrm{~h}$ at room temperature in a humidified chamber. After a final wash with PBS, cover glass was mounted with hard-set DAPI medium (Vector Laboratories, Burlingame, CA). Negative control was performed with the same procedure without primary antibody. Images were obtained with an epifluorescence microscope (EVOS, ThermoFisher Scientific). The microvessel density of co-labeled cells were analyzed in 6 regions of interest ( 3 in cortex and 3 in striatum) in the MCA territory using ImageJ, as described previously (39). 


\section{Real-Time Quantitative PCR}

RNA was extracted with the Direct-zol ${ }^{\mathrm{TM}}$ RNA MiniPrep Kit (Zymo Research) and reverse transcription was done using the QuantiTect Reverse Transcription Kit (Qiagen), according to manufacturer's protocols. QuantiTect primers (Qiagen) were used including: catalase, SOD, GSR, CD68, Nox2, VEGF, and TSP-1. Quantitative RT-PCR analysis was performed in duplicates for each sample using QuantiTect SYBR Green master mix (Qiagen) according to manufacturer's instructions and on the Roto-Gene thermocycler (Qiagen). Rat $18 S$ rRNA was used as a housekeeping gene to normalize expression of gene of interest depending on the experiment. Relative expression was calculated by the comparative CT $\left(2^{-\Delta \Delta C t}\right.$ values indicate fold change of the gene of interest in the samples relative to a selected control, $2^{-\Delta \mathrm{Ct}}$ values indicate relative expression of gene interest between samples normalized to $18 S$.

\section{Determination of VEGF concentration}

Brain tissue was homogenized using a bead mill and protein concentration was assessed by Bradford assay (DC Protein Assay, BioRad). Brain VEGF concentration was then determined with a commercially available rat VEGF-A sandwich-based ELISA kit (RayBiotech).

\section{Determination of TSP-1 concentration}

As with the VEGF ELISA, brain tissue was homogenized using a bead mill and protein concentration was assessed by Bradford assay (DC Protein Assay, BioRad). TSP-1 concentrations were determined as part of a rat inflammation V-plex panel ELISA (MesoScale Discovery). 


\section{Statistical Analysis}

Data are presented as mean \pm SEM. CD31+Desmin IHC was analyzed by a two-way analysis of variance (ANOVA), with a Tukey's post-hoc. RT-PCR was analyzed by a one-way repeated-measured ANOVA, with a Greenhouse-Geisser correction was performed to determine differences between groups. Protein levels were analyzed by a two-way analysis of variance (ANOVA), with a Tukey's post-hoc. In all cases, $\mathrm{p}<0.05$ was taken to reflect statistical significance.

\section{Results}

Figure 3-1 represents the immunohistochemistry (IHC) of the endothelial cell marker, CD31, and its co-labeling with desmin, a pericyte marker, in the cortex and striatum of the brain. The co-labeled cells are considered to be angiogenic microvessels. In LZRs, UCMS decreased the

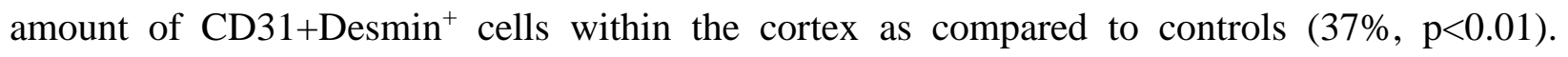
However, UCMS did not affect MVD in OZR-UCMS. Exercise had higher MVD as compared to LZR Controls $(18 \%, \mathrm{p}<0.05)$, and in OZR-Ex vs. their controls $(79 \%, \mathrm{p}<0.05)$. In fact, when exercise was paired with UCMS, exercise improved MVD to control levels in LZRs $(38 \%, \mathrm{p}<0.01)$ and higher than control levels in OZRs $(74 \%, \mathrm{p}<0.01)$. The same trend occurred in the striatum. UCMS decreased CD31+Desmin ${ }^{+}$cells by 27\% (p<0.01) as compared to LZR- and OZR-Controls, while in exercise, these cells were higher by $32 \%(\mathrm{p}<0.01)$ compared to controls. Exercise also improved MVD by 25\% (p<0.01) in LZR-UCMS+Ex, and also improved OZR-UCMS+Ex. MVD. The $\mathrm{CD} 31^{+}$cells mirrored the CD31+Desmin ${ }^{+}$results in both the cortex and striatum for all treatment groups.

Figure 3-2 illustrates mRNA expression and protein levels of angiogenic markers, VEGF and TSP-1. There were no significant changes in mRNA expression of VEGF between treatment 
groups (Fig. 3-2A), along with no change in protein levels (Fig. 3-2B). In TSP-1, no significant changes in mRNA expression were found between treatment groups (Fig. 3-2C), but OZR-UCMS had a significant decrease in TSP-1 protein levels as compared to OZR-Control and OZR-Ex (p<0.01; Fig. 3-2D). Figure 3-3 represents mRNA expression in several oxidative stress markers. There were also no significant changes in mRNA expression between groups with catalase, SOD, GSR, or Nox2 (Fig. 3-3A-D). No significant changes in mRNA expression occurred in CD68, a macrophage marker (Fig. 3-3).

\section{Discussion}

The results outlined here are part of preliminary data on the change in cerebral MVD during the comorbidity of MetS and depression, and what effect exercise had on the microvascular rarefaction associated with these conditions. Our data suggests that globally in LZRs, UCMS decreased cerebro-angiogenesis but this can be attenuated with the addition of exercise. In OZRs, UCMS did not further decrease angiogenesis but exercise did improve MetS-derived microvascular rarefaction. Also, when exercise was in combination with UCMS in OZRs, MVD was augmented as compared to OZR-Controls. Interestingly, there were no significant changes seen in mRNA expression of angiogenesis or oxidative markers. The lack of variation in mRNA expression between treatment groups could suggest that angiogenesis had already occurred in the brain, and transcription of these markers was back to basal levels.

The effect of depression on MVD has not been thoroughly studied. The present study showed that CD31+Desmin ${ }^{+}$cells were decreased with UCMS. There are several possible mechanisms that could have induced microvascular rarefaction. Patients with recurrent depressive disorder had lower circulating VEGF levels, which would attenuate angiogenesis (40). Endothelial 
progenitor cell numbers have also been found to be decreased in depressed patients, slowing angiogenesis in the brain (41). The elevated stress response associated with depression causes an increase in cortisol levels (16). Previous studies have also shown glucocorticoids can attenuate angiogenesis by inhibiting proliferation of cerebrovascular endothelial cells (21). In addition, pericyte apoptosis occurs with increased cortisol levels, where the glucocorticoid binds to receptors expressed on the pericytes, but when pericytes were treated with a glucocorticoid receptor antagonist, glucocorticoid-induced apoptosis was inhibited (24).

Exercise has been shown to reduce the physical symptoms of MetS and depression but also improve the pathophysiologies associated with each of the conditions $(9,29,42-44)$. Therefore, it was hypothesized that microvessel density would be higher with exercise in pre-existing MetS and in the comorbidity between MetS and depression. We have shown that MVD was higher with exercise in both LZRs and OZRs. Further, we also observed an improved MVD in LZR- and OZRUCMS+Ex. NO is important in capillary recruitment. One possible factor that could have contributed to the increase in cerebral MVD could be the increase in NO production following exercise. Exercise increases NO bioavailability in several ways including: increased eNOS expression (45-47), increased SOD activity (48), and reduced ROS production from NOX2 $(49,50)$ in skeletal muscle vasculature. Thus, NO bioavailability would be higher in the exercise groups, possibly leading to higher MVD. In addition, during acute bouts of exercise, mechanical forces such as shear stress and passive stretch lead to enhanced expression of angiogenic factors, including VEGF (51). Muscle contraction increases VEGF in the muscle interstitium, where VEGF acts on its receptors within the capillary endothelium to stimulate angiogenic processes (9). 


\section{Limitations and Future Directions}

One reason there were no significant changes in mRNA expression in any of the genes examined could be attributed to the variability in time it took to isolate and section the brain at time of terminal surgery. The period of time the brain was out of the rat to when it was flash frozen was not standardized, therefore, RNA degradation could have occurred. Stress has been known to cause different physical effects in individuals $(52,53)$. Exercise could also have been a stressor to certain rats, especially in the OZRs. The individual response of the animals to stress and exercise may have contributed to the variability in mRNA expression, influencing the statistical power of the data and preventing small changes to be detected.

Even though RT-PCR did not reveal any significant changes in mRNA expression, it was still important to determine if protein levels changed because mRNA to protein synthesis is not guaranteed $(54,55)$. The process of making protein from the mRNA transcript could be disrupted by many different mechanisms including: post-transcriptional adaptations, regulation by microRNAs, change in secondary structure of the transcript, disruption in ribosomal subunit recruitment, and proteasome activity (56-58). A change in any of these mechanisms could cause a decrease in protein synthesis or even an increase; therefore, western blots would need to be performed to determine if protein levels were affected by the experimental conditions.

Western blots for catalase, SOD, GSR, Nox2, and CD68 should have been done to determine the protein expression in the brain for each of these genes. Tissue is limited due to the many experiments already performed on the brain. ELISAs for VEGF and TSP-1 on brain homogenate are shown in this chapter, however, this is whole brain homogenate and more specific regional data is needed for correct evaluation of MVD changes in the cortex and striatum. It would be beneficial to separate these two regions and look at protein and mRNA expression in each. This 
would allow for direct comparison between the IHC results and factors that may be contributing to the higher MVD in exercise and lower MVD in UCMS.

RT-PCR and western blots for members of the MMP family should also be performed on the brain as these proteins are involved in angiogenesis. MMPs help with the degradation of the vascular basement membrane and remodeling of the ECM to allow endothelial cells to migrate and invade the surrounding tissue. They also enhance angiogenesis by several methods including: helping to detach pericytes from vessels, releasing ECM-bound angiogenic growth factors, exposing cryptic pro-angiogenic integrin binding sites in the ECM, generating pro-migratory ECM component fragments, and cleaving endothelial cell-cell adhesion. In contrast, MMPs can also inhibit angiogenesis by proteolytic cleavage of certain collagen chains, plasminogen, and certain receptor ligand-binding domains (59). A recent study found that pericyte-release of MMP-9 may contribute to early blood-brain barrier degradation after injury (60). Another target for PCR and westerns could be thromboxane $\mathrm{A}_{2}$. This metabolite, along with ATP, is released by platelets into the brain where they both act as potent constrictors of pericytes. Following constriction of the pericytes, contraction of the adjoining blood vessel wall would occur and could affect cerebral blood flow (61).

Another experiment that could have been done involves IHC probing for CD31 and Ki67. Unfortunately, we do not have enough brain slices to complete the investigation, nor are the slices reliably fresh to provide proper results. $\mathrm{Ki} 67$ is used as a cell proliferation marker because during mitosis, the Ki67 antigen is expressed on the surface of chromosomes. The colocalization of CD31 and $\mathrm{Ki} 67$ would indicate endothelial cells that are proliferating, giving a better idea to the extent of angiogenesis occurring within the brain. This process would involve the same procedure as the CD31 and desmin IHC previously shown. 
An increase in peroxynitrite levels can cause a reduction in NO bioavailability, but also pericyte contraction (62). In healthy conditions, pericytes help to regulate blood flow by contracting or relaxing (63). If peroxynitrite levels are chronically high, such as in MetS, pericyte contraction could become chronic and affect blood flow in the brain. Thus, staining for nitrotyrosine in the brain could have been beneficial to assess the amount of peroxynitrite present. Staining for nitrotyrosine would serve two purposes: 1) to support that the microvascular dysfunction shown in UCMS was at least in part mediated by ROS production and; 2) estimate the amount of pericyte dysfunction that would lead to chronic constriction of cerebral blood vessels.

Collagen staining could have provided evidence for tissue remodeling due to the fibrotic response induced by pericyte death (61). Perivascular fibroblasts are recruited to sites of necrotic capillary pericytes and deposit extracellular matrix molecules that form a fibrotic scar within the brain. This could cause a number of problems including a disruption in neuronal signaling and cerebral perfusion (61). To evaluate the number of pericytes that are damaged in the case of decreased MVD, TUNEL and desmin staining could have been used to show DNA-fragmentation within pericytes. Paired with collagen staining, we would have been able to determine the sites of tissue remodeling and compare that to pericyte damage/apoptosis.

Monocyte-derived macrophages secrete VEGF-A, which seems to be crucial to induction of angiogenesis in tissue repair. Both M1 and M2 macrophage phenotypes are suggested to be involved with angiogenesis, in which M1 macrophages express genes involved with angiogenesis initiation and M2 macrophages secrete MMP-9 and recruit pericytes (64). Macrophages interact directly with pericytes, promoting pericyte-endothelial interactions. Macrophages also stimulate collateral artery diameter enlargement through smooth muscle cell hypertrophy and proliferation (65). Therefore, macrophage recruitment could have been evaluated in order to explain the higher 
MVD with exercise. Staining brain slices with CXCL9 or CD86 would detect M1 macrophages and CXCR2 or CD23 would mark M2 macrophages (66). Flow cytometry could have been done on fresh brain slices to separate the macrophage phenotypes and compare population sizes.

\section{Clinical Implications and Conclusions}

Many pathologies that result in poor cardiovascular outcomes stem from vascular dysfunction, whether that dysfunction is in the endothelium or is due to a reduction in perfusion. The data presented here show that UCMS has an effect on cerebral angiogenesis and causes a loss of MVD in healthy animals. More importantly, exercise augments MVD in pre-existing MetS and in the case of the comorbidity between UCMS and MetS. Clinically, these data are relevant because they suggest a possible mechanism contributing to loss of MVD. These results also suggest that exercise can be used as a therapeutic for patients. 


\section{References}

1. Klein B, Kuschinsky W, Schröck H, Vetterlein F. Interdependency of local capillary density, blood flow, and metabolism in rat brains. Am J Physiol [Internet]. 1986;251(6 Pt 2):H1333-40. Available from: http://www.ncbi.nlm.nih.gov/pubmed/3098116

2. Lok J, Gupta P, Guo S, Kim WJ, Whalen MJ, Van Leyen K, et al. Cell-cell signaling in the neurovascular unit. Vol. 32, Neurochemical Research. 2007. p. 2032-45.

3. Rennels ML, Nelson E. Capillary innervation in the mammalian central nervous system: An electron microscopic demonstration. Am J Anat. 1975;144(2):233-41.

4. Zlokovic B V. The Blood-Brain Barrier in Health and Chronic Neurodegenerative Disorders. Vol. 57, Neuron. 2008. p. 178-201.

5. Hamel E. Perivascular nerves and the regulation of cerebrovascular tone. J Appl Physiol [Internet]. 2005;100(3):1059-64. Available from: http://jap.physiology.org/cgi/doi/10.1152/japplphysiol.00954.2005

6. Dore-Duffy P, LaManna JC. Physiologic angiodynamics in the brain. Antioxid Redox Signal [Internet]. 2007;9(9):1363-71. Available from: http://www.ncbi.nlm.nih.gov/pubmed/17627476

7. Maksimovic M, Vlajinac H, Radak D, Marinkovic J, Jorga J. Relationship between peripheral arterial disease and metabolic syndrome. Angiology [Internet]. 2009;60:54653. Available from: http://www.ncbi.nlm.nih.gov/pubmed/19147526

8. Falkner B, Cossrow NDFH. Prevalence of metabolic syndrome and obesity-associated hypertension in the racial ethnic minorities of the United States. Vol. 16, Current 
Hypertension Reports. 2014.

9. Hoier B, Hellsten Y. Exercise-induced capillary growth in human skeletal muscle and the dynamics of VEGF. Vol. 21, Microcirculation. 2014. p. 301-14.

10. Estato V, Nascimento A, Antunes B, Gomes F, Coelho L, Rangel R, et al. Cerebral Microvascular Dysfunction and Inflammation Are Improved by Centrally Acting Antihypertensive Drugs in Metabolic Syndrome. Metab Syndr Relat Disord [Internet]. 2017;15(1):26-35. Available from: http://online.liebertpub.com/doi/10.1089/met.2016.0085

11. Frisbee JC, Goodwill AG, Frisbee SJ, Butcher JT, Brock RW, Olfert IM, et al. Distinct temporal phases of microvascular rarefaction in skeletal muscle of obese Zucker rats. Am J Physiol Heart Circ Physiol [Internet]. 2014;307(12):H1714-28. Available from: http://www.ncbi.nlm.nih.gov/pubmed/25305181

12. Frisbee JC. Hypertension-independent microvascular rarefaction in the obese Zucker rat model of the metabolic syndrome. Microcirculation [Internet]. 2005;12(24):383-92. Available from: http://www.ncbi.nlm.nih.gov/pubmed/16020387

13. Chantler PD, Shrader CD, Tabone LE, d'Audiffret AC, Huseynova K, Brooks SD, et al. Cerebral Cortical Microvascular Rarefaction in Metabolic Syndrome is Dependent on Insulin Resistance and Loss of Nitric Oxide Bioavailability. Microcirculation [Internet]. 2015 Aug [cited 2015 Dec 11];22(6):435-45. Available from: http://www.ncbi.nlm.nih.gov/pubmed/26014499

14. Chandola T, Brunner E, Marmot M. Chronic stress at work and the metabolic syndrome: prospective study. Bmj [Internet]. 2006;332(7540):521-4. Available from: 
http://www.ncbi.nlm.nih.gov/entrez/query.fcgi?cmd=Retrieve\&db=PubMed\&dopt=Citati on\&list_uids=16428252\%5Cnhttp://pubmedcentralcanada.ca/picrender.cgi?accid=PMC13 88129\&blobtype $=$ pdf

15. Kyrou I, Tsigos C. Stress mechanisms and metabolic complications. In: Hormone and Metabolic Research. 2007. p. 430-8.

16. Chrousos GP. The role of stress and the hypothalamic-pituitary-adrenal axis in the pathogenesis of the metabolic syndrome: neuro-endocrine and target tissue-related causes. Int J Obes Relat Metab Disord. 2000;24 Suppl 2:S50-5.

17. d'Audiffret AC, Frisbee SJ, Stapleton P a, Goodwill AG, Isingrini E, Frisbee JC. Depressive behavior and vascular dysfunction: a link between clinical depression and vascular disease? J Appl Physiol. 2010;108(5):1041-51.

18. Avolio E, Fazzari G, Mele M, Al?? R, Zizza M, Jiao W, et al. Unpredictable Chronic Mild Stress Paradigm Established Effects of Pro- and Anti-inflammatory Cytokine on Neurodegeneration-Linked Depressive States in Hamsters with Brain Endothelial Damages. Mol Neurobiol [Internet]. 2016;1-13. Available from: http://dx.doi.org/10.1007/s12035-016-0171-1

19. Willner P. Neurobiology of Stress The chronic mild stress ( CMS ) model of depression : History , evaluation and usage. Neurobiol Stress [Internet]. 2017;6:78-93. Available from: http://dx.doi.org/10.1016/j.ynstr.2016.08.002

20. Tsigos C, Kyrou I, Chrousos G. Stress, endocrine physiology and pathophysiology. J Psychosom Res [Internet]. 2002;53(4):865-71. Available from: http://www.ncbi.nlm.nih.gov/pubmed/25905226 
21. Ekstrand J, Hellsten J, Wennström M, Tingström A. Differential inhibition of neurogenesis and angiogenesis by corticosterone in rats stimulated with electroconvulsive seizures. Prog Neuro-Psychopharmacology Biol Psychiatry. 2008;32(6):1466-72.

22. Golbidi S, Frisbee JC, Laher I. Chronic stress impacts the cardiovascular system: animal models and clinical outcomes. Am J Physiol - Hear Circ Physiol [Internet]. 2015;308(12):H1476-98. Available from: http://ajpheart.physiology.org/lookup/doi/10.1152/ajpheart.00859.2014

23. Isingrini E, Surget A, Belzung C, Freslon JL, Frisbee J, O’Donnell J, et al. Altered aortic vascular reactivity in the unpredictable chronic mild stress model of depression in mice. UCMS causes relaxation impairment to ACh. Physiol Behav [Internet]. 2011;103(5):5406. Available from: http://dx.doi.org/10.1016/j.physbeh.2011.04.002

24. Katychev A, Wang X, Duffy A, Dore-Duffy P. Glucocorticoid-Induced Apoptosis in CNS Microvascular Pericytes. Dev Neurosci. 2003;25(6):436-46.

25. Dell'Omo G, Penno G, Pucci L, Mariani M, Del Prato S, Pedrinelli R. Abnormal capillary permeability and endothelial dysfunction in hypertension with comorbid Metabolic Syndrome. Atherosclerosis. 2004;172(2):383-9.

26. Salmon P. Effects of physical exercise on anxiety, depression, and sensitivity to stress: A unifying theory. Vol. 21, Clinical Psychology Review. 2001. p. 33-61.

27. Cooney G, Dwan K, Mead G. Exercise for Depression. JAMA [Internet]. 2014;311(23):2432. Available from: http://jama.jamanetwork.com/article.aspx?doi=10.1001/jama.2014.4930 
28. Ströhle A. Physical activity, exercise, depression and anxiety disorders. Vol. 116, Journal of Neural Transmission. 2009. p. 777-84.

29. Donley DA, Fournier SB, Reger BL, DeVallance E, Bonner DE, Olfert IM, et al. Aerobic exercise training reduces arterial stiffness in metabolic syndrome. J Appl Physiol [Internet]. 2014;116(April):1396-404. Available from: http://www.ncbi.nlm.nih.gov/pubmed/24744384

30. Arvola P, Wu X, Kähönen M, Mäkynen H, Riutta A, Mucha I, et al. Exercise enhances vasorelaxation in experimental obesity associated hypertension. Cardiovasc Res. 1999;43(4):992-1002.

31. Machado MV, Vieira AB, da Conceição FG, Nascimento AR, da Nóbrega ACL, Tibirica E. Exercise training dose differentially alters muscle and heart capillary density and metabolic functions in an obese rat with metabolic syndrome. Exp Physiol [Internet]. 2017;0:1-13. Available from: http://doi.wiley.com/10.1113/EP086416

32. Chen LM, Zhang AP, Wang FF, Tan CX, Gao Y, Huang CX, et al. Running exercise protects the capillaries in white matter in a rat model of depression. J Comp Neurol. 2016;524(17):3577-86.

33. Wang X, Zhang M, Feng R, Li WB, Ren SQ, Zhang J, et al. Physical exercise training and neurovascular unit in ischemic stroke. Vol. 271, Neuroscience. 2014. p. 99-107.

34. Vollmayr B, Henn FA. Stress models of depression. Vol. 3, Clinical Neuroscience Research. 2003. p. 245-51.

35. Willner P. Validity, reliability and utility of the chronic mild stress model of depression: a 
10-year review and evaluation. Psychopharmacology (Berl) [Internet]. 1997;134(4):319-

29. Available from: http://www.ncbi.nlm.nih.gov/pubmed/9452163

36. Willner P, Muscat R, Papp M. Chronic mild stress-induced anhedonia: A realistic animal model of depression. Neurosci Biobehav Rev. 1992;16(4):525-34.

37. Frisbee JC, Brooks SD, Stanley SC, d'Audiffret AC. An Unpredictable Chronic Mild Stress Protocol for Instigating Depressive Symptoms, Behavioral Changes and Negative Health Outcomes in Rodents. J Vis Exp [Internet]. 2015;(106):1-8. Available from: http://www.ncbi.nlm.nih.gov/pubmed/26650668

38. Yalcin I, Aksu F, Belzung C. Effects of desipramine and tramadol in a chronic mild stress model in mice are altered by yohimbine but not by pindolol. Eur J Pharmacol. 2005;514(2-3):165-74.

39. Zechariah A, ElAli A, Doeppner TR, Jin F, Hasan MR, Helfrich I, et al. Vascular endothelial growth factor promotes pericyte coverage of brain capillaries, improves cerebral blood flow during subsequent focal cerebral ischemia, and preserves the metabolic penumbra. Stroke. 2013;44(6):1690-7.

40. Berent D, Macander M, Szemraj J, Orzechowska A, Galecki P. Vascular endothelial growth factor A gene expression level is higher in patients with major depressive disorder and not affected by cigarette smoking, hyperlipidemia or treatment with statins. Acta Neurobiol Exp [Internet]. 2014;74(1):82-90. Available from:

http://www.ncbi.nlm.nih.gov/pubmed/24718046

41. Dome P, Teleki Z, Rihmer Z, Peter L, Dobos J, Kenessey I, et al. Circulating endothelial progenitor cells and depression: a possible novel link between heart and soul. Mol 
Psychiatry [Internet]. 2009;14(5):523-31. Available from:

http://www.ncbi.nlm.nih.gov/pubmed/18180758

42. Liu W, Sheng H, Xu Y, Liu Y, Lu J, Ni X. Swimming exercise ameliorates depressionlike behavior in chronically stressed rats: Relevant to proinflammatory cytokines and IDO activation. Behav Brain Res. 2013;242(1):110-6.

43. ann het Rot M, Collins KA, Fitterling HL. Physical exercise and depression. Mt Sinai J Med. 2009;76(2):204-14.

44. Frisbee JC, Samora JB, Peterson J, Bryner R. Exercise training blunts microvascular rarefaction in the metabolic syndrome. Am J Physiol Heart Circ Physiol. 2006;291(5):H2483-92.

45. Laughlin MH, Pollock JS, Amann JF, Hollis ML, Woodman CR, Price EM. Training induces nonuniform increases in eNOS content along the coronary arterial tree. J Appl Physiol. 2001;90(2):501-10.

46. Sindler AL, Delp MD, Reyes R, Wu G, Muller-Delp JM. Effects of ageing and exercise training on eNOS uncoupling in skeletal muscle resistance arterioles. J Physiol. 2009;587(Pt 15):3885-97.

47. Green DJ, Maiorana A, O’Driscoll G, Taylor R. Effect of exercise training on endothelium-derived nitric oxide function in humans. J Physiol. 2004;561(Pt 1):1-25.

48. Cocks M, Wagenmakers AJM. The effect of different training modes on skeletal muscle microvascular density and endothelial enzymes controlling NO availability. J Physiol [Internet]. 2016;594(8):2245-57. Available from: http://doi.wiley.com/10.1113/JP270329 
49. Maiorana A, O'Driscoll G, Taylor R, Green D. Exercise and the Nitric Oxide Vasodilator System. Vol. 33, Sports Medicine. 2003. p. 1013-35.

50. Gomez-Cabrera MC, Domenech E, Viña J. Moderate exercise is an antioxidant: Upregulation of antioxidant genes by training. Free Radic Biol Med. 2008;44(2):126-31.

51. Tang K, Xia FC, Wagner PD, Breen EC. Exercise-induced VEGF transcriptional activation in brain, lung and skeletal muscle. Respir Physiol Neurobiol. 2010;170(1):1622.

52. Chen J, Wang Z zhen, Zuo W, Zhang S, Chu S feng, Chen $\mathrm{N}$ hong. Effects of chronic mild stress on behavioral and neurobiological parameters - Role of glucocorticoid. Horm Behav. 2016;78:150-9.

53. Kockler M, Heun R. Gender differences of depressive symptoms in depressed and nondepressed elderly persons. Int J Geriatr Psychiatry. 2002;17(1):65-72.

54. Hershey JW, Sonenberg N, Mathews MB. Principles of translational control: an overview. Cold Spring Harb Perspect Biol [Internet]. 2012;4(12):1-11. Available from: http://www.ncbi.nlm.nih.gov/entrez/query.fcgi?cmd=Retrieve\&db=PubMed\&dopt=Citati on\&list_uids $=23209153$

55. Hinnebusch AG, Ivanov IP, Sonenberg N. Translational control by 5 ' -untranslated regions of eukaryotic mRNAs. Science (80- ). 2016;352(6292):1413-6.

56. Jackson DA, Pombo A, Iborra F. The balance sheet for transcription: an analysis of nuclear RNA metabolism in mammalian cells. FASEB J [Internet]. 2000;14(2):242-54. Available from: http://www.ncbi.nlm.nih.gov/pubmed/10657981 
57. Selbach M, Schwanhausser B, Thierfelder N, Fang Z, Khanin R, Rajewsky N. Widespread changes in protein synthesis induced by microRNAs. Nature. 2008;455(7209):58-63.

58. Ogorodnikov A, Kargapolova Y, Danckwardt S. Processing and transcriptome expansion at the mRNA 3' end in health and disease: finding the right end. Vol. 468, Pflugers Archiv European Journal of Physiology. 2016. p. 993-1012.

59. Rundhaug JE. Matrix metalloproteinases and angiogenesis. J Cell Mol Med [Internet]. 2005;9(2):267-85. Available from: http://doi.wiley.com/10.1111/j.15824934.2005.tb00355.x

60. Underly RG, Levy M, Hartmann DA, Grant RI, Watson AN, Shih AY. Pericytes as Inducers of Rapid, Matrix Metalloproteinase-9-Dependent Capillary Damage during Ischemia. J Neurosci [Internet]. 2017;37(1):129-40. Available from: http://www.jneurosci.org/lookup/doi/10.1523/JNEUROSCI.2891-16.2017

61. Fernández-Klett F, Priller J. Diverse functions of pericytes in cerebral blood flow regulation and ischemia. J Cereb Blood Flow Metab [Internet]. 2015;35(6):883-7. Available from:

http://journals.sagepub.com/doi/abs/10.1038/jcbfm.2015.60?url_ver=Z39.882003\&rfr_id=ori\%3 Arid\%3Acrossref.org\&rfr_dat=cr_pub\%3Dpubmed\#.WJsEPQea9N0. mendeley

62. Yemisci M, Gursoy-Ozdemir Y, Vural A, Can A, Topalkara K, Dalkara T. Pericyte contraction induced by oxidative-nitrative stress impairs capillary reflow despite successful opening of an occluded cerebral artery. Nat Med [Internet]. 2009;15(9):1031-7. Available from: http://www.nature.com/doifinder/10.1038/nm.2022 
63. Hall CN, Reynell C, Gesslein B, Hamilton NB, Mishra A, Sutherland BA, et al. Capillary pericytes regulate cerebral blood flow in health and disease. Nature. 2014;508(1):55-60.

64. Spiller KL, Anfang RR, Spiller KJ, Ng J, Nakazawa KR, Daulton JW, et al. The role of macrophage phenotype in vascularization of tissue engineering scaffolds. Biomaterials. 2014;35(15):4477-88.

65. Bruce AC, Kelly-Goss MR, Heuslein JL, Meisner JK, Price RJ, Peirce SM. Monocytes are recruited from venules during arteriogenesis in the murine spinotrapezius ligation model. Arterioscler Thromb Vasc Biol. 2014;34(9):2012-22.

66. Ka MB, Daumas A, Textoris J, Mege J-L. Phenotypic Diversity and Emerging New Tools to Study Macrophage Activation in Bacterial Infectious Diseases. Front Immunol [Internet]. 2014;5. Available from: http://journal.frontiersin.org/article/10.3389/fimmu.2014.00500/abstract 


\section{Cortex}

A

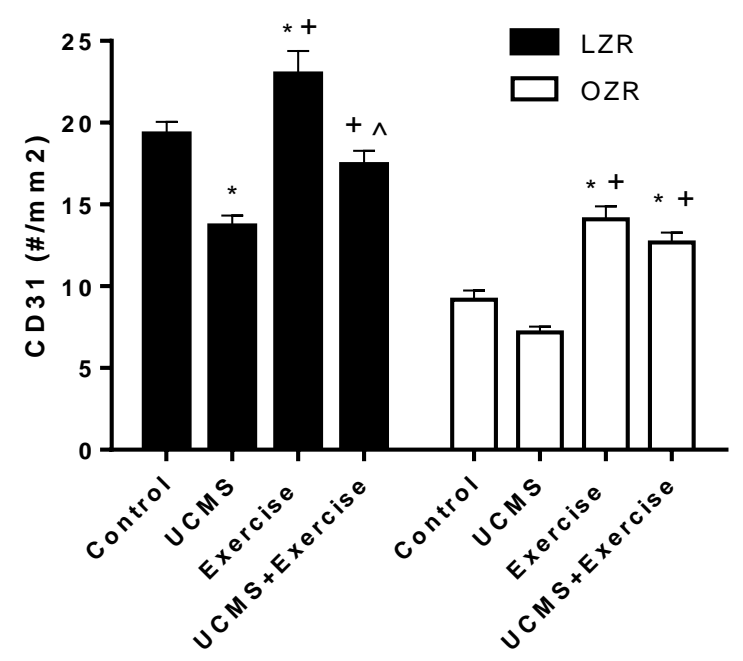

Striatu m

C

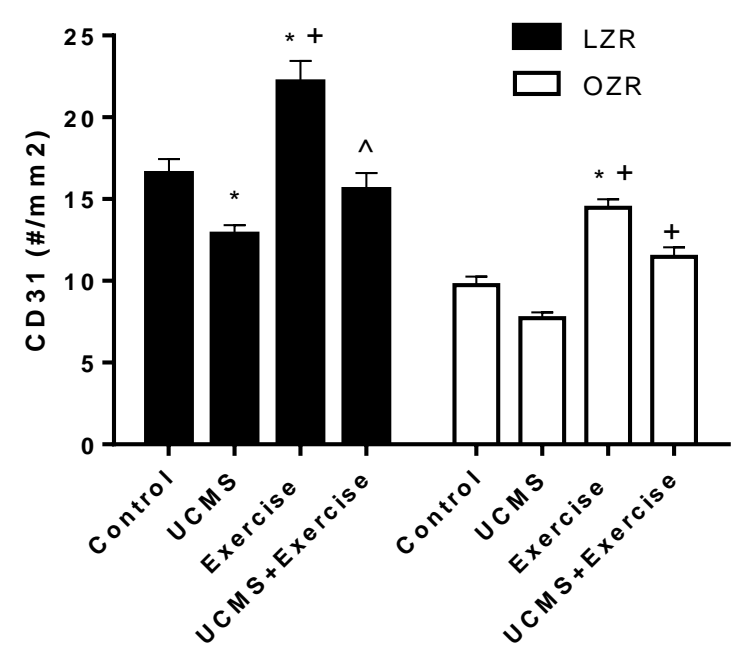

B

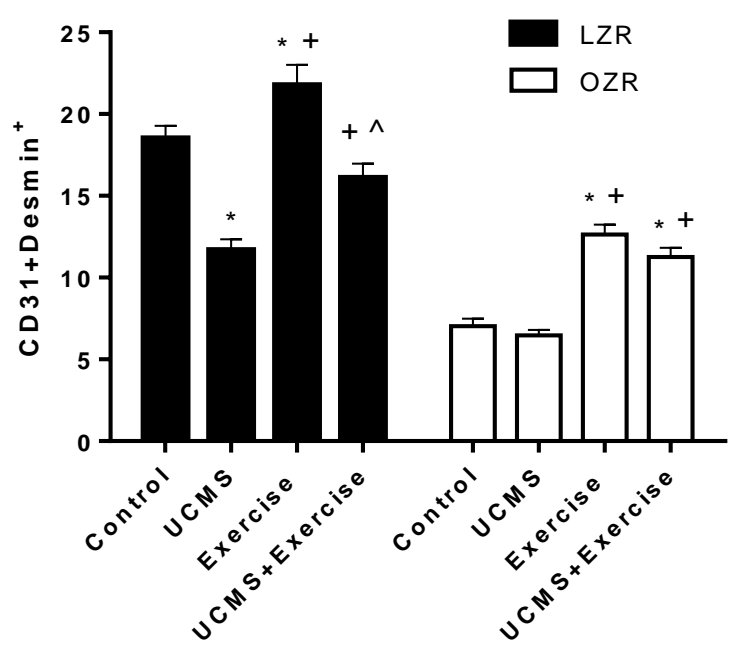

D

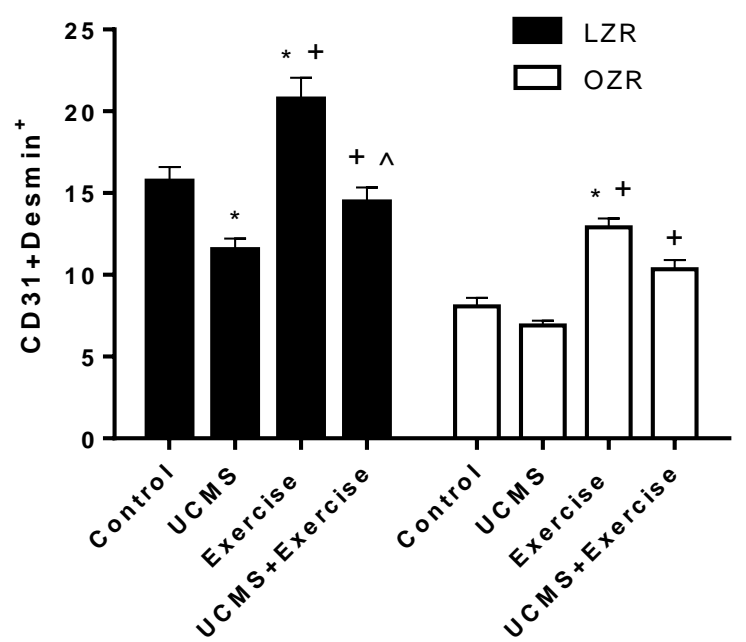

Figure 3-1. Quantification of CD31/Desmin ${ }^{+}$cells in the cortex and striatum. A, B) $\mathrm{CD}^{+} 1^{+}$and CD31+Desmin ${ }^{+}$cells in the cortex were decreased with UCMS in LZRs but not in OZRs. Increased in both Ex and UCMS+Ex; C, D) CD31 ${ }^{+}$and CD31+Desmin ${ }^{+}$cells in the cortex were decreased with UCMS in LZRs but not in OZRs. Increased in both Ex and UCMS+E. $n=6-8 /$ group. Mean \pm SEM. *p<0.01 vs. control, ${ }^{+} \mathrm{p}<0.05$ vs. UCMS, ${ }^{\wedge} \mathrm{p}<0.05$ vs. Ex. Please see text for additional details. 

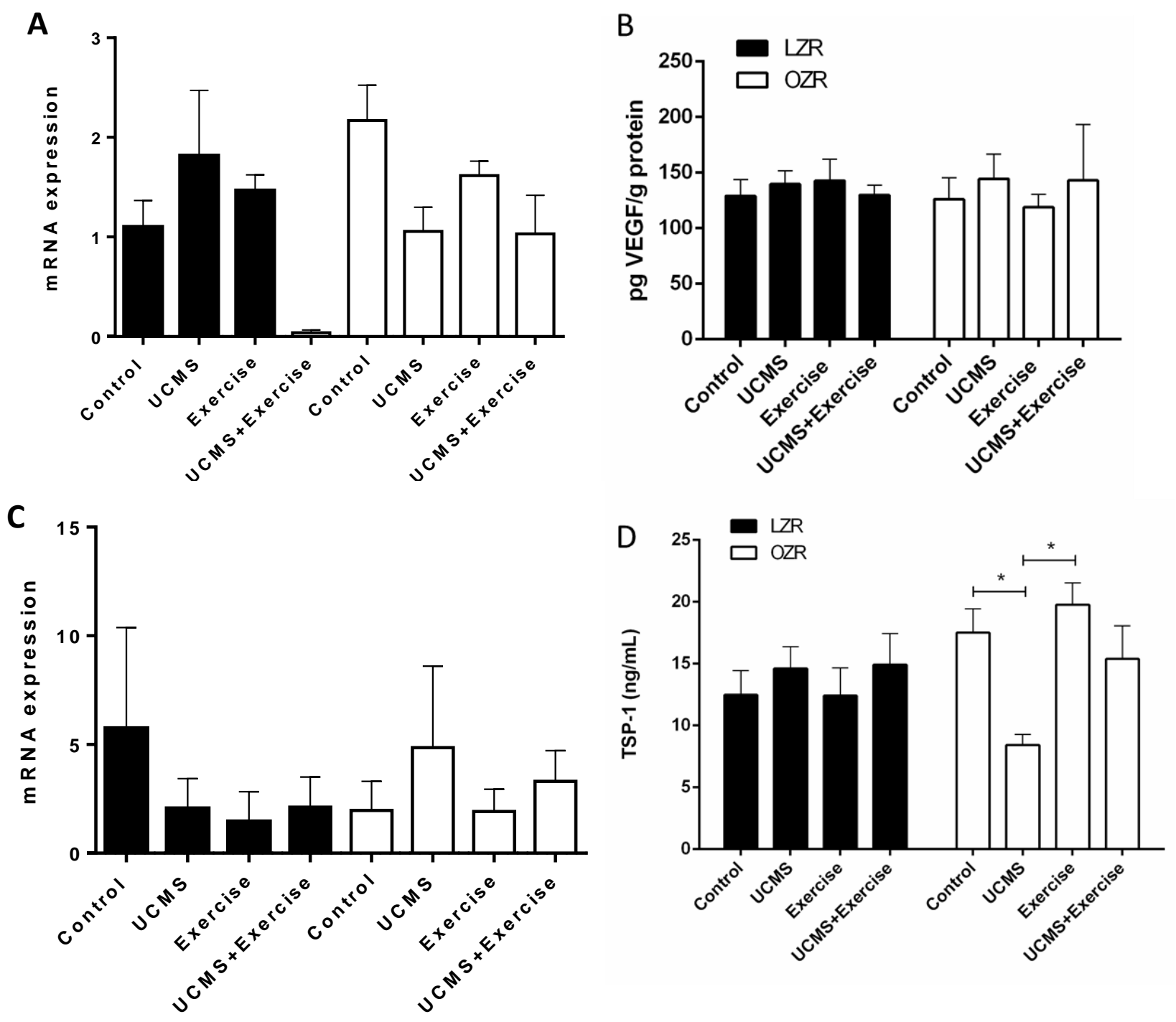

Figure 3-2. mRNA and protein expression of angiogenic factors in the brain. A) There were no significant changes in VEGF mRNA expression between treatment groups; B) There were no changes seen in VEGF protein expression between groups; C) There were no significant changes in TSP-1 mRNA expression between treatment groups; D) There was a significant decrease in TSP-1 protein levels in OZR-UCMS as compared to OZR-Control and -Ex. $n=6-8$ /group. Mean \pm SEM. ${ }^{*} \mathrm{p}<0.01$. 
A

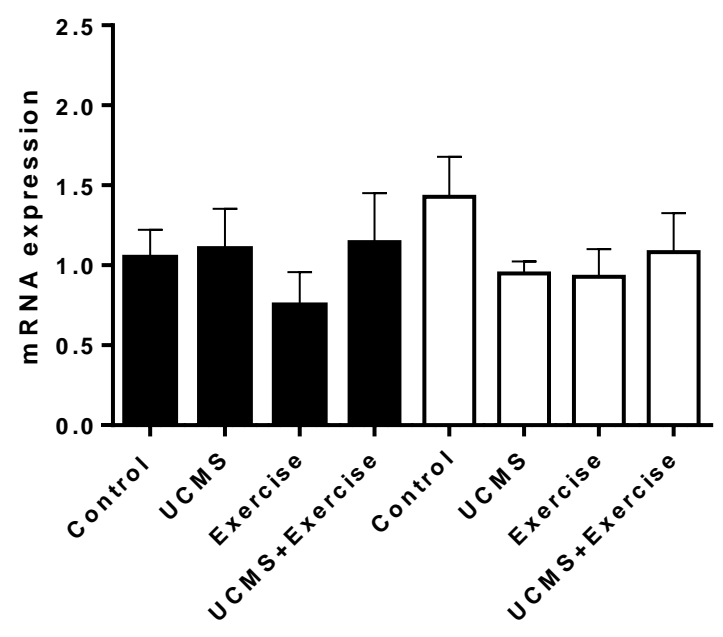

C

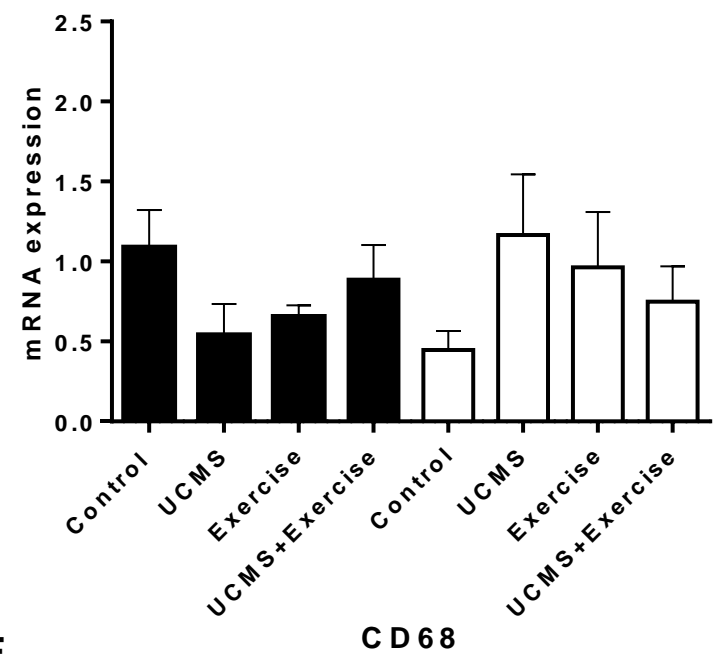

$\mathbf{E}$

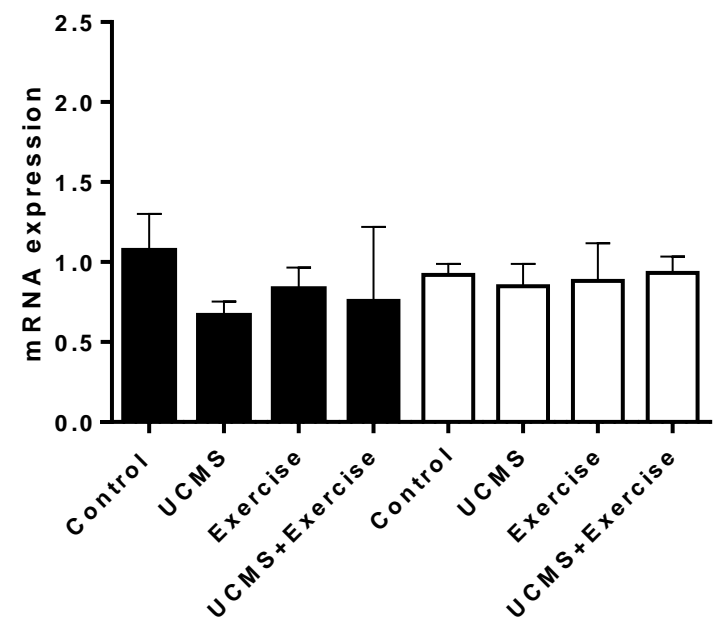

B

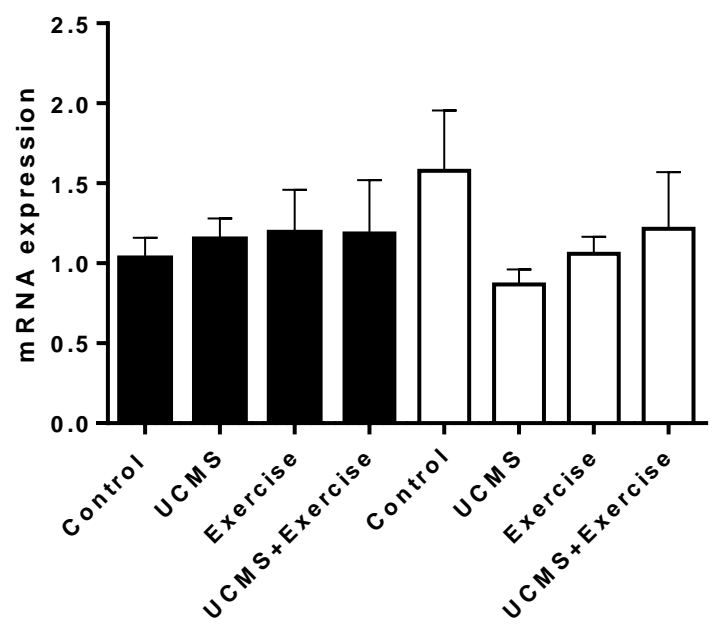

Nox 2

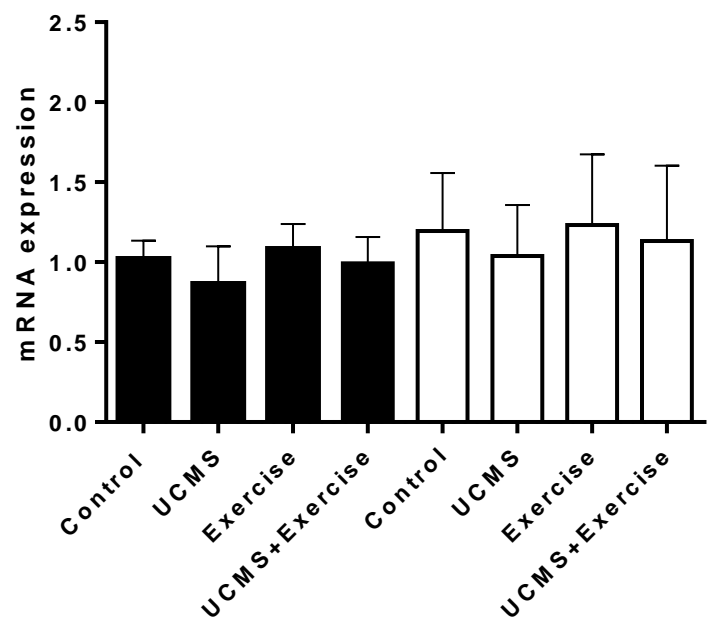

Figure 3-3. mRNA expression of oxidative stress markers in

the brain. A) There were no significant changes in catalase mRNA expression between treatment groups; B) There were no significant changes in SOD mRNA expression between treatment groups; C) There were no significant changes in glutathione reductase (GSR) mRNA expression between treatment groups; D) There were no significant changes in Nox 2 mRNA expression between treatment groups; E) There were no significant changes in CD68 mRNA expression between treatment groups. $n=6$-8/group. Mean \pm SEM. 


\section{CHAPTER 4 : Dissertation Discussion}

The effect of the comorbidity between MetS and depression on the peripheral microvasculature was unknown. Previous studies had examined the causative mechanisms of MetS and depression separately, but this dissertation focused on determining the impact of the comorbidity on the microvasculature of the skeletal muscle and brain, along with MVD. The studies performed previously have suggested a direct association between the vasculopathy caused by each disorder and the increase in oxidative stress on vascular reactivity and MVD. Poor cardiovascular outcomes are brought on by the endothelial dysfunction caused by MetS and depression. Therefore, it was important to determine if depression exacerbated the vascular dysfunction already present with MetS. This study used exercise as a therapeutic, which has been proven previously to augment NO bioavailability and decrease ROS, to improve endotheliumdependent dilation response in OZRs subjected to UCMS. Further, exercise attenuated loss of MVD.

The work detailed in this dissertation used the obese Zucker rat, a model of MetS, to determine that: 1) UCMS causes peripheral microvascular dysfunction in LZRs similar to that seen in OZRs; 2) Peripheral microvascular dysfunction seen in OZRs was not exacerbated with UCMS;

3) the peripheral microvascular dysfunction and loss of MVD are caused by reduced NO bioavailability and increase in oxidative stress; and 4) exercise improves peripheral microvascular dysfunction and rarefaction by increasing NO.

The second chapter of this dissertation focused on characterizing the effect of MetS and depression, together, on the skeletal muscle arterioles using an in vitro pressurized myobath system to evaluate endothelium-dependent dilation and constriction response. Previous studies from our 
collaborators have established the independent effects of MetS on the skeletal muscle arterioles and the effects of depression on the aorta $(1,2)$. In both cases, endothelium-dependent dilation was impaired but did not find a significant change in constriction response. The study presented in Chapter 2 subjected OZRs and LZRs to UCMS for 8 weeks, and at the end of the 8 weeks of treatment GAs were isolated to determine dose response to Ach and PE. A significant reduction in endothelium-dependent dilation in LZR-UCMS but the same impairment was not seen in OZRUCMS. Both LZR- and OZR-UCMS endothelium-independent dilation were attenuated, and constriction response was augmented only in OZR-UCMS. Treatment with the ROS scavenger, TEMPOL, increased dilation response in LZR-UCMS, OZR-Control, and OZR-UCMS. As to be expected, treatment with a NOS inhibitor, LNAME severely blunted LZR- and OZR-Control endothelium-dependent dilation. NO levels were lower in LZR-UCMS compared to their controls but did not significantly change between OZR-Control and OZR-UCMS. The same trends were seen with ROS levels in the respective groups.

The findings of this chapter provide evidence that a severe decrease in NO levels induced by UCMS and the added increase in ROS levels was the main cause of endothelium-dependent and -independent dilation in LZRs. The results of TEMPOL and LNAME treatment support this theory. In OZRs, the effect of UCMS on endothelium-dependent dilation is less drastic, which could be due to the fact that OZRs already have elevated ROS levels and reduced NO levels. This suggests the pre-existing impairment in OZRs may make them less susceptible to UCMS effects. The interesting finding involves the attenuation of OZR endothelium-independent dilation, which seems to be due to another NO-independent mechanism. Elevated thromboxane or Ang II could be the cause of the impairment, but further experiments are needed to confirm this hypothesis. Both of these metabolites have been shown to directly affect endothelium dilator function (3-6). 
The third chapter aimed to explore the possibility of using exercise as a therapeutic during the comorbidity of MetS and UCMS. This chapter built off the second chapter directly, meaning the same animals previously used in LZR- and OZR-Control and UCMS were used again, only LZR- and OZR-Ex and UCMS+Ex groups were added. Exercise by itself improved endotheliumdependent dilation in both LZRs and OZRs. It did not influence endothelium-independent dilation in LZRs; however, OZR-UCMS EID was significantly improved. Acute TEMPOL treatment did not further augment endothelium-dependent dilation in LZR- and OZR-Ex, but LNAME once again abolished dilation response in these groups. With exercise, NO production was significantly increased in both LZRs and OZRs as compared to controls. Of note, LZR-Ex had higher levels of ROS as compared to LZR-Control but ROS levels did not change in OZR-Ex. The most novel finding of this chapter was that exercise eliminated the deleterious effects of UCMS in LZR-and OZR-UCMS+Ex. In fact, OZR-UCMS+Ex EDD was improved beyond control values. Endothelium-independent dilation in both LZR- and OZR-UCMS+Ex was augmented as compared to UCMS groups. No further improvement was seen with TEMPOL and these effects were abolished with LNAME treatment. NO levels were subsequently increased in LZR- and OZR-UCM+Ex, while ROS levels remained high in these groups.

The outcomes of this chapter suggest that exposure to UCMS in LZRs resulted in vascular pathologies similar to those presented in OZR-Controls but without the other major changes in body mass, glucose, or lipid profile. Interestingly, the initial hypothesis for this paper was incorrect because exposure to UCMS in OZR did not further affect EDD when we had speculated that it would. The principle finding was that when Ex training was combined with UCMS, GA function was significantly improved in both LZRs and OZRs. 
LZR-UCMS sustained EID dysfunction, which means the vascular smooth muscle was affected. There are several mechanisms that could damage the smooth muscle and most involve cell signaling dysfunction on the level of second messengers and their receptors. Previous studies have shown that an increase in cortisol levels, as seen in MetS and UCMS, can inhibit cyclic adenosine monophosphate expression; therefore, myosin light chain kinase activity is not blocked leading to vasoconstriction (7). Sustained high cortisol levels also result in overproduction of Ang II, a vasoconstrictor. Ang II directly effects the blood vessel but also causes an increase in ET-1, $\mathrm{TxA}_{2}$, and ROS through the activation of $\mathrm{AT}_{1}$ receptors. Thus, increased circulating Ang II causes vasoconstriction and smooth muscle damage (8). Another secondary messenger, soluble guanylyl cyclase, is inhibited by increased levels of ROS. This disrupts the action of NO on the smooth muscle and reduces vasodilatory response $(9,10)$. Furthermore, increased cyclooxygenase signaling can lead to an imbalance of $\mathrm{PGI}_{2}$ and $\mathrm{TxA}_{2}$, causing an increase in $\mathrm{TxA}_{2}$. An increase in $\mathrm{TxA}_{2}$ induces vasoconstriction and smooth muscle cell dysfunction $(5,11)$.

There is a possibility that the elevated cortisol seen in the Ex and UCMS+Ex groups were caused by the forced treadmill Ex protocol. The rats were made to run to keep total work similar between the species. It is not surprising that this could cause some stress in the animals. The increase in cortisol could have caused an increase in hydrogen peroxide, superoxide, and peroxynitrite (12), which perhaps explains why higher ROS levels were seen in LZR-Ex and UCMS+Ex. It is known that DHE can interact with hydrogen peroxide and peroxynitrite as well as superoxide, meaning fluorescence intensity can only give a global measure of oxidative stress. Thus, the fact that ROS levels were higher in LZR-Ex and -UCMS+Ex could mean that hydrogen peroxide was significantly increased and not just superoxide. Exercise can increase hydrogen peroxide, where it acts as a vasodilator $(13,14)$. This is a limitation of this chapter because some 
of the improvement to EDD could be from hydrogen peroxide production in the UCMS+Ex groups.

The fourth chapter of this dissertation aimed to determine whether MVD in the brain was influenced by the comorbidity between MetS and depression. Ex training was also employed to see if MVD loss due to MetS and depression could be prevented. The first experiment performed was double IHC for the endothelial cell marker, CD31, and a pericyte marker, desmin. Pericytes are important for both microvessel function and angiogenesis. The CD31/Desmin ${ }^{+}$cells within the cortex and striatum were considered to be pro-angiogenic. UCMS significantly decreased MVD in LZR-UCMS but was not changed in OZR-UCMS. In LZR- and OZR-Ex, MVD was increased and when coupled with UCMS, exercise improved MVD in both LZR- and OZR-UCMS+Ex. RTPCR showed no differences in mRNA expression between groups in any of the angiogenic and oxidative stress markers examined.

All of the chapters presented here are connected, meaning the future directions of this research are interrelated. MetS and depression effect many different systems/mechanisms of the body and within those mechanisms are feed-forward and feed-back loops. Exercise also influences some of the same systems and more. In this regard, there are many avenues in which the research can branch, but for the sake of brevity this dissertation will only detail a few target areas.

MetS, depression, and exercise are the main focuses of this dissertation. There are several aspects of the studies presented previously that could be changed. For instance, the behavioral and physical characteristics of the rats undergoing UCMS and Ex could be further pursued. This could include better coat score analysis, implementation of the sucrose splash test, and perhaps use of the elevated plus maze to examine changes in behavior. Assessment of fat deposition could have been tracked using a rodent DEXA. Metabolic cages would have provided a more accurate way of 
measuring food intake, and a way to separate urine and feces samples so that circulating levels of metabolites of interest could be measured.

The first logical future experiment would be to determine the impact of UCMS on the arachidonic acid pathway in pre-existing MetS. Previous studies have shown that circulating $\mathrm{PGI}_{2}$ levels are decreased and TxA2 are increased in OZRs as compared to LZRs (4). This study also showed that endothelium-dependent dilation was impaired in skeletal muscle arterioles. Therefore, the impairment in EDD in LZRs and OZRs along with the attenuation of EID in LZRs, may be partially due to an imbalance of $\mathrm{PGI}_{2}$ and $\mathrm{TxA}_{2}$. Future experiments would involve microvessels, MCAs or GAs, hung in a pressurized myobath system and vessel reactivity would be assessed. The vessels would be exposed to increasing doses of iloprost, a synthetic analogue of $\mathrm{PGI}_{2}$, to evaluate dilation response in control, UCMS, Ex, and UCMS+Ex LZRs and OZRs. Vasoconstriction would be assessed by increasing doses of U46618, a TxA 2 mimetic. Incubation with indomethacin, a COX antagonist, would help to determine how much of the dilation response is due to arachidonic acid pathway involvement versus the NO pathway. Whether the mechanism is caused by dysfunction in COX2 or in synthase activity needs to be clarified, and incubation with carboxyheptyl imidazole $(\mathrm{CHI})$, a $\mathrm{TxA}_{2}$ synthase inhibitor, in addition to the indomethacin incubation would help verify this. ELISAs or westerns should be done to examine the protein expression of TxA 2 and $\mathrm{PGI}_{2}$ derivatives, and then compared to RT-PCR results for their respective synthases. These experiments would give a comprehensive view into how the arachidonic acid pathway is affected by the comorbidity between MetS and UCMS, especially when paired with the results previously outlined in this dissertation.

Exercise has been shown to increase production of hydrogen peroxide, where this molecule causes vasodilation. Our results showed an increase in ROS levels in LZR-Ex and -UCMS+Ex, 
when we would have expected a decrease as compared to LZR-UCMS. TEMPOL incubation did not further improve endothelium-dependent dilation in LZR-Control, -Ex, or -UCMS+Ex. It also did not increase endothelium-dependent dilation in OZR-Ex and -UCMS+Ex. Hydrogen peroxide could have partially caused the augmentation of EDD seen in the Ex and UCMS+Ex groups, and also explain the increase in ROS in LZR-Ex and -UCMS+Ex due to the previously outlined limitations in DHE staining. Therefore, to determine how much of the improvement was due to NO versus hydrogen peroxide, AmplexRed could be used to detect hydrogen peroxide levels as EPR does not detect nonradical oxidants (15). TEMPOL catalyzes the process of turning superoxide into oxygen and hydrogen peroxide (16). It would, therefore, be interesting to test if adding TEMPOL to the Ex and UCMS+Ex vessels when probing for DHE would increase fluorescence intensity even further. To determine if hydrogen peroxide was causing the increase in fluorescence intensity, the vessels exposed to DHE could also have been incubated with catalase, a hydrogen peroxide scavenger. Further, endothelium-dependent dilation could be assessed in the presence of catalase and compared to the maximum dilation found with TEMPOL, to differentiate how much of the augmentation was because of increased NO bioavailability or hydrogen peroxide production. Mitochondrial production of hydrogen peroxide is increased in nonphosphorylating respiration during endurance exercise $(17,18)$. It may be, therefore, beneficial to measure mitochondrial function through amperometric $\mathrm{O}_{2}$ sensors or ATP production via bioluminescence $(19,20)$.

VEGF expression has been thoroughly studied as a regulator of angiogenesis (21). Tang et al. (22) found that after one hour of exercise, VEGF transcriptional activity increased $38 \%$ in the brain, mRNA levels increased by $88 \%$, and protein levels increased by $66 \%$. Further, Tang and colleagues showed the major increase in VEGF expression occurred in the hippocampal region of 
the brain. The hippocampus has inhibitory control over HPA-axis activity and has a role in stress regulation (23). Depression has been shown to alter the hippocampus, including causing a decrease in VEGF expression in the region, which could contribute to the downregulation of neurogenesis by stress (24). A study by Morland et al. (25), illustrated the effect of exercise-induced lactate release on brain angiogenesis. They found that pericyte-like cells express lactate receptor, HCAR1, and when this receptor is activated, VEGFA expression and cerebral angiogenesis is induced. This discovery could be interesting to expand on in the realm of using exercise to improve MetS and depression. We have shown in this dissertation that MVD is decreased with MetS and depression, but that exercise can improve MVD in these groups. Lactate could be involved in this process as evidenced by the study by Morland et al. A future study expanding on the experiments presented in this dissertation could employ lactate injections in place of exercise and include the following groups in LZRs and OZRs: control, UCMS, daily lactate injections, and UCMS+lactate injections.

After 8 weeks of UCMS and lactate injections, evaluations of microvessel reactivity and MVD could be performed. Briefly, this would include baseline endothelium-dependent dilation response in the microvessels along with endothelium-dependent dilation response after incubations with TEMPOL and L-NAME, and IHC with CD31 and desmin to determine MVD in the brain. This experiment would isolate one aspect of Ex, lactate production, and demonstrate the ability of lactate to enhance cerebral angiogenesis. In addition, probing for CD31 and Ki67 would indicate endothelial cells that are proliferating and give a better idea to the extent of angiogenesis occurring within the brain. To evaluate involvement of pericytes expressing HCAR1 in cerebral angiogenesis, co-staining with desmin and HCAR1 antibodies could be used to quantify the number of pericytes in each treatment group that is expressing the receptor. Thus, if the number of HCAR1-expressing pericytes is higher in the lactate injection groups, it may suggest that lactate 
is mediating the increase in MVD. Determining VEGFA expression would also be important and would be done via western blots and RT-PCR. VEGFA expression would be expected to rise in the lactate injection groups, in addition to the increase in HCAR1-expressing pericytes. Such a study could offer an alternative therapy to Ex for patients that may be unwilling or unable to daily. 


\section{References}

1. d'Audiffret AC, Frisbee SJ, Stapleton PA, Goodwill AG, Isingrini E, Frisbee JC.

Depressive behavior and vascular dysfunction: a link between clinical depression and vascular disease? J Appl Physiol. 2010;108(5):1041-51.

2. Frisbee JC. Reduced nitric oxide bioavailability contributes to skeletal muscle microvessel rarefaction in the metabolic syndrome. Am J Physiol Regul Integr Comp Physiol. 2005;289(2):R307-16.

3. Flavahan S, Chang F, Flavahan NA. Local renin-angiotensin system mediates endothelial dilator dysfunction in aging arteries. Am J Physiol Heart Circ Physiol [Internet]. 2016;311(3):H849-54. Available from: http://www.ncbi.nlm.nih.gov/pubmed/27422988

4. Goodwill AG, James ME, Frisbee JC. Increased vascular thromboxane generation impairs dilation of skeletal muscle arterioles of obese Zucker rats with reduced oxygen tension. Am J Physiol Heart Circ Physiol [Internet]. 2008;295(4):H1522-8. Available from: http://www.pubmedcentral.nih.gov/articlerender.fcgi?artid=2593516\&tool=pmcentrez\&re ndertype $=$ abstract

5. Sparks MA, Makhanova NA, Griffiths RC, Snouwaert JN, Koller BH, Coffman TM. Thromboxane receptors in smooth muscle promote hypertension, vascular remodeling, and sudden death. Hypertension. 2013;61(1):166-73.

6. Xiang L, Naik JS, Hodnett BL, Hester RL. Altered arachidonic acid metabolism impairs functional vasodilation in metabolic syndrome. Am J Physiol Regul Integr Comp Physiol [Internet]. 2006;290(1):R134-138. Available from: http://ajpregu.physiology.org/cgi/content/abstract/290/1/R134 
7. Burgoyne JR, Madhani M, Cuello F, Charles RL, Brennan JP, Schroder E, et al. Cysteine Redox Sensor in PKGIa Enables Oxidant-Induced Activation. Science (80- ) [Internet]. 2007;317(5843):1393-7. Available from:

http://www.sciencemag.org/cgi/doi/10.1126/science.1144318

8. Carey RM. The intrarenal renin-angiotensin system in hypertension. Adv Chronic Kidney Dis. 2015;22(3):204-10.

9. Brüne B, Schmidt KU, Ullrich V. Activation of soluble guanylate cyclase by carbon monoxide and inhibition by superoxide anion. Eur J Biochem. 1990;192(3):683-8.

10. Weber M, Lauer N, Mülsch A, Kojda G. The effect of peroxynitrite on the catalytic activity of soluble guanylyl cyclase. Free Radic Biol Med. 2001;31(11):1360-7.

11. Dorn GW 2nd, Becker MW. Thromboxane A2 stimulated signal transduction in vascular smooth muscle. J Pharmacol Exp Ther. 1993;265(1):447-56.

12. Golbidi S, Frisbee JC, Laher I. Chronic stress impacts the cardiovascular system: animal models and clinical outcomes. Am J Physiol - Hear Circ Physiol [Internet]. 2015;308(12):H1476-98. Available from: http://ajpheart.physiology.org/lookup/doi/10.1152/ajpheart.00859.2014

13. Shimokawa H, Morikawa K. Hydrogen peroxide is an endothelium-derived hyperpolarizing factor in animals and humans. Vol. 39, Journal of Molecular and Cellular Cardiology. 2005. p. 725-32.

14. Robinson AT, Fancher IS, Mahmoud AM, Phillips SA. Microvascular Vasodilator Plasticity Following Acute Exercise. Exerc Sport Sci Rev [Internet]. 2017;1. Available 
from: http://insights.ovid.com/crossref?an=00003677-900000000-99800

15. Perry CGR, Kane DA, Lanza IR, Neufer PD. Methods for assessing mitochondrial function in diabetes. Vol. 62, Diabetes. 2013. p. 1041-53.

16. Nassar T, Kadery B, Lotan C, Da'as N, Kleinman Y, Haj-Yehia A. Effects of the superoxide dismutase-mimetic compound tempol on endothelial dysfunction in streptozotocin-induced diabetic rats. Eur J Pharmacol. 2002;436(1-2):111-8.

17. Zoladz JA, Koziel A, Woyda-Ploszczyca A, Celichowski J, Jarmuszkiewicz W. Endurance training increases the efficiency of rat skeletal muscle mitochondria. Pflugers Arch Eur J Physiol. 2016;468(10):1709-24.

18. Flack KD, Davy BM, DeBerardinis M, Boutagy NE, McMillan RP, Hulver MW, et al. Resistance exercise training and in vitro skeletal muscle oxidative capacity in older adults. Physiol Rep [Internet]. 2016;4(13):e12849. Available from: http://physreports.physiology.org/lookup/doi/10.14814/phy2.12849

19. Lanza IR, Nair KS. Functional assessment of isolated mitochondria in vitro. Methods Enzymol [Internet]. 2009;457(9):349-72. Available from: http://www.ncbi.nlm.nih.gov/pubmed/19426878\%5Cnhttp://www.pubmedcentral.nih.gov/ articlerender.fcgi?artid=PMC2782617

20. Gnaiger E. Polarographic Oxygen Sensors, the Oxygraph, and High-Resolution Respirometry to Assess Mitochondrial Function. In: Drug-Induced Mitochondrial Dysfunction. 2008. p. 325-52.

21. Shibuya M. Vascular Endothelial Growth Factor (VEGF) and Its Receptor (VEGFR) 
Signaling in Angiogenesis: A Crucial Target for Anti- and Pro-Angiogenic Therapies. Genes Cancer [Internet]. 2011;2(12):1097-105. Available from: http://gan.sagepub.com/lookup/doi/10.1177/1947601911423031

22. Tang K, Xia FC, Wagner PD, Breen EC. Exercise-induced VEGF transcriptional activation in brain, lung and skeletal muscle. Respir Physiol Neurobiol. 2010;170(1):1622.

23. Duman RS, Monteggia LM. A Neurotrophic Model for Stress-Related Mood Disorders. Vol. 59, Biological Psychiatry. 2006. p. 1116-27.

24. Heine VM, Zareno J, Maslam S, Joëls M, Lucassen PJ. Chronic stress in the adult dentate gyrus reduces cell proliferation near the vasculature and VEGF and Flk-1 protein expression. Eur J Neurosci. 2005;21(5):1304-14.

25. Morland C, Andersson KA, Haugen ØP, Hadzic A, Kleppa L, Gille A, et al. Exercise induces cerebral VEGF and angiogenesis via the lactate receptor HCAR1. Nat Commun. 2017;(7491):1-9. 